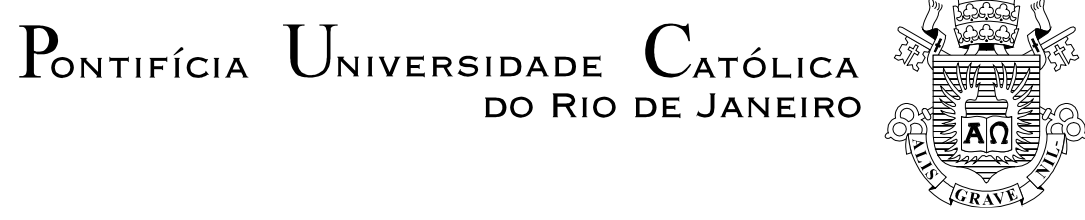

Carolina da Silva Grangeia

\title{
Plano de Mobilidade Corporativa (Sustentável) no Brasil: Um estudo de caso de uma empresa de energia
}

\author{
Dissertação de Mestrado
}

Dissertação apresentada como requisito parcial para obtenção do grau de Mestre pelo Programa de PósGraduação em Engenharia Urbana e Ambiental do Departamento de Engenharia civil e ambiental da PUC-Rio

Orientador: Prof. Nelio Domingues Pizzolato

Co-orientador: Prof. Luan Santos

Rio de Janeiro

Setembro de 2019 


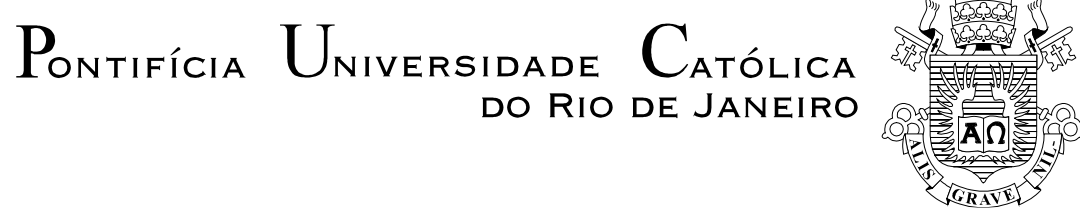

Carolina Da Silva Grangeia

Plano de Mobilidade Corporativa
(Sustentável) no Brasil: Um estudo de
caso de uma empresa de energia

Dissertação apresentada como requisito parcial para obtenção do grau de Mestre pelo Programa de Pós-Graduação em Engenharia Urbana e Ambiental do Departamento de Engenharia civil e ambiental da PUC-Rio. Aprovada pela Comissão Examinadora abaixo.

Prof. Nelio Domingues Pizzolato Orientador

Departamento de Engenharia Industrial - PUC-Rio

Prof. Luan dos Santos

Coorientador

Universidade Federal do Rio de Janeiro - UFRJ

Prof. Celso Romanel

Departamento de Engenharia Civil - PUC-Rio

Prof. Lino Guimarães Marujo

Universidade Federal do Rio de Janeiro - UFRJ

Rio de Janeiro, 12 de setembro de 2019. 
Todos os direitos reservados. É proibida a reprodução total ou parcial do trabalho sem a autorização da universidade, do autor e do orientador.

\section{Carolina da Silva Grangeia}

Bacharel em Engenharia civil pelo Centro Federal de Educação Tecnológica Celso Suckow da Fonseca, em 2015. Atuação em projetos relacionados a Logística e Planejamento Sustentável

Ficha Catalográfica

\section{Grangeia, Carolina}

Plano de Mobilidade Corporativa (Sustentável) no Brasil: Um estudo de caso de uma empresa de energia / Carolina da Silva Grangeia; orientador:Nelio Domingues Pizzolato; co-orientador: Luan Santos. - 2019.

123 f. ; $30 \mathrm{~cm}$

Dissertação (mestrado) - Pontifícia Universidade Católica do Rio de Janeiro, Departamento de Engenharia Civil e ambiental, Programa de Pós-Graduação em Engenharia Urbana e Ambiental, 2019.

Inclui bibliografia

1. Engenharia civil - Teses. 2. Engenharia urbana e ambiental - Teses. 3.. II. Pontifícia Universidade Católica do Rio de Janeiro. Programa de Pós-Graduação em Engenharia Urbana e Ambiental. III. Título. 


\section{Agradecimentos}

Aos meus pais, pelo apoio e amor incondicional ao longo do meu crescimento pessoal e profissional. Pelo encorajamento, e por se fazerem presentes em todas as minhas escolhas.

À minha irmã Camila, pela parceria e risadas nos momentos que precisei durante este período.

Ao meu irmão Gabriel, que precisa saber: É meu maior exemplo de determinação.

Ao professor Orientador Nelio Pizzolato, por ter aceitado o desafio de orientar uma Dissertação já iniciada, e principalmente pela confiança no desenvolvimento deste trabalho.

Ao meu co-orientador Luan Santos, por me aceitar como orientanda, pela paciência e prontidão no decorrer desta pesquisa, e principalmente por ser um exemplo de profissional. É uma honra.

Aos meus amigos e amigas, pela compreensão e motivação diária.

As demais instituições e profissionais que foram muito solícitos, e colaboraram de alguma maneira no desenvolvimento desta Dissertação. 


\section{Resumo}

Grangeia, Carolina da Silva; Pizzolato, Nelio Domingues (Orientador), Luan Santos (Co orientador). Plano de Mobilidade Corporativa (Sustentável) no Brasil: Um estudo de caso de uma empresa de energia. Rio de Janeiro, 2019. 123p. Dissertação de Mestrado - Departamento Engenharia Civil e Ambiental, Pontifícia Universidade Católica do Rio de Janeiro

Transporte é um instrumento direcionador do desenvolvimento urbano, e, com isso, novas metodologias de planejamento com foco no equilíbrio dos sistemas de transporte e sua coexistência no espaço urbano vêm sendo estudadas. Neste contexto, as empresas são consideradas polos geradores de viagens, quando, exercendo grande atratividade, potencializam os impactos no espaço urbano, principalmente, em termos de mobilidade e acessibilidade. Assim, esta Dissertação visa, por meio de estudo de caso, fomentar o desenvolvimento do Plano de Mobilidade Corporativa, que consiste em medidas integradas de sustentabilidade, como o uso da bicicleta, carona e carsharing, flexibilização da jornada de trabalho, e home-office. De maneira geral, o Plano define estratégias de gestão da demanda, trazendo qualidade de vida para funcionários, redução dos congestionamentos e da emissão de gases de efeito estufa. Foram, logo, utilizados o inventário de carbono da empresa e, elaborado um questionário origem-destino, com perguntas e condicionantes, traçando o perfil dos respondentes e levantando custos. Após diagnóstico, esta Dissertação propõe a elaboração do Plano, com base nos cenários propostos na ferramenta de quantificação de emissões de GEE (GHG Protocol,2019). Os resultados demonstraram redução dos impactos ambientais e financeiros, por exemplo: uso da bicicleta para pessoas que moram a menos de 8 $\mathrm{km}$ do local de trabalho, representando uma redução de GEE de 2,2 $\mathrm{tCO}_{2}$ eq e R \$ 44 no gasto médio diário dos funcionários da empresa. Com todos os cenários propostos, obteve-se um redução final de $\mathrm{R} \$ 273,42$ no gasto médio diário do total de funcionários, e 28,16 tCO2eq.

\section{Palavras-chave}

Mobilidade Corporativa; Impactos ambientais; Sustentabilidade. 


\section{Extended Abstract}

Grangeia, Carolina da Silva; Pizzolato, Nelio Domingues (Advisor), Luan Santos (Co-advisor). Corporate Mobility Plan (Sustainable) in Brazil: Case study of an energy company. Rio de Janeiro, 2019. 123p.

Dissertação de Mestrado - Departamento Engenharia Civil e Ambiental, Pontifícia Universidade Católica do Rio de Janeiro

Organizations and the entire corporate sector are fundamental in issues related to problems caused by (i)mobility and transports, such as logistics cost increases, traffic and environmental impacts, or being responsable to look for solutions to these issues. In Brazil, as the car-based model developed, problems with traffic, increase of overall travel time, and car dependence, were getting worse, resulting in many social and environmental impacts. As an example, the transport sector in Brazil in 2017 accounted for $32.7 \%$ of total energy consumption and accounted for $45.8 \%$ of $\mathrm{CO} 2 \mathrm{eq}$ emissions related to the country's energy sector (MME, 2018).

For Oliveira (2013), the spatial organization drives the profile of daily work displacements in the cities, thus, beyond investments in infrastructure, spatial and to urban planning policies must be created. These incentives linked to each other and urban equipment promote social inclusion, quality of life and contribute to the preservation of the environment. In addition, Cintra (2008) warns that the time spent in traffic jams compromises the competitiveness of the economy and people's quality of life, caused by stress, physical and psychological exhaustion.

The biggest motivation for Brazilian's travel is work, which corresponds to $50 \%$ of daily travelling in the country (WRI BRASIL, 2016). With this in mind, companies can be considered trip-generation hubs (TGH). Beyond their attractiveness to the population with goods and services, and new investments, they enhance the impacts on urban space, especially in terms of mobility and accessibility, being, then, one of the biggest causes of recurrent periods of congestion.

Planning mobility management in a company is a process that involves a culture of mobility in employees, customers and visitors, with direct impacts on travel times, reducing social and business costs, and retaining talent, as the new 
generations of professionals increasingly value such benefits. To this end, measures and strategies are implemented through a workplace mobility plan, so that these strategies have effectiveness (DECASTRO, 2014).

The contents of the Mobility Plan is different according to organization needs and the diagnosis determined found. It is based primarily on: i) Preparation, which involves the company needs and potential earnings; ii) Definition of scope and communication, which define the vision, goal and objectives of the Plan; iii) Diagnosis, which includes the characterization of the employees' profile and their way of travelling, the evaluation of accessibility and local Transportation offer, costs and policies already adopted; iv) Elaboration, which consists of indicators, budget and definition of the actions to establish the strategies; v) Implementation, which ensures the full operation of the Plan, promoting engagement and dissemination; vi) Monitoring, which consists in monitoring the actions proposed to ensure the goals and objectives. Plan should be reviewed if the performance is below expectations.

An example of international success by embracing a workplace mobility plan is the case of Seattle Children's Hospital, when in 2007, the hospital needed resources to invest in new beds and better care. As a solution, the hospital reduced the number of parking spaces, introduced daily charges instead of monthly charges, gave bonus to employees who booked non-motorized trips, and allowed bicycle rentals. As a result, the percentage of drive-alone commute trips reduced from $73 \%$ in 1995 to $43 \%$ in 2013.

Therefore, this study aims to bring discussions about the importance of Corporate Mobility Plan, through a case study of a company located in São Cristóvão, Rio de Janeiro, in which their employee profile has been mapped, costs, mobility and associated GHG emissions, and identificaded the company's current mobility management policies. Thus, after the diagnosis, this study suggests campaigns to change employees' behavior and proposes more sustainable alternatives and opportunities for commuting, such as modal diversification, using of apps, carsharing, rides, and meeting using teleconference, for example.

The Company's business is fuel and biofuel distribution. The building has 800 employees spread across the ground floor and its eleven floors, and has 409 parking spaces distributed between the building's internal and external area (that 
belong to the Company). In relation to these 409 parking spaces, 81 are private and the others are divided into: 3 for the disabled, 25 for motorcycles and 300 rotating. In addition, depending on the time of the day, there are, for free, parking spaces around the building, on the front and side streets. Also, the place is 400 meters from the subway and train stations, and 500 meters from the city bus terminals.

In 2017, to calculate the Greenhouse Gas Emissions (GHG) Inventory, which aims to be a management tool that allows the assessment of the organization's impacts on the global climate system, the Brazilian Program's tool GHG was used, in which 2,286 employees have participated.

For companies to manage emissions more efficiently, sources identified within the established limits should be classified as direct and indirect. To this end, the scope 1, 2 and 3 concepts were created, where: Scope 1 represents the GHG emissions from controlled (operational control) or owned (corporate participation) sources. Its quantification is mandatory according to the GHG Protocol methodology; Scope 2 represents energy acquisition-related GHG emissions that occur outside the unit's boundaries, such as the acquisition of electricity. Its quantification is also mandatory; Scope 3 considers indirect emissions. From the extraction and production of raw materials, transportation and travel of employees, emissions related to end use of the product, transportation of purchased fuels, and so on.

Thus, after disclosure of the Inventory, it was noted that the largest emissions were in scope 3, where emissions related to commuting employees represented $0.6 \%$ of scope 3 , and $0.55 \%$ of the total $\mathrm{CO}_{2}$ eq of the 2017 (carbon hidroxide in 2017) which amounted to a total of $610,746.64 \mathrm{t} \mathrm{CO}_{2}$ eq.

Based on the method proposed by Petzhold and Lindau (2015), which explores not only the needs of the case study company, but also the survey preparation and assessment, until the creation of indicators and future implementation, this study has as its main focus the diagnosis, because, from it, scenarios will be developed to mitigate the impacts generated by the working travels.

For the diagnosis, an on-line survey was elaborated, with a return of 110 answers. Questions, such as were asked: The time of entry and exit from work; if they had goods (car, motorcycle and others), and what fuel they would use if they 
had a vehicle; if the employee had any kind of company benefit such as transportation vouchers or fuel; if they had their own parking space, or if they could work remotely, so that was possible to identify how the company encourages the mobility of its employees. In addition, which alternatives would they use if they had no parking nearby and if they offer rides, to identify new travel possibilities beyond motorization and / or reduction of a single occupant in a vehicle. $48 \%$ of respondents were women and 52\% men, all between 25 and 40 years old, which configures the company by young and middle-aged employees. From these 110 employees, $35 \%$ receive transportation vouchers, $2 \%$ receive fuel vouchers and the others do not receive any transportation benefits. Peak hours on arrival at work are between 8 am and $9 \mathrm{am}$, and on departure between $5 \mathrm{pm}$ and $7 \mathrm{pm}$.

Regarding the distribution of employees by district, of the 110 respondents, 38 live in the South Zone, 36 in the North Zone, 19 in the West, 8 in the Center and the others outside the city. And, in concern to the average distances, only one way, it has: 7 employees travel up to $5 \mathrm{~km}, 29$ employees between 5 and $10 \mathrm{~km}, 39$ between 10 and $15 \mathrm{~km}$, and the others travel over $15 \mathrm{~km}$.

When asked if they had a car or motorcycle, 70 employees answered yes, and of these, only 9 did not have a parking space at the workplace (Figure 4). From those 70 employees, 61 have gasoline as their most used fuel, and 9 are divided between $\mathrm{CNG}$ and Ethanol.

Employees who use their own car every day were asked which modal would they use if the company did not have parking and the nearest parking place is 2 kilometers away: $14 \%$ said they would continue using the car, $39 \%$ would use the subway, $23 \%$ the bus, $2 \%$ the train, and the remaining $23 \%$ did not respond. Correlating the potential transportation modal with the distances traveled in one way by each employee, it produces Figure 1: 


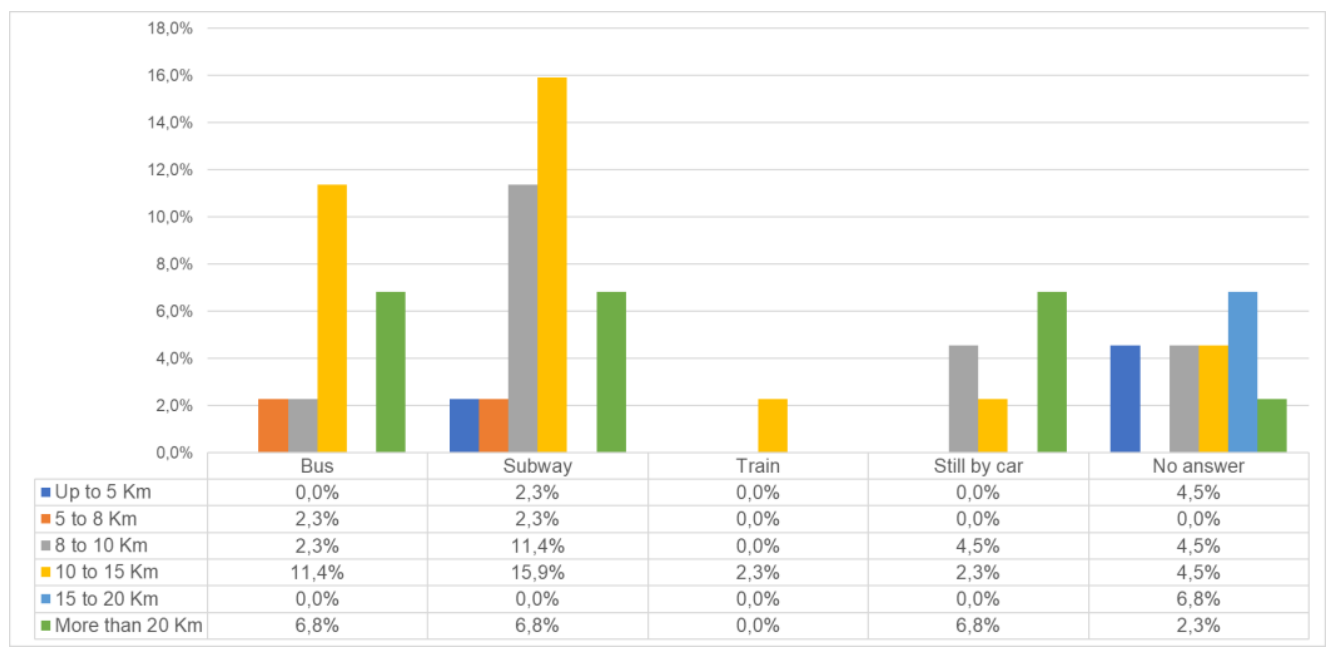

Figure 1: Transportation modal potential versus distance traveled in one way

Source: Author (2019)

Figures 2 and 3 illustrate the distribution in the use of modes for arrival and departure, respectively, in number of employees per frequency, considering that the same employee can diversify the use of modal during the week.

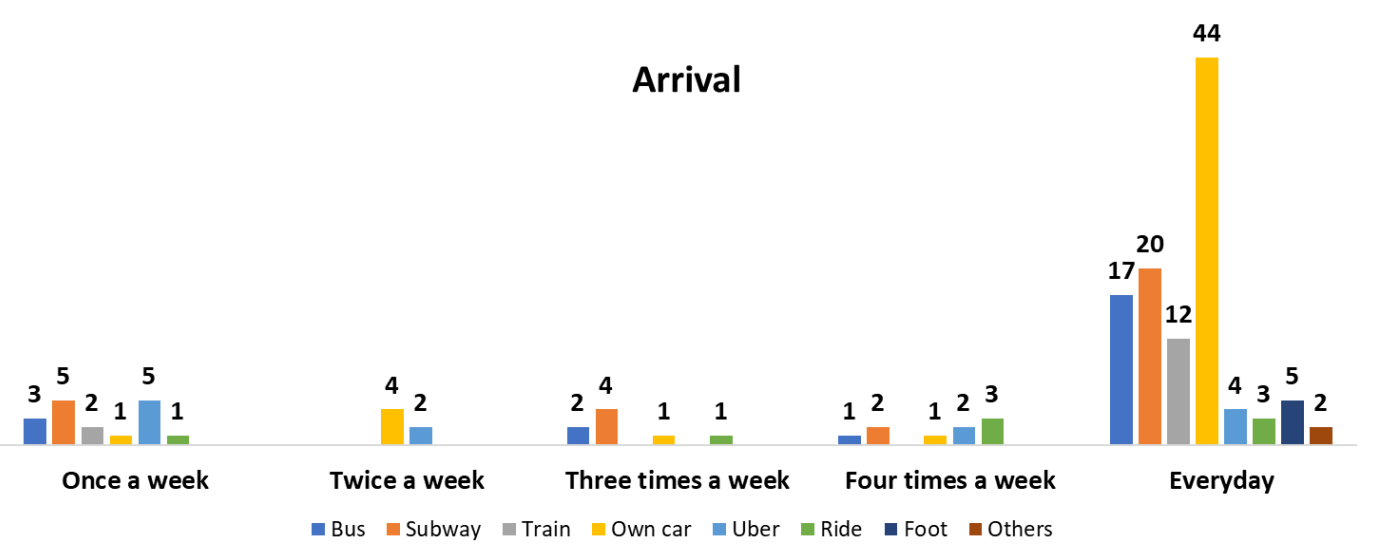

Figure 2: Modal distribution - Arrival

Source: Author (2019) 


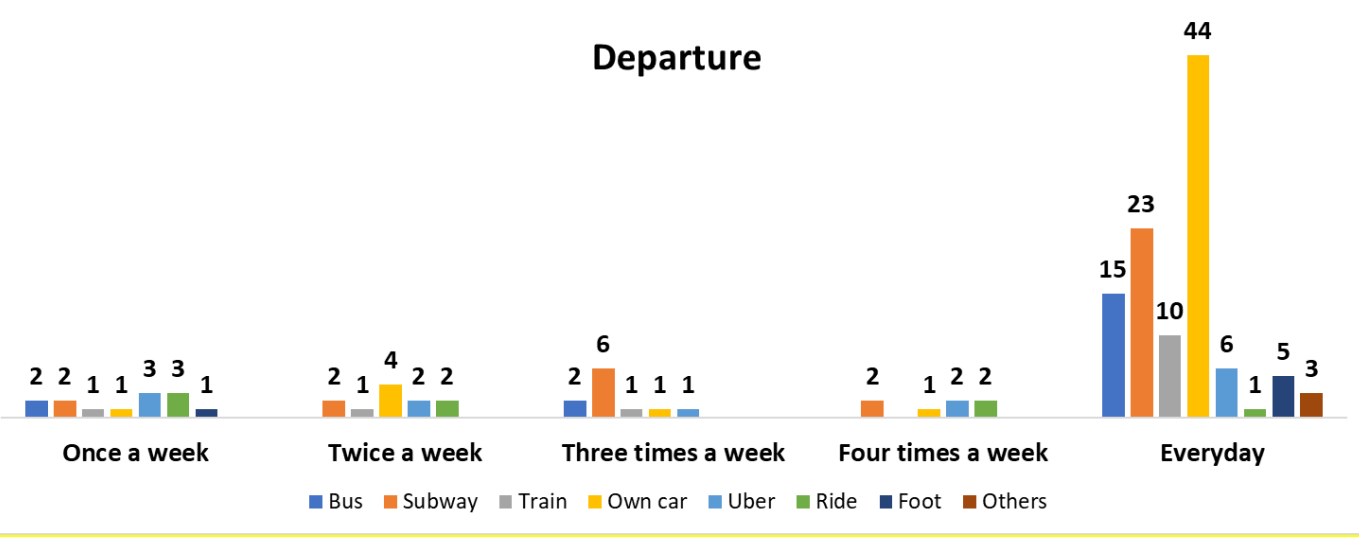

Figure 3: Modal distribution - Departure

Source: Author (2019)

It is possible to notice the non-use of the bike and the low use of the rides on the responses of employees. In addition, in the question about the possibility of home office, only 3 employees indicated to have this alternative.

In relation to the average time in the home-work journey, and correlating with the distances traveled in one way, it has the following percentages in Figure 4:

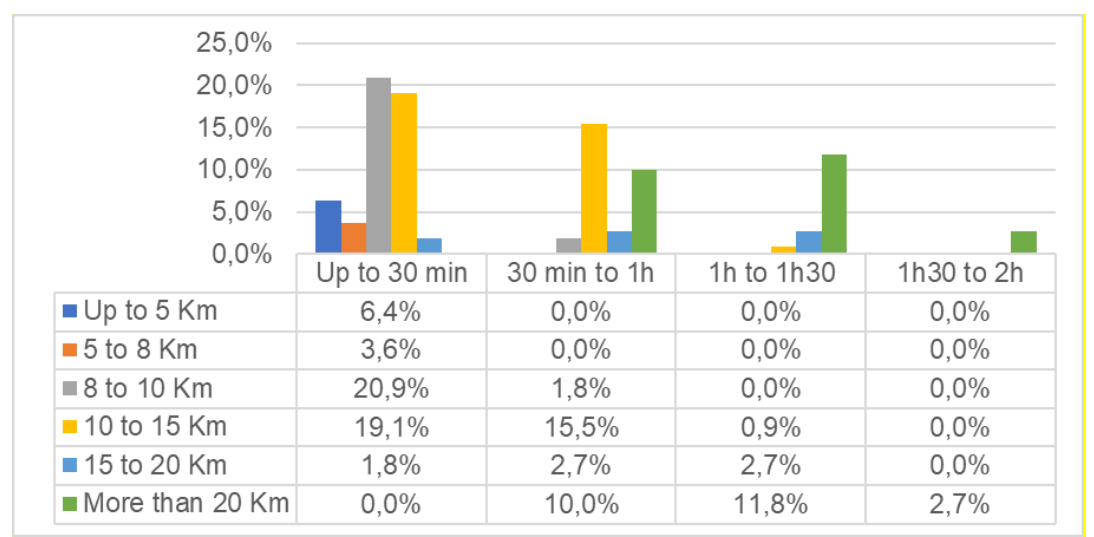

Figure 4: Journey time versus distance traveled - One way

Source: Author (2019)

Thus, the questionnaire responses were imputed to the GHG Protocol tool, resulting in total emissions of 77,50 t $\mathrm{CO}_{2} \mathrm{e}$, and 12,13 te $\mathrm{CO}_{2}$ of total biogenic in one year.

Regarding costs, these were calculated by counting the frequency which each employee uses a particular transportation modal, multiplied by the cost of 
gasoline or public Transportation taxes, resulting in a total cost of $\mathrm{R} \$ 1,179.02$ in the sum of the average daily expense (See APPENDIX E).

For the construction of scenarios in the tool and input in the Mobility Plan, the main goals to be achieved were: Increase of the use of bicycles, rides and public transport. For this, the assumption adopted and used in the scenario creation tool were:

- Employees with an average distance up to $8 \mathrm{~km}$ would use the bicycle as transport.

- Reduce by $20 \%$ the number of single-occupant vehicles by rides for those who responded using the car every day and have a distance from work less than $8 \mathrm{~km}$.

- Modalities changed for employees who responded that if they had no parking, and the nearest parking place was 2 kilometers away, they would use another transportation modal.

After inputting the constraints established in the questionnaire, it obtained the following curve of GHG emissions and costs associated with the use of modal, in kilogram and real respectively:

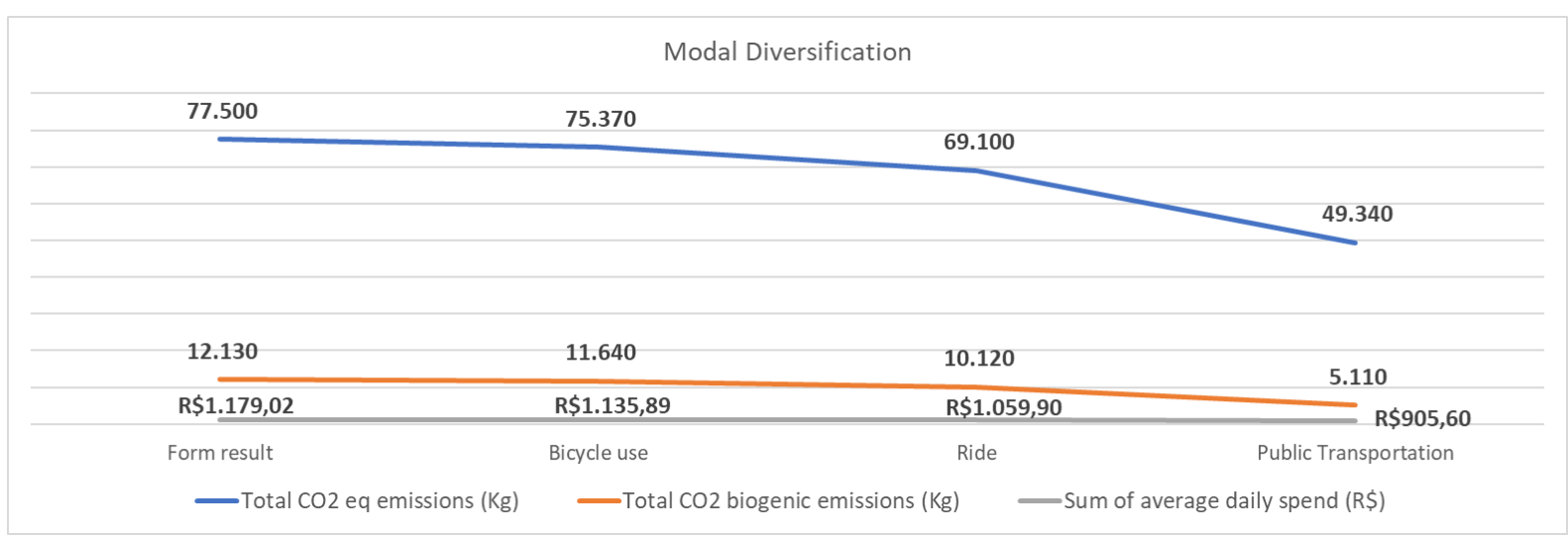

Also, calculating the opportunity cost of 61 employees who answered the questionnaire that they had parking space, it obtained $\mathrm{R} \$ 18.300,00$ per month with $\mathrm{R} \$ 300,00$ paid monthly per person, or R $\$ 14.030,00$ per month with a $\mathrm{R} \$ 10,00$ daily tax.

As an example of strategies to be adopted in the Corporate Mobility Plan based on this case study, there are: Improvements in the company's infrastructure, with the construction of a bicycle rack, which is currently absent; possible scores or benefits / parking space priority for those who offer ride; partnering with mobility 
applications, streamlining processes and making pricing more attractive; use of the communication plan to value the use of public transport, either through newsletters or news about cost / time benefits of these transportation modals.

As limitations, in addition to the disadvantages of submitting the questionnaire electronically, without the interface with the respondent, and with the likelihood of less feedback, stakeholder interest and intervention and Executive board support is required. However, the company's key product is fuel distribution, which hinders a radical change in car use, as employees are still encouraged to use it.

For future work, it is possible to explore business trips by employees, the use of corporate uber / taxi and its influence, and the truck fleets used by the company, which would generate new assessments and strategies for a new plan. For the calculations, it is also possible to use other tools, such as the Long-range Energy Alternatives Planning System (LEAP), modeling platform and management tool that enables the calculation of energy consumption and respective emissions, as well as the creation of mitigating scenarios.

\section{Keywords}

Corporate Mobility; Environmental Impacts; Sustainability. 


\section{Sumário}

\section{INTRODUÇÃO}

1.1. Justificativas 19

1.2. Objetivos 25

1.2.1 Objetivo Geral 25

1.2.2 Objetivos Específicos 26

1.3. Estrutura da Dissertação 26

2. PLANOS DE MOBILIDADE CORPORATIVA 29

2.1. Gerenciamento da Mobilidade 30

2.2. Oportunidades e desafios da Mobilidade Corporativa 31

2.3. Elaboração dos Planos de mobilidade corporativa 40

2.4. Principais experiências e casos de sucesso 42

3. ESTUDO DE CASO E ANÁLISES PRELIMINARES 47

3.1. Apresentação da Empresa 47

3.2. Política atual de mobilidade corporativa 48

4. RESULTADOS, PROPOSTAS E DISCUSSÕES 55

4.1. Preparação 56

4.2. Definição do escopo e comunicação 56

4.3. Diagnóstico 58

4.4. Elaboração 66

4.5. Análise Comparativa e estratégias do Plano 71

5. CONCLUSÕES, LIMITAÇÕES E FUTUROS ESTUDOS 74

5.1. Principais conclusões 74

5.2. Limitações do estudo 75

5.3. Recomendações para futuros estudos 76 
APÊNDICE A - DADOS DO INVENTÁRIO 2017

APÊNDICE B - DADOS DO QUESTIONÁRIO 116

APÊNDICE C - Cálculo das tarifas no Rio de Janeiro 118

APÊNDICE D - Cálculo do preço médio da gasolina 119

APÊNDICE E - Custo de deslocamento (Questionário) 120

APÊNDICE F - Questionário

121 


\section{Lista de tabelas}

Tabela 1: Divisão por município e distâncias médias até o local de trabalho

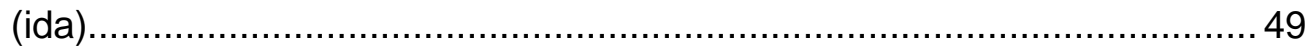

Tabela 2: Distribuição por bairro do município do Rio de Janeiro ......................50

Tabela 3: Distribuição de funcionários - Questionário ........................................6 60

Tabela 4: Distribuição de funcionários por distância - Questionário ....................60

Tabela 5: Custo diário do deslocamento segundo questionário ........................69 


\section{Lista de figuras}

Figura 1: Evolução da taxa de motorização no Brasil entre 2001 e 2014 ........... 20

Figura 2: Produção de veículos novos no Brasil ........................................... 20

Figura 3: Pôster do órgão de planejamento de Münster, Alemanha...................23

Figura 4: Esquemático de Plano de Mobilidade Corporativa ............................ 40

Figura 5: Monitoramento da implementação de medidas de mobilidade corporativa .................................................................................... 44

Figura 6: Resultado do questionário das empresas do projeto piloto ................. 45

Figura 7: Área de estacionamento no entorno do prédio em estudo .................. 48

Figura 8 : Detalhamento das emissões de $\mathrm{CO}_{2}$ eq por escopo .........................5 54

Figura 9: Método proposto para um Plano de Mobilidade Corporativa ................ 55

Figura 10: Visão, Objetivo e Meta ......................................................... 57

Figura 11: Vagas de estacionamento por funcionário ..................................... 61

Figura 12: Potencial modal de transporte versus distância percorrida em um

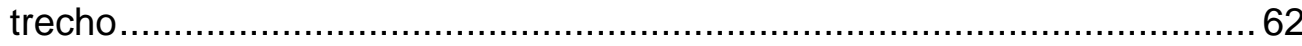

Figura 13: Distribuição modal dos respondentes - Chegada ............................63

Figura 14: Distribuição modal dos respondentes - Saída ..............................63

Figura 15: Quantidade de funcionários por Quantidade de modais - Chegada . 64

Figura 16: Quantidade de funcionários por Quantidade de modais - Saída....... 64

Figura 17: Duração viagem de ida versus distância percorrida em um trecho.... 65

Figura 18: Duração viagem de volta versus distância percorrida em um trecho. 65 


\section{LISTA DE ABREVIATURAS E SIGLAS}

\begin{tabular}{|c|c|}
\hline ANFAVEA & Associação Nacional dos Fabricantes de Veículos Automotores \\
\hline ANP & Agência Nacional de Petróleo \\
\hline ANTP & Associação Nacional de Transportes Públicos \\
\hline CENU & Centro Empresarial das Nações Unidas \\
\hline CBIO & Crédito de Descarbonização \\
\hline CET & Companhia de Engenharia de Tráfego \\
\hline DEFRA & Department for Environment Food \& Rural Affairs \\
\hline GEE & Gases de Efeito Estufa \\
\hline GHG & Greenhouse Gases \\
\hline IPCC & Intergovernmental Panel on Climate Change \\
\hline ISP & Instituto de Segurança Pública \\
\hline ITDP & Instituto de Políticas de Transporte e Desenvolvimento \\
\hline LEAP & Long-range Energy Alternatives Planning System \\
\hline MM & Mobility Management \\
\hline MME & Ministério de Minas e Energia \\
\hline NDC & Nationally determined contributions \\
\hline O/D & Origem e Destino \\
\hline PGV & Polos Geradores de Viagens \\
\hline TDM & Transportation Demand Management \\
\hline USEPA & United States Environmental Protection Agency \\
\hline VT & Vale Transporte \\
\hline WRI & World Resources Institute \\
\hline WTC & World Trade Center \\
\hline
\end{tabular}




\section{INTRODUÇÃO}

Este capítulo apresenta como justificativa da pesquisa o panorama atual da mobilidade nas cidades brasileiras, caracterizando a problemática das cidades, traçando comparativos entre o Brasil e outros países, além de demonstrar o papel fundamental das organizações na melhoria da distribuição espacial das cidades, gestão da mobilidade e consequente qualidade de vida.

\subsection{Justificativas}

O transporte é um importante instrumento de direcionamento do desenvolvimento urbano das cidades. A mobilidade urbana bem planejada, com sistemas integrados e sustentáveis, facilita o acesso dos cidadãos às cidades e proporciona qualidade de vida e desenvolvimento socioeconômico (MINISTERIO DAS CIDADES, 2013).

No Brasil, à medida que o modelo de desenvolvimento baseado no automóvel foi se consolidando, observou-se também a expansão dos congestionamentos e o aumento de tempo de deslocamento nas viagens diárias. Além disso, a dispersão de áreas residenciais e serviços para as periferias, uso de energias não renováveis, poluição sonora e visual, redução da produtividade, aumento das emissões de poluentes na atmosfera, entre outras consequências do uso do automóvel, vêm trazendo prejuízos econômicos, ambientais e à saúde pública das cidades (BERTOLINI \& LE CLERQ, 2008).

O padrão da mobilidade urbana no país tem se modificado nos últimos anos. A frota de veículos no Brasil aumentou em 32,3 milhões de 2001 a 2014, com isso, a taxa de motorização passou de 14,4 automóveis para cada 100 habitantes em 2001 para 28,1 auto/100 hab em 2014, ilustrado na Figura 1 por regiões. 

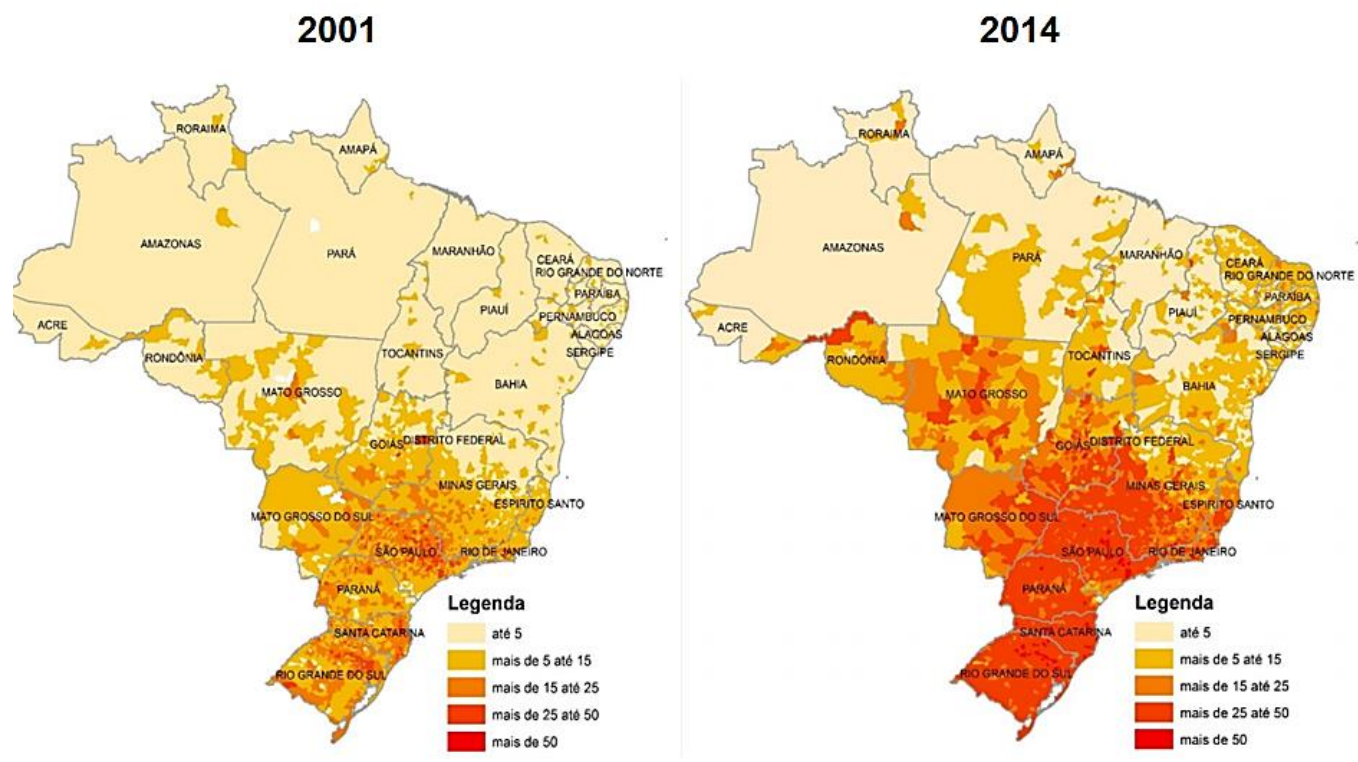

Figura 1: Evolução da taxa de motorização no Brasil entre 2001 e 2014

Fonte: Observatório das Metrópoles, INCT, 2015

A Figura 2 ilustra o aumento da produção de veículos (carros, caminhões e ônibus) no Brasil em 2017 segundo a Associação Nacional dos Fabricantes de Veículos Automotores (ANFAVEA). No início de 2018, a ANFAVEA divulgou sua projeção para o ano, que apontava uma produção de 3,05 milhões de veículos, o que representaria um aumento de $13,2 \%$ sobre os 2,7 milhões fabricados em 2017. No entanto, a produção ficou em 2,89 milhões, alta de $6,7 \%$ em relação à produção do ano anterior. Para 2019, a ANFAVEA estima uma produção de 3,15 milhões de unidades, o que representa um aumento de 9\% (ANFAVEA, 2019).

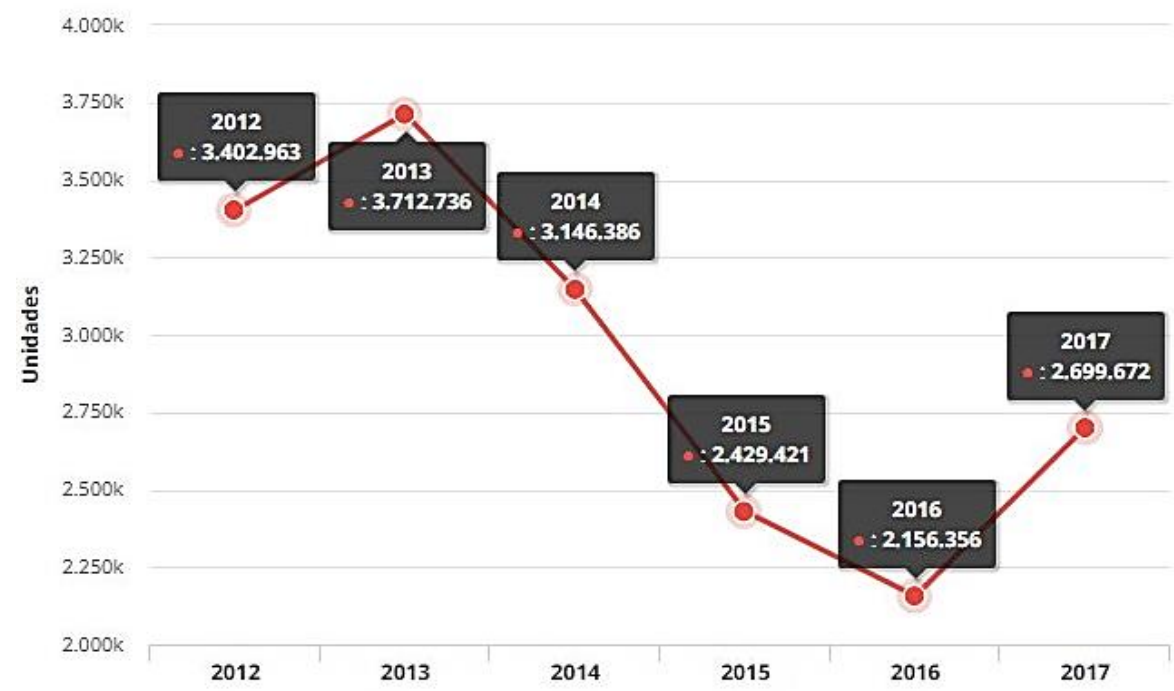

Figura 2: Produção de veículos novos no Brasil 
Fonte: ANFAVEA, 2019

A evolução da participação de cada modal entre 2003 e 2014, a partir dos dados do relatório desenvolvido pela Associação Nacional de Transportes Públicos (ANTP), reflete o padrão atual da mobilidade urbana no país no Quadro 1 (ANTP, 2016 ).

Quadro 1': Evolução da divisão modal (\%)

\begin{tabular}{lcccccccccccc}
\hline Sistema & $\mathbf{2 0 0 3}$ & $\mathbf{2 0 0 4}$ & $\mathbf{2 0 0 5}$ & $\mathbf{2 0 0 6}$ & $\mathbf{2 0 0 7}$ & $\mathbf{2 0 0 8}$ & $\mathbf{2 0 0 9}$ & $\mathbf{2 0 1 0}$ & $\mathbf{2 0 1 1}$ & $\mathbf{2 0 1 2}$ & $\mathbf{2 0 1 3}$ & $\mathbf{2 0 1 4}$ \\
\hline Ônibus & 22,2 & 21,8 & 21,7 & 21,5 & 21,5 & 21,2 & 21,1 & 20,6 & 20,5 & 20,2 & 20,2 & 19,5 \\
Municipal & 4,8 & 4,6 & 4,6 & 4,6 & 4,6 & 4,7 & 4,8 & 4,8 & 4,9 & 4,9 & 4,9 & 5,0 \\
Ônibus Metrop. & 4,8 & 2,9 & 2,9 & 3,1 & 3,3 & 3,5 & 3,6 & 3,7 & 3,9 & 3,9 & 3,9 & 3,8 \\
Trilho & 2,9 & 29,5 & 29,4 \\
\hline TC- total & 29,8 & 29,3 & 29,2 & 29,1 & 29,3 & 29,4 & 29,4 & 29,1 & 29,1 & 29,0 & 29,0 & 28,4 \\
\hline Auto & 26,9 & 27,1 & 27,2 & 27,3 & 27,2 & 27,0 & 26,9 & 27,1 & 27,3 & 27,3 & 26,9 & 27,0 \\
Moto & $1,9 \%$ & 2,0 & 2,2 & 2,3 & 2,5 & 2,8 & 3,0 & 3,2 & 3,5 & 3,6 & 3,8 & 4,0 \\
\hline TI- total & 28,8 & 29,1 & 29,3 & 29,6 & 29,7 & 29,8 & 30,0 & 30,4 & 30,8 & 31,0 & 30,7 & 31,0 \\
\hline Bicicleta & 2,4 & 2,6 & 2,6 & 2,7 & 2,8 & 2,9 & 3,1 & 3,2 & 3,4 & 3,6 & 3,8 & 4,1 \\
A pé & 38,9 & 39,0 & 38,9 & 38,6 & 38,1 & 37,9 & 37,5 & 37,3 & 36,8 & 36,4 & 36,5 & 36,5 \\
\hline$T N M-$ total & 41,4 & 41,6 & 41,5 & 41,3 & 40,9 & 40,8 & 40,6 & 40,5 & 40,2 & 40,0 & 40,3 & 40,6 \\
\hline Total & $\mathbf{1 0 0 , 0}$ & $\mathbf{1 0 0 , 0}$ & $\mathbf{1 0 0 , 0}$ & $\mathbf{1 0 0 , 0}$ & $\mathbf{1 0 0 , 0}$ & $\mathbf{1 0 0 , 0}$ & $\mathbf{1 0 0 , 0}$ & $\mathbf{1 0 0 , 0}$ & $\mathbf{1 0 0 , 0}$ & $\mathbf{1 0 0 , 0}$ & $\mathbf{1 0 0 , 0}$ & $\mathbf{1 0 0 , 0}$ \\
\hline TC- Transporte coletivo & & & & & & & & & & & \\
TI- Transporte individual & & & & & & & & & & & \\
TNM- Transporte não motorizado & & & & & & & & & & & &
\end{tabular}

Fonte: ANTP, 2016

O Quadro 1 mostra pequenas variações, porém é importante observar a inversão de posição entre o transporte individual e o coletivo de 2003 para 2014. Em 2003, o transporte coletivo representava $29,8 \%$ na divisão modal do país, enquanto o transporte individual, 28,8\%. Já em 2014 houve uma inversão deste quantitativo, onde $28,4 \%$ representou o transporte coletivo e $31 \%$ do individual.

Nesse sentido, os congestionamentos têm se agravado nas principais metrópoles brasileiras. Para Downs (2004), o tráfego congestionado é indesejável, porque aloca indevidamente recursos, além de causar ineficiência econômica e estresse psicológico. Ainda segundo o autor, os congestionamentos trazem dois grandes problemas sociais: perda de dinheiro e de tempo. Ao ocorrerem atrasos nas mercadorias ou aumento da margem de tempo para as pessoas se planejarem, há redução da produtividade e aumento do preço do transporte, além do aumento do tempo médio das viagens. Para Ross e Yinger (2000), o impacto do individualismo também colabora para o aumento dos congestionamentos, visto

\footnotetext{
${ }^{1}$ Estes dados representam um conjunto de 438 municípios, com mais de 60 mil habitantes, que integram o sistema de informações da mobilidade da ANTP.
} 
que é cada vez mais comum o uso do transporte individual em detrimento ao transporte público, e ainda mais comum a média de um passageiro por veículo.

Como exemplo, o estudo da Fundação Getúlio Vargas sobre os custos dos congestionamentos na cidade de São Paulo revelou que "o prejuízo de manter as filas intermináveis de carros parados" já equivale a $1 \%$ do Produto Interno Bruto (PIB) do Brasil. Em 2002, este estudo estimou um prejuízo coletivo na ordem de $\mathrm{R} \$ 10$ bilhões, baseado em índices da Companhia de Engenharia de Tráfego (CET) de frota congestionada e gastos com combustível em determinadas velocidades médias, além de gastos com saúde e hora/salário. Já em 2012, este valor quadruplicou, estimado em $\mathrm{R} \$ 40$ bilhões (CINTRA, 2014).

No Rio de Janeiro não foi diferente. Um estudo realizado pelo Instituto de Economia da Universidade Federal do Rio de Janeiro (IE/UFRJ) demonstrou que as estimativas de perdas anuais no deslocamento casa-trabalho no Estado do Rio de Janeiro (ano-base de 2010) estariam entre $R \$ 7,8$ e $R \$ 15,7$ bilhões (YOUNG, AGUIAR, POSSAS, 2013). No cálculo foram considerados os custos do tempo perdido no deslocamento, valorado como uma proporção do rendimento médio. Neste mesmo estudo, apenas a perda de produtividade (horas desperdiçadas em trânsito) foi considerada. Os custos associados à emissão de poluentes, poluição sonora, risco de acidentes e consequências à saúde devem também ser considerados para uma estimativa mais apurada.

Em fevereiro de 2017, a empresa americana INRIX divulgou a pesquisa intitulada Global Traffic Scorecard, que analisou os congestionamentos e o custo associado de 1.064 cidades em diversas regiões do mundo. Entre as 10 cidades mais congestionadas do mundo em 2016, com relação à média de horas, São Paulo é a 6 colocada, atrás apenas de Los Angeles, Moscou, Nova York, São Francisco e Bogotá, respectivamente. Dentre as 100 mais congestionadas, as cidades brasileiras além de São Paulo são: Belém (24루), Rio de Janeiro (29aํㅡ),

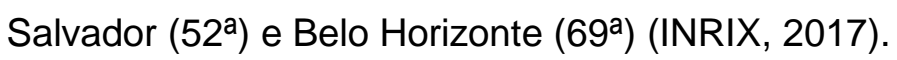

Com base nas conclusões deste levantamento, os motoristas da capital paulista gastaram em média 77 horas em engarrafamentos em 2016, enquanto a $1^{\text {a }}$ colocada Los Angeles obteve média de 104 horas, o que resultou em uma 
produção sacrificada ${ }^{2}$ para os Estados Unidos, somando as demais cidades norteamericanas, na ordem de $\$ 300$ bilhões (INRIX, 2017).

Neste contexto, a dinâmica da circulação urbana é diretamente proporcional à demanda de transportes, ainda com forte apelo ao transporte individual motorizado e, consequentemente, ao aumento de congestionamentos, da economia sacrificada ${ }^{2}$ e do consumo de energia no setor. A Figura 3 ilustra o espaço necessário para transportar a mesma quantidade de passageiros de bicicleta, carro e ônibus. Ela demonstra o quanto esta dinâmica da circulação urbana poderia se beneficiar com o uso do transporte público ou meios alternativos de locomoção.
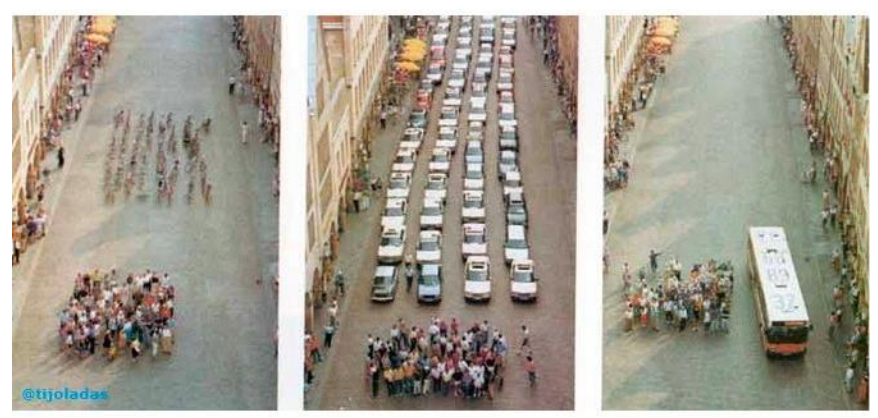

Figura 3: Pôster do órgão de planejamento de Münster, Alemanha Fonte: O Globo ${ }^{3}$

O incentivo a políticas públicas voltadas à melhoria da infraestrutura de transportes, principalmente para o transporte coletivo e para meios não motorizados, além do incentivo ao uso de biocombustíveis ou de veículos híbridos e elétricos, e o desincentivo ao uso de veículos particulares através de penalidades ou limitações, possibilitariam a redução de carros nas ruas, reduzindo assim acidentes, e emissão de poluentes na atmosfera (SANTOS, 2013).Para Oliveira (2013), além dos investimentos em infraestrutura, políticas de planejamento territorial e urbano devem ser criadas, pois a organização espacial dita o perfil dos deslocamentos diários nas cidades. Estes incentivos conectados

\footnotetext{
2 Representa o que deixa de ser produzido na economia devido ao tempo perdido nos deslocamentos ou, ainda, o quanto poderia ser produzido no mesmo tempo gasto com deslocamentos.

3 Disponível em: <http://oglobo.globo.com/blogs/ecoverde/posts/2011/02/09/carrobicicleta-ou-onibus-que-ocupa-mais-espaco-361868.asp > . Acessado em: 29 de agosto de 2017.
} 
entre si e a equipamentos urbanos promovem a inclusão social e contribuem para a preservação do meio ambiente (DECASTRO, 2014).

Entre os impactos gerados ao meio ambiente, o setor de transportes no Brasil em 2017 respondeu a aproximadamente $32,7 \%$ do consumo total de energia, e responsável por $45,8 \%$ das emissões de $\mathrm{CO}_{2}$ eq, relativas ao setor de energia do país (MME, 2018). Com o intuito de fortalecer a resposta global à ameaça da mudança do clima e reforçar a capacidade dos países para lidarem com os impactos gerados, em 2016 foi aprovado o Acordo de Paris na 21aㅡ Conferência das Partes com objetivo claro de redução das emissões de gases de efeito estufa (GEE) no contexto do desenvolvimento sustentável. Foram estipuladas metas, chamadas de Contribuição Nacionalmente Determinada (NDC), cuja função é oficializar o compromisso dos governos participantes com ações de mitigação dos GEE e limitação do aumento da temperatura global.

O Brasil, como país integrante e de acordo, firmou o compromisso de reduzir suas emissões em até $37 \%$ até 2025 , com vistas a chegar a $43 \%$ em 2030 . A NDC brasileira destacou principalmente:

i) Mudança no uso da terra e florestas, com o fortalecimento do Código florestal, restauração, reflorestamento e medidas contra o desmatamento e a favor do manejo sustentável de florestas nativas;

ii) Aumento da participação de energias renováveis na matriz energética até 2030 , em cerca de 45\%. Além da energia hídrica, maior participação da energia eólica, biomassa e solar.

iii) Quanto ao setor de transportes, o principal foco é a expansão do uso de biocombustíveis, aumentando a oferta do etanol, e biodiesel na mistura do diesel. Neste contexto, em dezembro de 2017 foi sancionada a Lei que cria a Política Nacional de Biocombustíveis, RenovaBio. Esta Política incentiva a produção de etanol e biodiesel, estabelecendo metas anuais de redução de emissões de gases de efeito estufa através da comercialização de créditos de descarbonização (CBIOs) entre produtores/importadores e distribuidoras.

A maior motivação para o deslocamento dos brasileiros é o trabalho, que corresponde a $50 \%$ dos deslocamentos diários no país, podendo chegar a $80 \%$, se somados os deslocamentos por motivos de estudo (WRI BRASIL, 2016). 
Segundo um estudo publicado em 2015 pelo Sistema Firjan, mais de 17 milhões de brasileiros demoraram mais de 114 minutos no deslocamento casa-trabalhocasa, considerando apenas os deslocamentos acima de 30 minutos. Este mesmo estudo apresentou os dados da região metropolitana do Rio de Janeiro: 2,8 milhões de trabalhadores levaram mais de 141 minutos, o maior tempo de deslocamento (SISTEMA FIRJAN, 2015).

Cintra (2008) alerta para o aumento das horas de trabalho desperdiçadas, pois comprometem a competitividade da economia e a qualidade de vida das pessoas, causadas por estresse, esgotamento físico e psicológico em decorrência do trânsito parado. Mihessen, Machado e Pero (2014) apontam a correlação entre o planejamento do uso do solo e o panorama dos transportes das cidades, no qual a população com menor renda e nível de escolaridade, cuja moradia é situada nas margens dos centros urbanos é penalizada com o acesso aos transportes. Com isso, leva-se mais tempo no deslocamento, gerando restrições às oportunidades do mercado de trabalho, atualmente centralizados, além de agravar as desigualdades sociais (MIHESSEN, MACHADO \& PERO, 2014).

Observa-se com este panorama, o papel fundamental das empresas na gestão da mobilidade de seus funcionários. Este gerenciamento mostra-se como uma ferramenta viável para adequação da demanda crescente por transportes, propondo alternativas para otimizar recursos naturais, humanos, financeiros, e de infraestrutura (ALEXANDRE, 2008; LITMAN, 2011; MENEZES E BALASSIANO, 2005).

\subsection{Objetivos}

Esta seção apresenta os objetivos geral e específicos desta dissertação, trazendo a necessidade do estudo de caso para comprovação dos fatores teóricos e ações a serem implementadas.

\subsubsection{Objetivo Geral}

O objetivo principal desta dissertação é, por meio de um Plano de Mobilidade Corporativa, identificar de que modo as empresas podem contribuir para a 
mobilidade urbana sustentável, considerando-se os impactos ambientais e financeiros das ações atuais, bem como cenários alternativos de mobilidade.

\subsubsection{Objetivos Específicos}

Dentre os objetivos específicos, estão:

- Avaliar a infraestrutura modal da região onde a empresa do Estudo de Caso está situada e condições de (i)mobilidade;

- Analisar, com base no inventário de emissões, a atual política de mobilidade corporativa da empresa estudada, assim como o perfil do funcionário, custos e emissões;

- Por meio do questionário, elaborar o diagnóstico atual com o perfil dos funcionários da empresa estudada (socioeconômico, deslocamento origem-destino - O/D - tempo distância, uso do transporte individual/coletivo, notas de qualidade do transporte, potencial de uso de outros modais e medidas corporativas de sustentabilidade);

- Propor medidas de melhoria da mobilidade dos funcionários à empresa estudada por meio da pesquisa O/D, identificando oportunidades como: diversificação modal, carsharing, carona, aplicativos, teleconferências, flexibilidade de horários, entre outros;

- Avaliar as ações de mobilidade já implementadas e os resultados obtidos ou esperados, de modo a sugerir possíveis ações futuras a serem adotadas, com base em benchmark;

\subsection{Estrutura da Dissertação}

Com o propósito de discutir os problemas de deslocamento das cidades, seus impactos e o papel das empresas na busca por soluções sustentáveis, esta dissertação apresentará a temática da Mobilidade Corporativa, pauta das novas estratégias empresariais que buscam a sustentabilidade corporativa e a gestão da 
mobilidade, além de analisar um Estudo de Caso de uma empresa situada no Rio de Janeiro.

Serão exemplificadas práticas já existentes nesta empresa, o perfil da mobilidade dos funcionários e custos associados, além dos fatores de emissão através do Inventário de emissões de GEE já desenvolvido no ano de 2017. Com isso, para a elaboração de propostas, será apresentado também um questionário o qual seus funcionários responderão a uma pesquisa de Origem-Destino e alternativas para sua mobilidade. Esta pesquisa, que caracterizará o perfil do funcionário atual e o modo como ele se desloca para o trabalho (ano de 2018), será utilizada para identificação de oportunidades de melhoria de custo, consumo energético e redução das emissões de GEE, além de diversificação modal da região estudada. Esses resultados tornam-se fundamentais para a criação de estratégias do Plano de Mobilidade de uma empresa.

Além da pesquisa para a classificação e diagnóstico do padrão de viagens e perfil dos funcionários, realizada por meio do questionário eletrônico e entrevista, serão realizadas entrevistas com o setor de Sustentabilidade e, possivelmente, Recursos Humanos, com o objetivo de analisar práticas de mobilidade já implementadas ou em projeto, entender o perfil da empresa e funcionários frente à sustentabilidade, além de estimular novas políticas e elaboração de um Plano de Mobilidade.

Para elaboração e simulação dos cenários, o inventário de emissões de carbono e o software Excel serão utilizados. Ainda, a localização da empresa, com representatividade para ser designada como polo gerador de viagens, será estudada através de sistemas de informação geográfica e estudos de viabilidade locais, além de banco de dados do trânsito e tráfego da cidade. Práticas de Mobilidade implementadas nas filiais ou até mesmo na sede desta empresa serão analisadas e utilizadas como base para benchmark.

Dessa forma, esta dissertação está estruturada em seis capítulos, incluindo a Introdução, descritos de forma breve:

Capítulo 1 - Introdução: este capítulo apresenta as considerações iniciais para contextualização da temática e pesquisa, caracterização da problemática, assim como sua justificativa, objetivo geral e específico, e procedimento metodológico. 
Capítulo 2 - A mobilidade e os planos de mobilidade corporativa: este capítulo apresenta a revisão de literatura sobre gerenciamento da demanda por transportes, e polos geradores de tráfego. Além disso, destaca algumas estratégias de mobilidade corporativa com suas vantagens e limitações, que podem vir a ser adotadas, mostrando a importância das empresas na dinâmica da economia urbana como elementos de atração na configuração dos deslocamentos, e como um plano de mobilidade corporativa, assim como o que ele é, se configura dentro das empresas trazendo melhorias financeiras, de produtividade e qualidade de vida.

Capítulo 3 - Estudo de Caso: neste capítulo, a empresa de estudo é apresentada, com localização geográfica, dimensões, estrutura interna e do entorno, e ações e investimentos na mobilidade dos seus funcionários já consolidadas. Além disso, o perfil dos funcionários, modo de deslocamento, custos e emissões de GEE associados a estes deslocamentos também são apresentados com base no Inventário de GEE da empresa no ano anterior.

Capítulo 4 - Propostas: por meio do procedimento metodológico de questionário/formulário, uma pesquisa origem-destino é elaborada para alguns funcionários da empresa estudada e, por meio dela, são identificadas oportunidades de melhoria na mobilidade dos funcionários. São traçados cenários de deslocamentos alternativos, com base nos dados do capítulo 3 , e oportunidades encontradas após análise dos respondentes do questionário. Temse, então, insumo para elaboração do Plano de mobilidade corporativa da empresa, baseado nas melhorias de custo e redução das emissões de GEE encontradas nos diversos cenários.

Capítulo 5 - Resultados: o capítulo apresenta os resultados do estudo de caso proposto, com base nos cenários elaborados no capítulo 4 .

Capítulo 6 - Conclusão: neste capítulo são apresentadas as conclusões, considerações finais e limitações encontradas na pesquisa. Além disso, são apresentadas recomendações para continuidade do tema tratado. 


\section{PLANOS DE MOBILIDADE CORPORATIVA}

Este capítulo apresenta a revisão bibliográfica, sobre gestão da demanda por transportes, com cases de sucesso e ações que caracterizam a mobilidade corporativa, e que podem ser adotadas pelas empresas brasileiras. Além disso, conceitua-se o Plano de mobilidade corporativa, revelando sua importância na organização empresarial.

Segundo Portugal e Goldner (2003), polos geradores de viagens (PGV) são locais ou instalações de distintas naturezas que desenvolvam atividades de porte e escala capazes de produzir um número significativo de viagens. Alguns autores propõem que esta concepção de PGV seja ampliada, considerando os potenciais impactos nos sistemas viários e de transportes, na estrutura urbana, como também no desenvolvimento socioeconômico e qualidade de vida da população (PORTUGAL e GOLDNER, 2003; KNEIB, 2004; REDPGV, 2012).

Empresas podem ser consideradas PGV quando exercem grande atratividade sobre a população, com oferta de bens e serviços, potencializando impactos na acessibilidade e mobilidade onde se localizam. Neste contexto, deve-se considerar a importância das empresas na dinâmica da economia dos centros urbanos como elementos de atração na configuração dos deslocamentos, e seu papel como indutor da forma metropolitana (ROSA et al., 2005). O modo como se caracterizam os movimentos pendulares dos funcionários, normalmente com horário padrão de chegada e saída, e apenas um funcionário por veículo, pode e deve ser influenciado pelo setor, desde que promova o desenvolvimento socioeconômico sustentável. Estratégias que se baseiam na Gestão da Demanda de Viagens (do inglês Travel Demand Management) no meio corporativo, por exemplo, fazem parte do conceito de mobilidade corporativa (PETZHOLD \& LINDAU, 2015).

São escassos os estudos nacionais sobre o papel das empresas na mobilidade urbana (mobilidade corporativa), e o resultado das estratégias de gestão da demanda de viagens casa trabalho. Faz-se necessário que as empresas consideradas PGV estejam dispostas a implementar ações mitigadoras dos problemas da mobilidade em seu entorno, nas cidades como um todo, e monitorá-las, bem como estudos que as auxiliem neste processo. 


\subsection{Gerenciamento da Mobilidade}

Formas de manter o uso equilibrado dos sistemas de transporte e sua coexistência pacífica no espaço urbano vêm sendo estudadas, e novos métodos e conceitos de planejamento vêm sendo aplicados nas cidades. De maneira geral, elas apresentam um enfoque interdisciplinar, no qual as variáveis socioeconômicas, ambientais e a dinâmica da nova realidade das cidades devem ser consideradas. Neste contexto, o modelo de crescimento espacial conhecido como urban spraw/ ${ }^{4}$, cujo pilar reforça o papel da indústria automobilística, abre espaço para modelos de cidades mais compactas, smart growth ${ }^{5}$, bem como a adoção de estratégias de gestão da demanda, mantendo a oferta da rede de infraestrutura (CASTRO, 2006).

Sobre o gerenciamento da demanda por viagens, ou gerenciamento da mobilidade, o TDM (Transportation Demand Management), nos Estados Unidos, e MM (Mobility Management), na Europa, vêm se constituindo como fundamentos à inserção de políticas de mobilidade no Brasil, com intuito de promover a sustentabilidade, considerando a integridade ambiental, a equidade social e a eficiência econômica (ALEXANDRE, 2008; MENEZES E BALASSIANO, 2005).

O TDM surgiu pela primeira vez nos Estados Unidos nos anos 70, ganhando ênfase em duas grandes crises: a crise do petróleo, em 1973, que fez o preço dos produtos derivados do petróleo dispararem, e, em 1979, com a crise energética, quando houve um aumento significativo do preço do combustível e da inflação. Viu-se, então, a necessidade de se buscar alternativas para a redução do consumo energético e, consequentemente, da dependência dos combustíveis fosseis.

Da mesma forma, o MM surgiu na Europa, com o objetivo de entender o comportamento das pessoas na escolha do modal de suas viagens e, assim,

\footnotetext{
${ }^{4}$ A expressão "sprawl" traduzida para o português pode significar espraiamento. O termo possui diferentes definições na literatura. Pode ser utilizado para designar uma expansão populacional, em sua maioria incontrolada, para áreas com menor densidade urbana. Esta expansão envolve riscos ambientais, a saúde, e efeitos sociais indesejáveis, aumentando a fragilidade da região. FRANZ, G.; MAIER, G.; SCHRÖCK, P. Urban sprawl: how useful is this concept?, Viena, 2006.

${ }^{5}$ Smart growth surge nos Estados Unidos no final do século XX como reação ao modelo de expansão do subúrbio americano e a busca pela sustentabilidade no modelo baseado na Europa de cidade compacta. DUANY, A; SPECK, J; LYDON, M. The Smart growth manual. Nova York: McGraw Hill, 2010.
} 
promover mudanças de atitude, como o uso de transportes mais sustentáveis. No centro das estratégias do MM, encontram-se medidas soft, como informação e comunicação, organização e coordenação de atividades de diferentes parceiros, as quais aumentam a eficácia de medidas hard no transporte urbano, tais como construção de novas linhas de tráfego, avenidas, ciclovias, dentre outras, e muitas vezes não requerem grandes investimentos financeiros.

Assim, tanto o TDM quanto o MM, consistem em um conjunto de medidas, políticas, programas orientados, serviços de mobilidade inovadores e produtos que buscam incentivar o uso de alternativas de transportes mais sustentáveis, reduzindo o número de viagens por automóveis, especialmente aquelas com um único ocupante. Este gerenciamento busca entender o comportamento das pessoas na escolha do modal de transporte, promovendo ações que atendam toda a demanda, de maneira mais sustentável e economicamente eficiente (LITMAN, 2011).

\subsection{Oportunidades e desafios da Mobilidade Corporativa}

Uma das causas dos períodos de congestionamentos recorrentes ${ }^{6}$ é a atividade das empresas consideradas polos geradores de viagens, pois estas empresas geram um tráfego que se repete com frequência em um mesmo horário. O planejamento do gerenciamento da mobilidade em uma empresa, portanto, é um processo que envolve a construção de uma cultura de mobilidade nos funcionários, clientes e visitantes, com reflexos diretos no tempo de deslocamento, além de reduzir custos sociais e empresariais, e reter talentos, visto que cada vez mais as novas gerações de profissionais valorizam tais benefícios. Para isso, são implementadas medidas e estratégias, a fim de que sejam aderidas e tenham eficácia.

Estas medidas e estratégias são baseadas em um diagnóstico do padrão de viagem dos envolvidos. O resultado do diagnóstico trará subsídios para a

\footnotetext{
${ }^{6}$ Congestionamento recorrente trata-se da perda de capacidade de escoamento de uma via, com retenção e redução gradual de veículos que circulam com frequência nos mesmos horários, geralmente nos horários de pico. McGROARTY, J. Neihoff Urban Studio - W10. 2010.
} 
elaboração de um plano de mobilidade com metas e objetivos claros, o que, por sua vez, auxiliará na tomada de decisão sobre quais medidas e estratégias oferecerão melhor custo-benefício (DECASTRO, 2014).

O incentivo à mobilidade corporativa deve envolver parcerias entre os setores públicos e privados, em conjunto com instrumentos que apoiem e encorajem a mudança de atitude e comportamento em relação aos modos de transporte, promovendo o uso racional dos mesmos (CASTRO, 2006).

O uso do transporte coletivo, bicicletas e caminhada são algumas alternativas de deslocamento sempre incentivadas pelas empresas que já adotam um plano de mobilidade corporativa. Além destas alternativas, programas de carona e carsharing, fornecimento de ônibus fretado, compartilhamento de taxis, escalonamento de horários e semana comprimida, estímulo ao home-office e teleconferências, entregas por bicicleta, sistemas de gestão de estacionamento, incentivos e desincentivos financeiros, entre outros, são algumas estratégias adotadas por empresas do mundo todo, e ainda pouco disseminadas no Brasil (EMBARQ BRASIL, 2014).

Em parceria com algumas instituições, a EMBARQ BRASIL elaborou o Guia de Estratégias de mobilidade para organizações, buscando estimular e promover debates sobre mobilidade urbana, bem como sobre os desafios no engajamento e na articulação interna das organizações. Esse guia contém referências e boas práticas já adotadas por algumas instituições, enfatizando sete estratégias de mobilidade corporativa, com base em publicações desenvolvidas por instituições governamentais e departamentos internacionais de transporte, além das experiências da própria organização EMBARQ BRASIL (EMBARQ BRASIL, 2017).

Dentre as estratégias do Guia, destacam-se: Transporte a pé, bicicleta, transporte coletivo, transporte fretado, carona, teletrabalho e estacionamento. São relacionadas ações a serem realizadas para fomentar o uso da estratégia em questão, Barreiras e como superá-las, destacando os desafios enfrentados e como solucioná-los, Estudo de caso nacional, indicando as motivações e os resultados alcançados, Dúvidas frequentes, mencionando as dúvidas mais frequentes dentre os gestores, e Referências adicionais, indicando material para consulta (EMBARQ BRASIL, 2017; PERTH, 2013; BRACKNELL FOREST COUNCIL, 2011; LITMAN, 2011; NZ TRANSPORT AGENCY, 2011). 


\section{Transporte a pé}

A caminhada é uma alternativa saudável, acessível e barata, frente a carros e outros veículos, para realizar viagens de curta distância. Algumas ações propostas pela literatura são: criação de grupos de corrida e caminhada, incluindo grupos que compartilhem pontos de origem comuns; disponibilização de vestiários, armários, acesso exclusivo e guarda-chuvas na recepção; flexibilização dos horários de entrada e saída para que os funcionários aproveitem a luz do dia; elaboração de mapa do entorno com informações de serviços da região, atalhos e locais seguros de travessia; bonificações e incentivo ao uso de pedômetro; manutenção das calçadas e; qualificação das rotas de pedestres para que se conectem a serviços e pontos de integração modal.

Um dos maiores desafios para o incentivo aos deslocamentos a pé é a demonstração de que é uma alternativa viável. Fatores preponderantes na escolha vão desde segurança à acessibilidade, o que inclui manutenção e iluminação dos locais de passagem. Neste caso, é necessário trabalho em conjunto com a alçada pública, e priorização dos requisitos de exclusividade de acesso (EMBARQ BRASIL, 2017; LITMAN, T, 2011). Outro fator é a necessidade do carro para as pessoas que exercem outras atividades antes ou após o expediente. Como solução, empresas podem prover vouchers e carros compartilhados.

Com relação às dificuldades no incentivo à mobilidade ativa, a empresa, propondo grupos de caminhada, possibilita um maior número de pessoas circulando nas ruas, o que propicia o aumento da sensação de segurança. $\mathrm{Na}$ inviabilidade de locais para higiene ou bicicletários, é possível buscar convênios com serviços locais e comércio que já tenham espaço disponível. Quanto a funcionários com origens mais distantes do local de trabalho, a multimodalidade é essencial. A integração entre o uso do transporte de massa com a caminhada dispõe dos mesmos benefícios de funcionários com moradia mais próxima do trabalho (EMBARQ BRASIL, 2017; LITMAN, 2011).

\section{Uso de bicicleta}

A bicicleta vem ocupando um importante espaço na mobilidade urbana, sendo cada vez mais utilizada, principalmente nos deslocamentos ao trabalho e/ou 
estudo. A expansão da malha cicloviária deve ser promovida pelo setor público, além da integração desta malha a outros modais, e incentivada pelas organizações que, por sua vez, devem fornecer estrutura, como vestiários e bicicletários, adequada para os utilizadores deste meio de transporte.

Fato é que o uso contínuo da bicicleta permite maior fluidez e economia de tempo e custo, com o aumento do espaço para a circulação de pessoas e dos transportes coletivos. É um meio leve, ágil, eficiente em deslocamentos de curta distância, humanizado, silencioso e democrático (EMBARQ BRASIL, 2017; PERTH, 2013; BRACKNELL FOREST COUNCIL, 2011; LITMAN, T, 2011). Proporciona aumento na qualidade de vida, na medida em que promove melhoria na saúde pública da população, a emissão zero de poluentes atmosféricos, socialização e reduzido impacto na paisagem.

Assim, para a criação de uma cultura e incentivo ao hábito do transporte por bicicleta, organizações podem promover algumas ações, a saber: disponibilização de estrutura e equipamentos adequados como vestiários, chuveiros e armários, bicicletários ou paraciclos, ou obter parcerias com academias e prédios vizinhos que possam dispor de tais recursos; implantação de acessos exclusivos para pedestres e ciclistas; criação de grupos de ciclistas e promoção de atividades de ciclismo; disponibilização de bicicletas compartilhadas para deslocamento ao trabalho ou durante o horário de intervalo; elaboração e circulação de mapas com rotas seguras para bicicletas e; em parceria com o poder público, influenciar e cobrar a disponibilização de rotas e ciclovias iluminadas e seguras, além de calçamento e integração das ciclovias e ciclo faixas aos demais modais.

As barreiras para a implementação e incentivo ao uso do transporte por bicicleta tangem, além da conveniência, e segurança pública e viária, fatores mais específicos, como receio de furto da bicicleta, medo de circulação no trânsito, necessidade de higienização, ou topografia do local. A fim de se criar alternativas para estas barreiras, as organizações podem: flexibilizar os horários para evitar saídas em horários de pico, além de dispor horários ainda à luz do dia e possibilidade de criação de grupos; investir em recursos para os vestiários e sua manutenção, além de bicicletários que melhoram a segurança contra os furtos; promoção de palestras sobre segurança no trânsito; entre outras ações que minimizam possíveis acidentes, a saber, que todo acidente envolvendo funcionário a caminho do trabalho ou retornando pode ser considerado acidente de trabalho; em relação à topografia, garantir que haja integração modal nos 
deslocamentos, e até mesmo o incentivo ao uso de bicicletas elétricas através de financiamento da organização (EMBARQ BRASIL, 2017; PERTH, 2013; BRACKNELL FOREST COUNCIL, 2011; LITMAN, T, 2011).

\section{Transporte coletivo}

O serviço de transporte coletivo desempenha o papel de conectar as áreas residenciais às áreas de lazer, atividades produtivas e terciárias. Portanto, a proximidade a estações e terminais de transporte coletivo, e corredores de ônibus ou linhas de metrô e trem é atraente para empresas de todos os portes. O transporte coletivo proporciona maior capacidade para locomoção, velocidade adequada, acessibilidade, segurança e custo acessível, no entanto, entende-se que esses aspectos e funcionamento variam por localidade.

No Brasil, segundo a Constituição Federal em seu artigo 30, inciso V, a competência executiva do transporte urbano é do Município enquanto a do transporte Intermunicipal fica a cargo do Estado. Dito isto, as organizações que buscam consolidar seus planos de mobilidade corporativa devem estreitar relações de parceria e diálogo com o poder público, no intuito de melhorias do transporte coletivo urbano, a fim de incentivar o uso do mesmo por seus funcionários (EMBARQ BRASIL, 2017; NZ TRANSPORT AGENCY, 2011).

Para que haja a migração do uso do transporte individual para o coletivo, algumas medidas podem ser tomadas pelas empresas, tais como: disponibilização de mapas e informações sobre linhas que passam no entorno, assim como itinerário e tabela horária; indicação de aplicativos de rotas do transporte coletivo; flexibilização dos horários de entrada e saída do expediente para evitar o uso do transporte coletivo em horários de pico; implementação de integração seja por carona, grupos a pé, ou fretados nas estações e terminais; redução ou isenção do desconto de $6 \%$ (no caso do Brasil) do vale transporte na folha salarial; priorização de instalação de escritórios em regiões com boa oferta de transporte coletivo; além disso, é importante o diálogo com o poder público para qualificação das estações, terminais e pontos de parada com melhoria nos abrigos, disponibilização de informação e iluminação; qualificação dos percursos para os usuários e trajeto/rota para os veículos do transporte coletivo, com calçamento e iluminação adequada e; até mesmo modificação de tabela horário do transporte coletivo, caso o ponto final do mesmo seja próximo as organizações 
e estações de trabalho (EMBARQ BRASIL, 2017; NZ TRANSPORT AGENCY, 2011).

Existem barreiras organizacionais e comportamentais para o maior uso do transporte individual em detrimento do coletivo, como: baixa frequência de circulação ou ausência em determinadas regiões; falta de confiabilidade e segurança nos veículos; disponibilidade de informação, e integração modal; entre outras que podem ser superadas com a devida ação do poder público com extensão das linhas de ônibus, melhorias no acesso, qualificação da frota e trajeto, aumento da oferta de veículos, além, da melhor distribuição dos serviços e oportunidades na área urbana, reduzindo, assim, os impactos do espraiamento recorrente nas cidades. Ainda, as organizações também podem rever suas políticas de estacionamento, auxílio-combustível e uso de veículos corporativos, além da redução do desconto máximo de $6 \%$ em folha de pagamento para o vale transporte, estimulando o uso sustentável do transporte coletivo (EMBARQ BRASIL, 2017; NZ TRANSPORT AGENCY, 2011).

\section{Transporte fretado}

O transporte fretado apresenta a personalização, flexibilidade e comodidade dos veículos particulares, porém, com características do transporte coletivo, como a capacidade. Em sua maioria, organizações adotam o fretado para locais onde há baixa oferta de transporte coletivo, aumentando a produtividade e reduzindo atrasos, podendo também contribuir como fator de inclusão social.

Para um melhor aproveitamento do transporte fretado, as organizações podem adotar sistemas e softwares de otimização/roteirização; política de retorno rápido em casos emergenciais, com a disponibilização de voucher ou veículos compartilhados; comodidades no veículo como wi-fi e ar-condicionado; disponibilização de informações como, horário e o itinerário; Implementação de áreas de embarque/desembarque próximas as organizações e integração das rotas com locais estratégicos como shoppings, estações de metrô e trem, terminais de ônibus (EMBARQ BRASIL, 2017).

Entre os desafios deste tipo de fretamento estão o custo e a legislação. 0 custo está associado ao planejamento das rotas e aderência dos funcionários ao sistema, visto que a capacidade deste tipo de transporte considera apenas 
pessoas sentadas, e as rotas devem ser bem definidas, evitando gastos excessivos em um modelo de fluxo que poderia ser mais bem aproveitado, e a legislação, principalmente no transporte intermunicipal/estadual, onde o tipo de contratação e serviços oferecidos dependem da regulamentação local.

No Brasil, a escolha pelo fretamento acontece principalmente nas indústrias, universidades e empresas com fábricas, em sua maioria, localizadas fora dos centros das cidades para auxiliar o ir e vir de seus funcionários, assegurando a produtividade (EMBARQ BRASIL, 2017).

\section{Programas de carona}

Estimular a carona é uma das formas mais eficientes de reduzir o número de viagens em automóveis com apenas um ocupante. Ela já ocorre informalmente, porém, um programa de carona pode potencializar seus benefícios.

Trata-se de uma oportunidade não só de otimizar o uso do carro de maneira mais sustentável, como também se volta a redução de custos e socialização das pessoas ao longo do deslocamento. Para o incentivo aos programas, as organizações podem ceder espaços exclusivos em estacionamento para quem oferece carona, ou até mesmo descontos caso as vagas sejam cobradas. Além disso, as organizações podem promover eventos de integração possibilitando o encontro de indivíduos com rotas comuns, pontos de carona e a adoção de aplicativos e softwares de carona (EMBARQ BRASIL, 2017).

Como toda estratégia empresarial, a organização deve estudar a viabilidade de suas ações, como um programa de carona neste caso. A organização deve mapear a quantidade de funcionários, e seus destinos e rotas comuns. No entanto, mesmo com rotas e horários comuns, ainda podem existir barreiras como, por exemplo, a realização de atividades antes ou após o expediente. Neste caso, seria interessante verificar alguma similaridade nas atividades a fim de incentivar o compartilhamento da viagem. Outra barreira pode ser o porte da empresa. Em casos de empresas menores, é possível a busca por parceiros em organizações próximas ou mesma torre comercial viabilizando a carona. Nesta forma de compartilhamento, muitas organizações podem inferir o medo por rotatividade, o que não se confirma visto que, em sua maioria, o que faz o funcionário deixar uma empresa é o que ela não promove ou promove mal. 
De forma geral, para aumentar a aceitação e utilização de programas de carona, é importante condicioná-los, com perfis e preferências pré-determinadas (EMBARQ BRASIL, 2017).

\section{Teletrabalho: Home-Office e Teleconferência}

O teletrabalho pode ser definido como uma modalidade de trabalho intelectual, que pode ser realizada à distância e fora do local de trabalho (exemplo: Em domicílio, escritório satélite, espaços de coworking, ou até mesmo em cafés e aeroportos), através de tecnologias de informação e comunicação. Para tanto, as atividades realizadas à distância, podem ser escalonadas ou com periodicidade, variando de acordo com a estratégia da organização (EMBARQ BRASIL, 2017).

Ao alcançar tal abertura para o teletrabalho, a organização deve promover treinamentos e capacitações aos funcionários (ferramentas de vídeochamadas ou conferência), além de disponibilizar suporte remoto, materiais como fones de ouvido e webcam, e mesas rotativas nos escritórios.

Para consolidação de tais atividades, é importante a implementação de uma política institucional que defina os custos relacionados ao funcionário em virtude do teletrabalho (luz, internet, equipamentos de informática, móveis e telefone) e os critérios de elegibilidade (EMBARQ BRASIL, 2017). Ainda, podem existir barreiras, como a ausência de postura gerencial, visto que não há um monitoramento físico das atividades, além dos critérios para elegibilidade e burocracias contratuais envolvidas, como benefícios (vale transporte e alimentação), despesas e horas trabalhadas.

O departamento jurídico e de recursos humanos devem deixar transparentes as cláusulas contratuais e a forma como deve ser monitorado o regime de teletrabalho. Assim, a aplicação dessas tecnologias poupa tempo e aumenta a produtividade dos funcionários, reduzindo os deslocamentos e contribuindo para a redução da emissão de poluentes na atmosfera (EMBARQ BRASIL, 2017).

\section{Sistemas de gestão de estacionamento}

A otimização do uso de estacionamentos é essencial para a política de mobilidade corporativa. Estacionamentos, além de incentivar o uso constante do 
carro devido ao conforto e praticidade, representam custos diretos às empresas, seja na manutenção, vigilância, iluminação e seguro, como na necessidade do aluguel de mais vagas.

$\mathrm{Na}$ literatura, identificam-se algumas ações como: cobrança de taxa pelo uso do estacionamento, de preferência diária, evitando uma deseconomia com vagas não utilizadas; redução do número de vagas para carros, substituindo por vagas de bicicletas, pessoas com mobilidade reduzida e visitantes; vagas dedicadas a estacionamento de curto período; priorização de vagas para quem oferece carona; distribuição das vagas de acordo com a demanda (critérios de acessibilidade/proximidade ao local de trabalho, necessidade operacional, mobilidade reduzida ou gestante) e não por hierarquia ou tempo de empresa; acordos com a comunidade local e funcionários, até mesmo autoridades, caso exista abundância de estacionamentos gratuitos no entorno da organização.

É importante salientar que mudanças na política de estacionamento podem ser desafiadoras. É preciso ações mais abrangentes para desenvolver a aceitação dos funcionários, e medidas que incentivem o uso de transportes mais sustentáveis implementadas antes de qualquer alteração ou restrição do uso de estacionamentos. Destaca-se que a abordagem das estratégias supracitadas dentro de um plano integrado, potencializa uma redução de até $24 \%$ no número de viagens em automóvel com um único ocupante (IRELAND, 2011; UNITED KINGDOM, 2008).

Assim, a gestão da mobilidade corporativa traz benefícios como: redução nas taxas de absenteísmo; retenção de talentos; diminuição de gastos com saúde; melhoria da produtividade; redução de custos com transporte e estacionamento; ganhos de imagem; redução de emissões de gases de efeito estufa na atmosfera; qualidade de vida das cidades, entre outros. Estes benefícios são comprovados após o monitoramento das ações implementadas por cada empresa através do Plano de Mobilidade Corporativa (NZ TRANSPORT AGENCY, 2011).

A adequação a medidas e estratégias, depende do diagnóstico de cada empresa onde serão analisadas as ações a serem tomadas, os impactos causados e os benefícios gerados. É válido ressaltar que nem todas as empresas se adequarão a todas as medidas, e o importante é que no âmbito da mobilidade sustentável, todas tenham a sua contribuição. 


\subsection{Elaboração dos Planos de mobilidade corporativa}

As questões do transporte no âmbito corporativo vão muito além do número de vagas de estacionamento. O setor corporativo tem influência direta na configuração dos deslocamentos das cidades e na busca por soluções às dificuldades relacionadas à mobilidade urbana. Estas soluções devem ser estudadas e planejadas integrando os responsáveis do setor (PETZHOLD \& LINDAU, 2015; VAN MALDEREN et al., 2012).

A introdução de um Plano de Mobilidade nas empresas tem o papel fundamental de estimular a mudança nas formas de deslocamento para um modelo que promova o bem-estar dos funcionários e redução dos impactos ambientais nas cidades. O Plano consiste em medidas integradas para promoção de deslocamentos mais sustentáveis, através de ações como uso de bicicletas, caminhadas, promoção de carona e carsharing, utilização de biocombustíveis, flexibilização ou escalonamento dos horários da jornada de trabalho, home-office, entre outras (BRACKNELL FOREST COUNCIL, 2011).

O conteúdo para elaboração de um Plano de Mobilidade é diferenciado. Cada organização deve adaptar a metodologia conforme necessidade. O Plano é baseado fundamentalmente pela sequência metodológica representada na Figura 4.

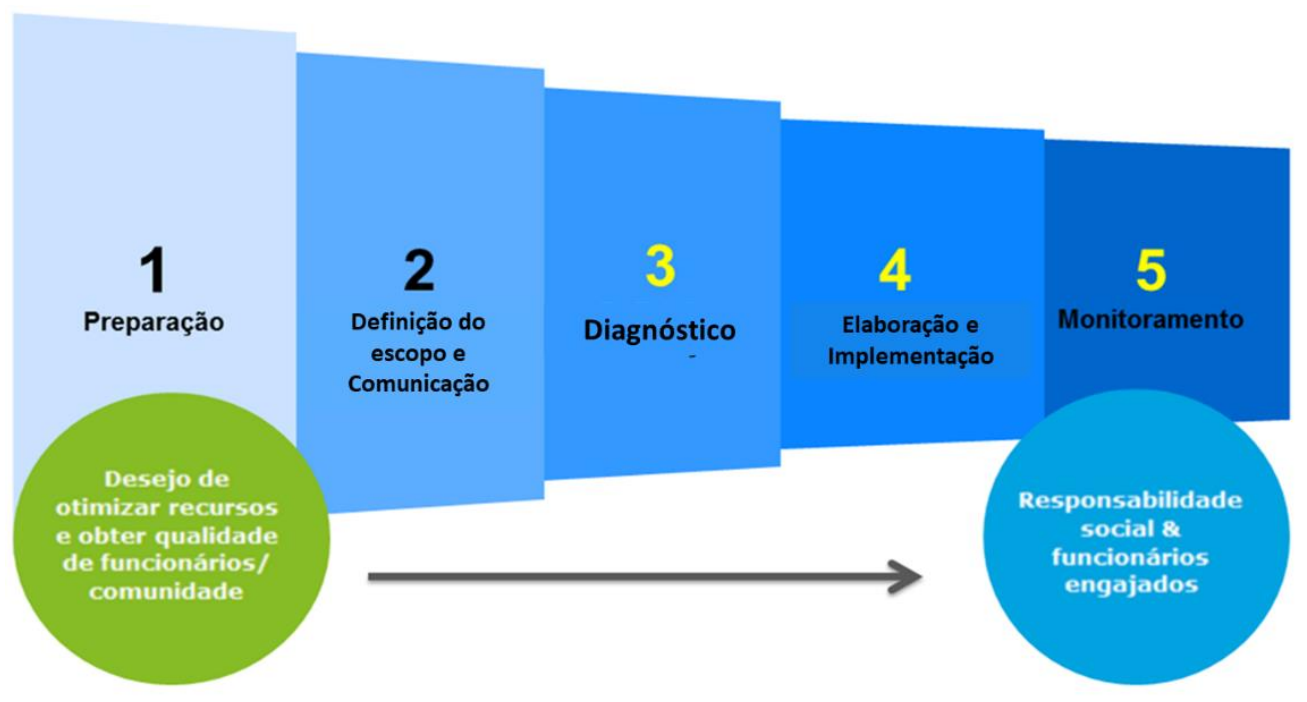

Figura 4: Esquemático de Plano de Mobilidade Corporativa

Fonte: Elaboração Própria. 
Estas fases possibilitam não só o aumento do número de funcionários sem a necessidade de expansão de estacionamentos ou espaço físico dos escritórios, como também auxiliam na redução de viagens e custos de transporte, como estacionamento, combustível, vale transporte, desembolso de taxis e afins (EMBARQ Brasil, 2014).

Inicialmente, é feita a preparação onde são mapeados os atores envolvidos e necessidades da organização, alinhados com os gestores e diretoria, além da definição do escopo inicial, onde são definidos a visão, objetivos e metas a serem alcançadas com o Plano (EMBARQ BRASIL, 2014). Com isso, faz-se necessário a elaboração de um diagnóstico. Este diagnóstico prevê a caracterização do perfil dos funcionários e suas formas de deslocamento, as influências diretas e indiretas, avaliação das condições e ofertas de transporte no entorno, incentivos para a diversificação modal, além das políticas da organização que podem influenciar no Plano.

$\mathrm{Na}$ fase de elaboração, o escopo é reavaliado com base nos resultados do diagnóstico. São criados indicadores de desempenho e alocados recursos para a implementação do Plano, o orçamento é revisto, contemplando as medidas e ações estabelecidas, e é definido um programa de ações com cronograma estabelecido para cada uma delas (EMBARQ Brasil, 2014).

A implementação assegura a operação do Plano de forma plena. A organização deve promover incentivos para que os funcionários continuem engajados e que as medidas sejam divulgadas. Para a garantia das metas e dos objetivos estabelecidos, é necessário o monitoramento das ações propostas. O Plano deve ser revisto caso o desempenho esteja abaixo do previsto (EMBARQ Brasil, 2014).

Embora as organizações não determinem a escolha do modal ou como deve ser o deslocamento casa-trabalho ou estudo, a utilização dos Planos de Mobilidade Corporativa potencializa a mudança de hábitos das pessoas para meios mais sustentáveis. Os Planos podem contribuir para as diretrizes de responsabilidade social da organização pela ISO 26000, a política ambiental da organização pela ISO 14001, ou até mesmo para o desempenho dos índices de sustentabilidade em bolsas de valores e nas metas da NDC brasileira (Contribuição Nacionalmente Determinada). 


\subsection{Principais experiências e casos de sucesso}

Esta seção faz menção a casos internacionais e nacionais, onde as práticas de mobilidade corporativa foram aplicadas e obtiveram êxito com melhorias significativas, em sua maioria mensuráveis.

\section{SEATTLE CHILDREN'S HOSPITAL ${ }^{7}$}

Em 2007, a direção do Hospital decidiu duplicar suas instalações, e para isso, seria necessário também ampliar o estacionamento (500 novas vagas), com gastos na ordem de US\$20 milhões. Com intuito de utilizar os recursos para investimento em novos leitos e melhor atendimento, o hospital decidiu, então, intensificar a adoção de medidas de mobilidade corporativa de um plano existente desde 1995. Através de ações como redução das vagas de estacionamento, cobrança de tarifas diárias no lugar de mensais para seu uso, bonificações para os que registram viagens não motorizadas, e aluguel de bicicletas, o percentual de deslocamentos com um único ocupante que em 1995 era de $73 \%$ caiu para $51 \%$ em 2007.

\section{PROJETO PILOTO DE MOBILIDADE CORPORATIVA CENU-WTC E PROJETO PILOTO SANTA FÉ, MÉXICO. ${ }^{8}$}

A região da Avenida Engenheiro Luís Carlos Berrini, possui um dos maiores congestionamentos da região metropolitana de São Paulo, com o maior índice de uma pessoa por veículo segundo a pesquisa Origem-Destino do metrô de São Paulo (METRO-SP, 2007).

Assim, o Banco Mundial em parceria com a World Resources Institute (WRI) e Embarq Brasil iniciou um projeto piloto em 2012, voluntário, com o objetivo de implementar medidas que mitigassem os transtornos causados pelos congestionamentos naquela região, através do uso de meios alternativos de locomoção pelos colaboradores. Estas medidas foram apresentadas às empresas

\footnotetext{
7 Informações disponíveis em: < https://www.lume.ufrgs.br/bitstream/handle/10183/138301/ 000989145. pdf?sequence=1>. Acesso em Junho de 2018.

8 Dados do Projeto disponíveis em: < $<$ http://www.worldbank.org/content/dam/Worldbank/document/ Energy/TDM-Pilot-ReportDec2013-SP-Mex.pdf>. Acesso em Junho de 2018
} 
sediadas no Centro Empresarial das Nações Unidas (CENU) e World Trade Center (WTC), onde trabalham em torno de 6.000 pessoas.

Para garantia e confiabilidade no projeto, foram fechadas parcerias com Bike Anjo (Fornece dicas, recomendação de rotas, acompanhamento do trânsito), Caronetas (Estimula a obtenção de carona entre funcionários das empresas), Transfretur (Disponibiliza serviços fretados), TC Urbes (Empresa de desenho urbano que desenvolve melhorias para o transporte alternativo), e Zazcar (Empresa de aluguel de veículos).

$\mathrm{Na}$ fase de diagnóstico, ao todo 20 empresas participaram. Na fase de implementação, restaram 10 que iniciaram a elaboração dos planos de mobilidade. Realizaram-se reuniões com as empresas envolvidas, e coleta de dados para traçar a pesquisa e recomendações, elaborando seu plano de mobilidade.

Segundo os dados recolhidos, dos colaboradores que dirigiam para o trabalho: $42 \%$ optariam pela bicicleta (destes, $77 \%$ optariam pela bicicleta se houvesse vestiário e armários no local, e $23 \%$ caso tivessem um companheiro para pedalar); $83 \%$ iriam de carona (destes, $46 \%$ optariam caso tivessem opção de retornar em casos de emergência, $42 \%$ caso a carona fosse do mesmo prédio, e $30 \%$ se tivessem um meio de se locomover ao longo do dia); $80 \%$ optariam por ônibus fretado (destes, $72 \%$ utilizariam caso tivessem mais de uma opção de horário, $38 \%$ se o serviço fosse pago, $36 \%$ optariam caso tivessem opção de retornar em casos de emergência, e $20 \%$ se fossem pessoas do mesmo prédio); $66 \%$ optariam pelo transporte público. ${ }^{9}$

Assim, após análise de dados em 2013, recomendou-se três medidas principais: Implementação de home-office; Cadastro das empresas no Caronetas; Compartilhamento dos serviços de ônibus fretados; entre outras ações.

Após quatro meses na implementação do projeto piloto em São Paulo, como resultado (Figura 5), em sua maioria, as empresas envolvidas obtiveram reduções significativas nas viagens com um único ocupante, após adoções de estratégias de mobilidade corporativa, principalmente no uso do serviço de caronas, onde não há custo para a empresa ou o funcionário. Em uma análise mais detalhada das

9 Dados encontrados em: < http://thecityfixbrasil.com/2012/10/09/conheca-o-projetopiloto-de-mobilidade-corporativa-cenu-wtc-em-sao-paulo/>. Acesso em Junho de 2018. 
empresas cuja porcentagem aumentou, verificou-se haver pouca relação com a implementação dos programas, devido à baixa taxa de resposta, comparada a base de dados antes da implementação dos programas, além de algumas iniciativas estarem sendo realizadas apenas para novos funcionários.

\begin{tabular}{|c|c|c|c|c|c|c|}
\hline \multirow{2}{*}{\begin{tabular}{|c|}
$\begin{array}{c}\text { Estacionamento nas } \\
\text { empresas }\end{array}$ \\
Consulado Canadense
\end{tabular}} & \multirow{2}{*}{$\begin{array}{c}\begin{array}{c}\% \text { Viagens com } \\
\text { um único } \\
\text { ocupante (inicio) }\end{array} \\
50 \%\end{array}$} & \multirow{2}{*}{$\begin{array}{c}\text { \% Viagens com um único } \\
\text { ocupante } \\
\text { (após implementação de } \\
\text { estratégias) }\end{array}$} & \multicolumn{4}{|c|}{ Estratégias de mobilidade adotadas } \\
\hline & & & Caronetas & & & \\
\hline Compuware & $74,30 \%$ & $67,20 \%$ & Caronetas & Teletrabalho & $\begin{array}{c}\text { Workshop } \\
\text { sobre }\end{array}$ & \\
\hline Dow Corning & $78,30 \%$ & $72,50 \%$ & & & & \\
\hline Hotel Hilton & $37,60 \%$ & $55,80 \%$ & Caronetas & & & \\
\hline Hotel Sheraton & $34,80 \%$ & $41,30 \%$ & Caronetas & $\begin{array}{c}\text { Workshop } \\
\text { sobre }\end{array}$ & & \\
\hline IBGC & $41,6 \%$ & $27 \%$ & Caronetas & Teletrabalho & $\begin{array}{c}\text { Subsídio ao } \\
\text { vale }\end{array}$ & $\begin{array}{c}\text { Parking Cash } \\
\text { out }\end{array}$ \\
\hline Universidades Laureate & $67,10 \%$ & $52,30 \%$ & Caronetas & & & \\
\hline Tishman Speyer & $58,10 \%$ & $65,50 \%$ & & & & \\
\hline Toyota & $51,90 \%$ & $35,10 \%$ & & & & \\
\hline WTC & $36,70 \%$ & $41,00 \%$ & Caronetas & & & \\
\hline
\end{tabular}

Figura 5: Monitoramento da implementação de medidas de mobilidade corporativa Fonte: Adaptado da dissertação de Salas et al.(2015).

Assim como em São Paulo, outro projeto piloto em parceria com o Banco Mundial e EMBARQ México, também com o objetivo de identificar dinâmicas e restrições que propiciam possibilidade de estratégias de gestão da mobilidade e o papel indutor das organizações nestas mudanças, foi realizado na Cidade do México (SALAS et al., 2015).

Um dos principais distritos comerciais da Cidade do México, Santa Fé foi escolhida para o projeto piloto, onde estão localizadas empresas como a Microsoft, IBM e HP, que nos Estados Unidos já aplicam metodologias de gestão da mobilidade nos deslocamentos de seus funcionários.

Foram organizados seminários, onde foram apresentados os objetivos e potenciais benefícios do projeto, assim como o recrutamento das organizações que se voluntariaram. Em Santa Fé, também foram fechadas parcerias com empresas de ônibus fretado, aluguel de bicicletas, e carpooling, este com a empresa Aventones, pioneira na venda de softwares de carpooling para companhias da Cidade do México.

Em Santa Fé, a pesquisa foi realizada com três companhias finais, onde observou-se que a média de uso de veículo com um único ocupante foi de 59\%, 
apenas $7 \%$ dos funcionários fizeram pelo menos um dia de teletrabalho nas duas últimas semanas antes da pesquisa, e o número de vagas de estacionamento gratuitas oferecidas pelas organizações era alto, favorecendo o uso do automóvel.

Para melhor compreensão da influência do estacionamento gratuito no comportamento dos funcionários e decisões das empresas, três companhias do projeto piloto de SP e duas do México, responderam um questionário (Figura 6) onde ficou evidenciada a dificuldade de implementação de medidas de TDM enquanto o uso do estacionamento continuar fortalecido, como exemplo, das cinco empresas, apenas duas cobravam pelas vagas de estacionamento extra de seus funcionários, enquanto o restante oferecia sem custo adicional.

Além disso, o aumento da oferta destas vagas traz dificuldades na adoção do "parking cash out", por exemplo, estratégia de TDM a qual a empresa oferece dinheiro no lugar de espaço no estacionamento, quando este é gratuito ou subsidiado. Ou seja, o funcionário recebe uma compensação pela não utilização do estacionamento gratuito.

\begin{tabular}{|l|c|c|c|c|c|}
\hline \multirow{2}{*}{ Estacionamento nas empresas } & \multicolumn{3}{|c|}{ São Paulo } & \multicolumn{2}{c|}{ Cidade do Mexico } \\
\cline { 2 - 6 } & Microsoft & Compuware & IBGC & SCA & Cinepolis \\
\hline Número de funcionários & 900 & 67 & 33 & 381 & 87 \\
\hline $\begin{array}{l}\text { Vagas de estacionamento incluídas no contrato } \\
\text { de locação }\end{array}$ & 150 & 6 & 12 & 106 & 49 \\
\hline Vagas alugadas de estacionamento & 465 & 45 & 2 & 82 & 23 \\
\hline \# de funcionários com estacionamento gratuito & 615 & 6 & 12 & 188 & 72 \\
\hline $\begin{array}{l}\text { \# de funcionários que são cobrados pelo uso de } \\
\text { vagas adicionais }\end{array}$ & 0 & 45 & 2 & 0 & 0 \\
\hline $\begin{array}{l}\text { \% de funcionários com vagas subsidiadas ou } \\
\text { gratuitas }\end{array}$ & $68 \%$ & $76 \%$ & $36 \%$ & $49 \%$ & $83 \%$ \\
\hline Custo por vaga (USD) & $\$ 200$ & $\$ 151$ & $\$ 100$ & N/A & $\$ 110$ \\
\hline $\begin{array}{l}\text { Gasto mensal de estacionamento - USD - } \\
\text { cenário com manobrista }\end{array}$ & $\$ 93,000$ & $\$ 6,795$ & $\$ 200$ & N/A & $\$ 2,530$ \\
\hline
\end{tabular}

Figura 6: Resultado do questionário das empresas do projeto piloto

Fonte: Adaptado da dissertação de Salas et al.(2015). 


\section{GRUPO SANTANDER}

Em 2010 o Grupo Santander ${ }^{10}$ iniciou uma política voltada para o bem-estar dos funcionários, após mudança de endereço para a Vila Olímpia em São Paulo, onde circulam em torno de 6.800 funcionários e prestadores de serviço diariamente, nos seus 31 andares, onde o estacionamento comporta 2.391 carros.

Com resultado surpreendente, desde a redução de até 2.000 veículos das ruas de São Paulo a meta de redução de $9 \%$ dos gases causadores do efeito estufa entre 2016 e 2018, o Grupo Santander contou com:

- Linhas de ônibus fretado ligando os principais edifícios administrativos às estações de trem e metrô mais próximas. Sistema de reuniões on-line, com 3 salas de telepresença e 27 de videoconferência na Sede Santander, além de 159 salas de videoconferência na rede, principais agências, diretorias e superintendências regionais.

- Infraestrutura com vestiários, armários, sala de alongamento e produtos de higiene e manutenção de equipamentos. No total, 105 vagas no bicicletário da Sede Santander.

- Programa Carona Amiga, onde o funcionário tem 35\% de desconto no estacionamento, e 10\% no Lava Jato da sede.

- Do total das vagas de estacionamento, metade é destinado aos cargos mais altos pagando $50 \%$ do valor praticado em mercado da região, e outra parte destina-se ao programa Carona Amiga.

- Flexibilidade, onde os funcionários podem entrar entre $7 \mathrm{~h}$ e $10 \mathrm{~h}$ e sair entre $16 \mathrm{~h}$ e $19 \mathrm{~h}$.

- Facilidades no próprio prédio, como academia, salão de beleza, sapateiro, lavanderia e restaurantes.

\footnotetext{
10 Dados da política disponíveis em: 


\section{ESTUDO DE CASO E ANÁLISES PRELIMINARES}

A gestão da mobilidade é uma forma de se conduzirem os deslocamentos de forma sustentável e eficiente, sendo importante que todos os segmentos da sociedade interajam e legitimem a implementação de políticas de gestão (DECASTRO, 2014). Com isso, a dissertação busca demonstrar de que forma as estratégias de Gerenciamento da Mobilidade Corporativa, incentivando mudanças e padrão de comportamento, podem beneficiar empresas, funcionários e a dinâmica da circulação urbana nas cidades considerando-se os impactos ambientais.

Percebe-se ainda uma ausência de estudos no Brasil sobre a temática da mobilidade corporativa. Esta ausência implica na existência de um espaço a ser preenchido com discussões, estratégias e aplicações práticas nas organizações. Para tanto, este capítulo analisa uma empresa sediada no bairro de São Cristóvão, na cidade do Rio de Janeiro, traçando o perfil de seus funcionários e levantando informações sobre as formas de deslocamento, custos e emissões de GEE associados, além de identificar as atuais políticas de gestão da mobilidade da empresa. Objetiva-se, dessa forma, explorar possibilidades de mudança de comportamento, utilização de novos modais ou otimização dos mesmos, além da possibilidade de implementação de um Plano de mobilidade corporativa a partir do diagnóstico obtido.

\subsection{Apresentação da Empresa}

A Empresa estudada possui sua sede na região administrativa de São Cristóvão e seu ramo é representado pela distribuição de combustíveis e varejo. O prédio sede possui 800 funcionários, distribuídos nos seus onze andares e áreas do térreo. Possui 409 vagas de estacionamento, distribuídas entre área interna e externa do prédio (terreno da empresa). Destas 409 vagas, 81 são cativas e as demais se dividem em 3 para deficientes, 25 para motos e 300 rotativas. Além disso, existem vagas para estacionamento gratuito, dependendo da hora, no entorno do prédio, na rua à frente e laterais (Figura 7). Quanto à localização geográfica, está a 400 metros das estações de metrô e trem do bairro, e em um raio de 500 metros, próximo a dois terminais importantes de ônibus da cidade. 


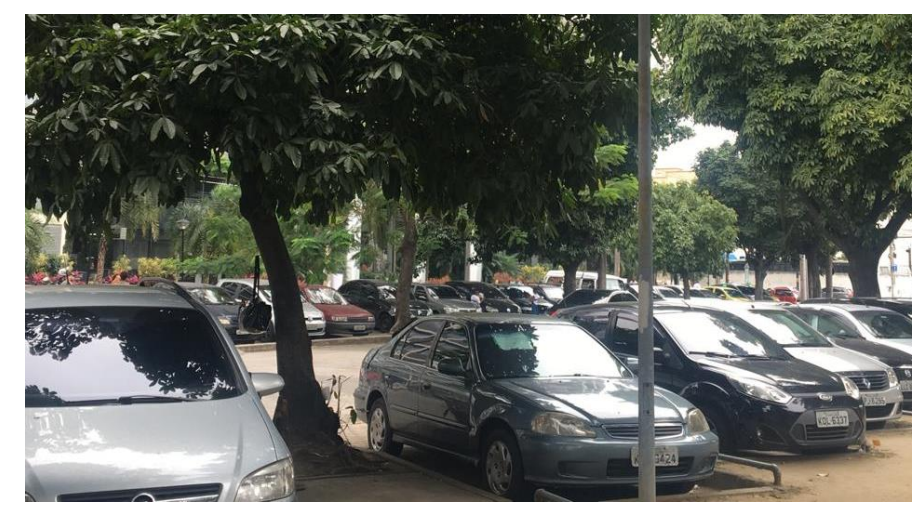

Figura 7: Área de estacionamento no entorno do prédio em estudo

Fonte: Arquivo pessoal

A sede funciona além dos dias úteis, aos sábados, em eventuais setores da empresa, e o horário pico de entrada dos funcionários na empresa é entre $8 \mathrm{~h}$ e $9 \mathrm{~h}$, e saída entre $17 \mathrm{~h}$ e $18 \mathrm{~h}$.

\subsection{Política atual de mobilidade corporativa}

\subsubsection{Perfil da mobilidade}

A empresa estudada é pautada principalmente em negócios envolvendo comercialização de combustíveis e biocombustíveis, dito isso, entende-se que sua cultura é voltada para a motorização.

Anualmente esta empresa contrata uma terceirizada para levantamento de dados e consequente elaboração do Inventário de emissões de gases de efeito estufa (GEE), com a finalidade de ser um instrumento gerencial, permitindo a avaliação dos impactos da organização sobre o sistema climático global.

Para tanto, infere-se uma metodologia que envolve a definição da abrangência da organização, identificação de fontes e sumidouros de GEE e contabilização de suas respectivas emissões e remoções, possibilitando a caracterização das emissões resultantes das atividades desta organização.

Para este inventário, foi considerado o ano-base de 2017, onde a organização foi responsável por $100 \%$ das emissões de GEE das operações sobre as quais tem controle operacional. 
Uma planilha foi então elaborada com os dados de origem destino dos funcionários, e através do Google Maps, calculadas as distâncias (Ver APÊNDICE A).

Para esta demonstração foram considerados apenas colaboradores que residem no estado do Rio de Janeiro com destino ao prédio matriz, e, das 708 respostas válidas, identificou-se que: $80 \%$ reside na cidade do Rio de Janeiro, e percorrem em média $16 \mathrm{~km}$ até a empresa estudada; $8 \%$ reside em Niterói, e percorrem em média $23 \mathrm{~km}$ ao local de trabalho; 2,5\% reside em Duque de Caxias, com distância média de 29 km; 2,4\% mora em São Gonçalo e 2,1\% em Belford Roxo, onde em média percorrem 31 e $33 \mathrm{~km}$, respectivamente, de onde residem ao local de trabalho. Dados estes ilustrados na Tabela 1.

Tabela 1: Divisão por município e distâncias médias até o local de trabalho (ida)

\begin{tabular}{|l|c|c|}
\hline \multicolumn{1}{|c|}{ Município } & $\%$ Total & $\begin{array}{c}\text { Distância média } \\
\mathbf{( k m )}\end{array}$ \\
\hline RIO DE JANEIRO & $79,9 \%$ & 16 \\
\hline NITERÓI & $7,9 \%$ & 23 \\
\hline DUQUE DE CAXIAS & $2,5 \%$ & 29 \\
\hline SÃO GONÇALO & $2,4 \%$ & 31 \\
\hline BELFORD ROXO & $2,1 \%$ & 33 \\
\hline NOVA IGUAÇU & $1,6 \%$ & 41 \\
\hline NILÓPOLIS & $0,6 \%$ & 31 \\
\hline SÃO JOÃO DE MERITI & $0,6 \%$ & 25 \\
\hline MARICA & $0,4 \%$ & 54 \\
\hline MAGÉ & $0,3 \%$ & 47 \\
\hline PETRÓPOLIS & $0,3 \%$ & 62 \\
\hline ARARUAMA & $0,1 \%$ & 118 \\
\hline ITAGUAÍ & $0,1 \%$ & 72 \\
\hline JAPERI & $0,1 \%$ & 73 \\
\hline MESQUITA & $0,1 \%$ & 29 \\
\hline MIGUEL PEREIRA & $0,1 \%$ & 114 \\
\hline PARACAMBI & $0,1 \%$ & 80 \\
\hline QUEIMADOS & $0,1 \%$ & 49 \\
\hline SEROPÉDICA & $0,1 \%$ & 67 \\
\hline TERESÓPOLIS & $0,1 \%$ & 89 \\
\hline VOLTA REDONDA & $0,1 \%$ & 131 \\
\hline
\end{tabular}

Fonte: Própria

Com relação aos benefícios oferecidos pela empresa, dos 708 respondentes, 565 , o que representa $79,8 \%$ dos funcionários, não possuem vale transporte, enquanto 143 , cerca de $20,2 \%$, possuem. 
Destrinchando entre os municípios, a exemplo do Rio de Janeiro, com 566 funcionários respondentes, tem-se que $84,5 \%$ não possuem vale transporte, destes, $12 \%$ residem no bairro da Tijuca, a $9 \mathrm{~km}$ de distância do trabalho, e possivelmente, utilizam o carro ou apenas não veem necessidade do benefício. Dos 56 funcionários residentes em Niterói, segunda maior representatividade nas respostas, $82 \%$ não possuem vale transporte, em sua maioria, $30 \%$ dos que não possuem, residem no bairro de Icaraí, seguido de Santa Rosa. Já em Duque de Caxias, dos 18 funcionários respondentes, 56\% não possuem vale transporte.

Quanto à localização, referente a bairros, no município do Rio de Janeiro, os funcionários são distribuídos da seguinte forma (Tabela 2):

Tabela 2: Distribuição por bairro do município do Rio de Janeiro

\begin{tabular}{|l|c|c|}
\hline \multicolumn{1}{|c|}{ Zona } & Quant & Distância média $\mathbf{( k m )}$ \\
\hline Centro & 33 & 4,63 \\
\hline Zona Norte & 275 & 11,87 \\
\hline Zona Oeste & 133 & 31,06 \\
\hline Zona Sul & 125 & 12,13 \\
\hline Total Geral & $\mathbf{5 6 6}$ & \\
\hline
\end{tabular}

Fonte: Própria

*Distância apenas de ida ao trabalho

Com relação aos demais benefícios do prédio Matriz em termos de mobilidade, o local, apesar de ter academia e vestiário próprio, não possui bicicletário, e ao entorno é possível verificar falta de luminosidade no percurso até as estações de trem e metrô, e falta de policiamento/segurança.

Segundo dados da Polícia Militar, em 2018 no estado do Rio de Janeiro, o número de Homicídios doloso (quando a pessoa tem a intenção de matar) chegou a 4.936, onde somente no município do Rio, foram 1.334. Traçando um comparativo com a região da Delegacia de Polícia de São Cristóvão, onde de acordo com o Instituto de Segurança Pública se situa na RISP 1, AISP 4, temse o ilustrado no Quadro 2 (ISP, 2018). 
Quadro 2: Comparativos dados ISP 2018

\begin{tabular}{|l|r|r|r|}
\hline \multicolumn{1}{|c|}{ Ano de 2018 } & $\begin{array}{c}\text { Quantidade - } \\
\text { Estado do RJ }\end{array}$ & $\begin{array}{c}\text { Quantidade - } \\
\text { Município do RJ }\end{array}$ & $\begin{array}{c}\text { Quantidade } \\
\text { AISP 4, RISP 1 }\end{array}$ \\
\hline Total de roubos & 231.624 & 121.135 & 5.718 \\
\hline Total de furtos & 143.866 & 82.486 & 4.073 \\
\hline Latrocínio & 171 & 63 & 4 \\
\hline Tentativa de homicídio & 6.247 & 1.987 & 164 \\
\hline Homicídio culposo & 1.937 & 630 & 28 \\
\hline Homicídio doloso & 4.936 & 1.334 & 38 \\
\hline Tráfico de drogas & 1.656 & 504 & 24 \\
\hline Sequestro & 4 & - & - \\
\hline Estupro & 5.310 & 1.642 & 42 \\
\hline
\end{tabular}

Fonte: ISP, 2018

Estes números corroboram com os relatos das dificuldades enfrentadas pelos transeuntes, neste caso os funcionários do prédio Matriz, na saída do local de trabalho, principalmente a pé ou bicicleta em horários tardios.

\subsubsection{Custos de transporte}

Para os custos associados aos benefícios oferecidos aos funcionários e devidos descontos, a legislação rege a obrigatoriedade do empregador oferecer ao empregado contratado em regime CLT (Consolidação das Leis do Trabalho) a remuneração do vale transporte, entre outras remunerações. Vale ressaltar que o vale transporte não integra a remuneração salarial do empregado, ou seja, não será contabilizado para contribuições previdenciárias, Fundo de Garantia do Tempo de Serviço (FGTS) e imposto de renda (JUSBRASIL, 2019).

Sobre o vale transporte, tem-se que o empregador pode descontar da folha de pagamento o percentual de até $6 \%$ sobre o valor do salário base do empregado. Caso o valor calculado seja inferior ao gasto com transportes, o empregador deve arcar com o custo faltante, assim como, se o valor calculado do desconto for superior ao gasto, o empregado pode optar pela não utilização deste benefício.

No levantamento do Inventário, com os dados dos 708 colaboradores residentes no estado do $\mathrm{RJ}$ com destino ao prédio matriz, tem se que 143 funcionários utilizam o vale transporte, o que se refere a um gasto médio mínimo diário de $R \$ 8,90$ para os funcionários que residem dentro do município, 
o que implica em um gasto mensal mínimo de $R \$ 204,70$, e $R \$ 15,88$ para os que residem fora do município, implicando no valor mensal mínimo de $R \$$ 365,24 , por funcionário, gastos no percurso de ida e volta do local de trabalho, considerando os valores de tarifa aplicados no ano de 2019, para viagens municipais e intermunicipais respectivamente (Ver APÊNDICE C). Entende-se que os 143 funcionários que utilizam VT fizeram o cálculo para avaliação do gasto versus o desconto em folha, ou seja, para os funcionários que residem no município subentende-se que recebem um salário de até $R \$ 3.412,00$, e os que residem fora do município, salário abaixo de $R \$ 6.087,00$, considerando o desconto de $6 \%$ usual nesta empresa.

Para os demais, pode-se considerar que o valor gasto é inferior ao descontado, não havendo necessidade de VT, ou que todos os 565 funcionários utilizam o carro/motocicleta para seu deslocamento, onde considerando o uso da gasolina, com preço médio de $R \$ 4,091$, considerando também a média anual 2017 da ANP, tem-se média de gasto total diário de $R \$$ 43,05 por funcionário, referente a $\mathrm{R} \$$ 990,15 mensais em média, desconsiderando as diferenças de localidade dentro do estado do Rio de Janeiro (Ver APÊNDICE D).

\subsubsection{Emissões de GEE}

Com os mesmos dados de levantamento dos funcionários para verificação do perfil de deslocamento, além de outras informações de atividades da empresa, de forma geral, foram levantadas as emissões por escopo, as quais foram publicadas no Inventário da empresa do ano de 2017.

Para o cálculo do Inventário, foi utilizada a ferramenta do Programa Brasileiro GHG Protocol. O Programa Brasileiro tem por objetivo estimular a cultura corporativa para elaboração e publicação de inventários de emissão de gases de efeito estufa (GEE), e a ferramenta utilizada, GHG Protocol ${ }^{11}$, permite quantificar e gerenciar essas emissões.

Para que as empresas gerenciem as emissões de forma mais eficiente, as fontes identificadas dentro dos limites estabelecidos, devem ser classificadas

11 The Green House Gas Protocol - Protocolo de Gases de Efeito Estufa, foi lançado em 1998 pela World Resources Institute (WRI) em associação a World Business Council for Sustainable Development (WBCSD). 
como diretas e indiretas. Para isso, foram criados os conceitos de escopo 1, 2 e $3^{12}$ :

a) Escopo 1: São emissões de GEE oriundas de fontes controladas (controle operacional) ou pertencente (participação societária). A sua quantificação é obrigatória segundo a metodologia do GHG Protocol;

b) Escopo 2: São emissões de GEE relacionadas à aquisição de energia, que ocorrem fora dos limites da unidade, a exemplo da aquisição de energia elétrica. Sua quantificação também é obrigatória;

c) Escopo 3: São consideradas emissões indiretas. Provenientes da extração e produção de matérias-primas, transporte e viagem de funcionários, emissões relativas ao uso final do produto, transporte de combustíveis adquiridos etc;

Para este cálculo, as premissas adotadas foram: considerados todos os 2.286 colaboradores respondentes no nível Brasil (incluindo os 708 do estado do RJ com destino ao prédio matriz), dentre os quais foram avaliadas as distâncias médias até o local de trabalho, e desconsideradas as distâncias superiores a $330 \mathrm{~km}$. Além disso, para distâncias não encontradas, foi assumido a mediana das distâncias encontradas; Para os deslocamentos totais foi considerada a viagem casa-trabalho-casa; Usuários que tem o vale transporte, utilizam o ônibus como meio de locomoção, enquanto os que não tem vale transporte, utilizam o carro particular movido à gasolina; Para usuários do ônibus, foi adotada a unidade de medida $\mathrm{km}^{\star}$ passageiro $\left(\mathrm{km}^{\star}\right.$ pax), pois a emissão total do deslocamento de um ônibus não pode ser atribuída a apenas um passageiro. Para o escopo 1, foram considerados: Combustão móvel e estacionária, resíduos sólidos e efluentes líquidos, e fugitivas. Para o escopo 2, foi considerada a aquisição de energia elétrica. E para o escopo 3, foram considerados: Bens e serviços comprados, atividades relacionadas a combustível e energia não citadas no escopo 1 e 2, transporte e distribuição upstreame downstream, resíduos gerados nas operações, viagens a negócios, e deslocamento dos funcionários (casa-trabalho), este último com maior enfoque neste trabalho de dissertação. 
A empresa tem a sede em São Cristóvão, onde é contemplado o estudo de caso, e mais algumas unidades operacionais, que no Inventário de GEE, para o escopo 1 e 2 , somaram no total em 2017, 17.763,59 $\mathrm{tCO}_{2}$ eq, equivalente ao ano de 2016, onde foram contabilizados 18.456,39 $\mathrm{tCO}_{2}$ e. Para o escopo 3, em 2017 foram 592.983,06 $\mathrm{tCO}_{2}$ eq, contra 374.582,51 $\mathrm{tCO}_{2}$ eq de 2016. Para estes números, a incerteza do inventário, definida a partir da incerteza dos fatores de emissão, foi de $-0,26 \%$ e +0,53\% (INVENTARIO, 2017).

Com um maior detalhamento, verifica-se que os processos que envolvem transportes são os mais representativos em todos os escopos. No escopo 1, observa-se que em fontes de combustão móvel, tem-se 1,8\% das emissões, estas, que envolvem as atividades terceirizadas de transporte, coleta e distribuição de combustíveis. Também no escopo 1, o consumo de diversos combustíveis em motores estacionários próprios representa $0,6 \%$ das emissões totais. Ainda, verifica-se que as maiores emissões se encontram no escopo 3, nas atividades de transporte e distribuição upstream e downstream, onde estas contemplam a coleta, distribuição e transporte marítimo de determinado setor. Há de se notar também no escopo 3, que as emissões referentes ao deslocamento de funcionários casa-trabalho representam $0,6 \%$ do escopo 3, e 0,55\% do total de $\mathrm{CO}_{2}$ eq do ano de 2017 (Figura 8).

\begin{tabular}{l|l|r|r|}
\hline \multirow{2}{*}{ Escopo } & Categoria & Emissões (tCO2e) & Emissões (\%) \\
\hline \multirow{5}{*}{ Escopo 3 } & Transporte e distribuição (upstream) & $489.015,55$ & $80,1 \%$ \\
\cline { 2 - 4 } & Transporte e distribuição (downstream ) & $88.188,17$ & $14,4 \%$ \\
\cline { 2 - 4 } & Bens e Serviços comprados & $5.447,56$ & $0,9 \%$ \\
\cline { 2 - 4 } & Deslocamento de funcionários (casa-trabalho) & $3.479,35$ & $0,6 \%$ \\
\cline { 2 - 4 } & Resíduos gerados nas operações & $3.244,71$ & $0,5 \%$ \\
\cline { 2 - 4 } & Viagens a negócios & $3.094,39$ & $0,5 \%$ \\
\cline { 2 - 4 } & Outras emissões do escopo 3 & 513,32 & $0,1 \%$ \\
\hline \multirow{4}{*}{ Escopo 1 } & Combustão móvel & $10.957,06$ & $1,8 \%$ \\
\cline { 2 - 4 } & Combustão estacionária & $3.689,22$ & $0,6 \%$ \\
\cline { 2 - 4 } & Resíduos & 66,17 & $0,0 \%$ \\
\cline { 2 - 4 } & Fugitivas & 3,58 & $0,0 \%$ \\
\hline \multirow{2}{*}{ Escopo 2 } & Aquisição de energia elétrica & $3.047,55$ & $0,5 \%$ \\
\hline \multirow{2}{*}{ Total } & & $\mathbf{6 1 0 . 7 4 6 , 6 4}$ & $\mathbf{1 0 0 , 0 \%}$ \\
\hline
\end{tabular}

Figura 8 : Detalhamento das emissões de $\mathrm{CO}_{2}$ eq por escopo

Fonte: Inventário, 2017 


\section{RESULTADOS, PROPOSTAS E DISCUSSÕES}

Este capítulo aborda o passo a passo para a elaboração de um Plano de Mobilidade Corporativa para a empresa deste Estudo de Caso, com base no roteiro adaptado de Guillermo Sant'anna Petzhold e Luis Lindau, que analisou 16 métodos de países onde o conceito já está estabelecido, e propôs uma nova metodologia (PETZHOLD, LINDAU, 2015), ilustrada na Figura 9.

É explorado desde o mapeamento das necessidades da empresa do estudo de caso, elaboração do questionário de perguntas e avaliação do diagnóstico, à preparação com a criação de indicadores e futura implementação. O presente estudo, tem como foco principal a etapa 4 (Figura 9), diagnóstico, pois, a partir dele, são desenvolvidos cenários através da ferramenta do Programa Brasileiro GHG Protocol13 para cálculo de emissões de gases de efeito estufa, demonstrando, então, possibilidades de mitigação dos impactos gerados pelo atual perfil da empresa de estudo, e do grupo de funcionários respondentes no questionário criado, fomentando a necessidade do plano estruturado de mobilidade corporativa.

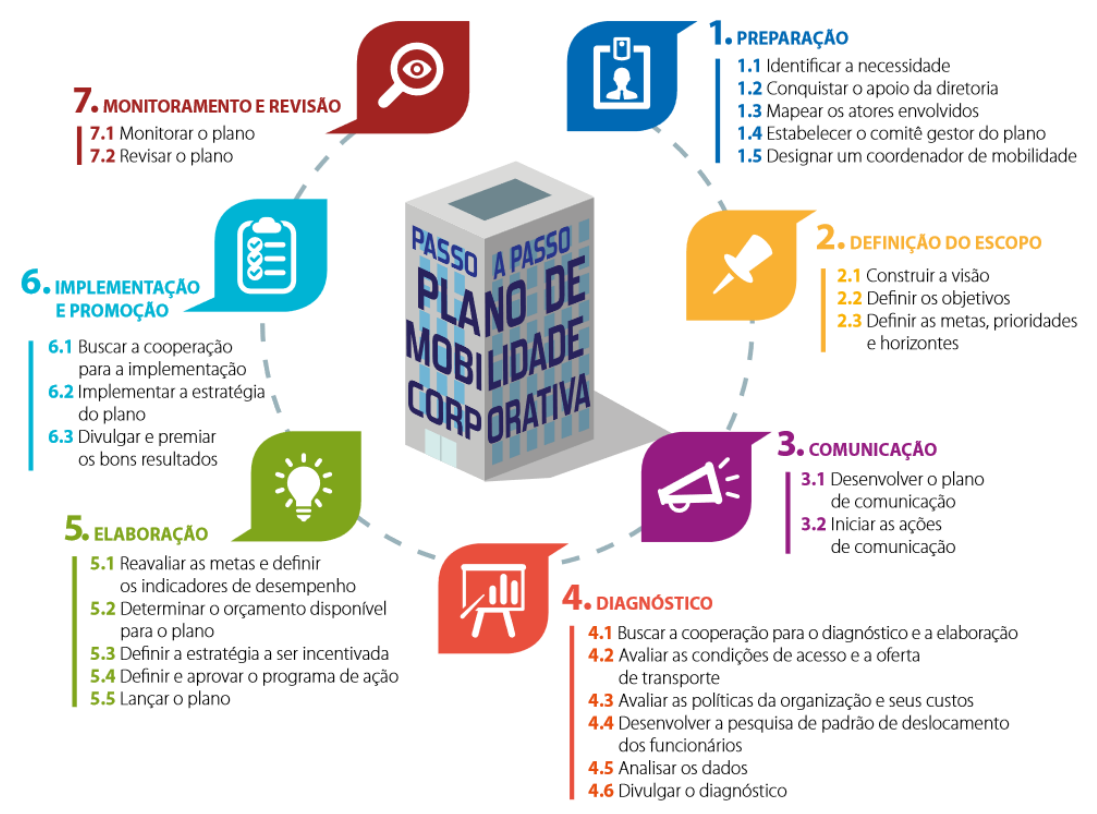

Figura 9: Método proposto para um Plano de Mobilidade Corporativa

Fonte: EMBARQUE Brasil, 2014

${ }^{13}$ Site do Programa Brasileiro GHG Protocol: <http://www.ghgprotocolbrasil.com.br/> 


\subsection{Preparação}

Esta etapa consiste em entender as necessidades da empresa em estudo, e potenciais ganhos advindos de um plano de mobilidade corporativa, possibilitando a argumentação com departamentos estratégicos da empresa e sua futura estruturação.

Para mapeamento dos atores envolvidos no processo, e posterior conquista de apoio, o método proposto sugere a criação de uma Matriz de influência e interesse. Os atores com maiores influências e interesse deverão participar do Comitê Gestor do Plano. Este Comitê tem como principal função auxiliar na elaboração do Plano, desde a definição de sua visão, objetivos e metas, até seu monitoramento e revisão.

Para o estudo de caso em questão, o primeiro setor a ser contactado e envolvido foi o de Meio Ambiente e Sustentabilidade, sendo este setor o responsável pela elaboração dos inventários de carbono da empresa em todas as esferas. Por ser uma empresa com foco em distribuição de combustíveis, existe uma elevada aderência ao uso do automóvel pelos funcionários, assim como benefícios diversos como desconto no combustível e grandes áreas de estacionamento, o que se tornou não só um desafio com relação ao apoio da Diretoria, mas uma vantagem, devido à margem para mudança de comportamento dos funcionários ser alta e propiciar redução de custo e impactos significativos. Além disso, a empresa está situada em uma região central, onde existem modal rodoviário e ferroviário nas proximidades, o que facilita a argumentação e apelo ao incentivo no uso do transporte público pela empresa em estudo (EMBARQ BRASIL, 2014).

\subsection{Definição do escopo e comunicação}

A primeira atividade para a elaboração do Plano, é a definição da Visão. Ela representa o que a organização e seus funcionários almejam em termos da mobilidade para o horizonte da vigência do plano. A partir da visão, tem-se a definição dos objetivos e metas a serem alcançadas, assim como as ações a serem tomadas. 
Os objetivos representam a razão pela qual a empresa está elaborando seu Plano de Mobilidade e devem expressar a relação com as melhorias desejadas. Assim como as metas devem ser mensuráveis, e permitirem o monitoramento do progresso relativos aos objetivos traçados. Além disso, as metas devem ser atingíveis, para não expor a empresa e seus funcionários ao descontentamento e consequente descontinuidade do Plano, e com prazos estabelecidos (EMBARQ BRASIL, 2014).

Para este estudo de caso, a Figura 10 sintetiza a visão e objetivos. Para as metas, as mesmas são validadas e ajustadas no decorrer da elaboração do plano, de acordo com os resultados do diagnóstico, a seguir.

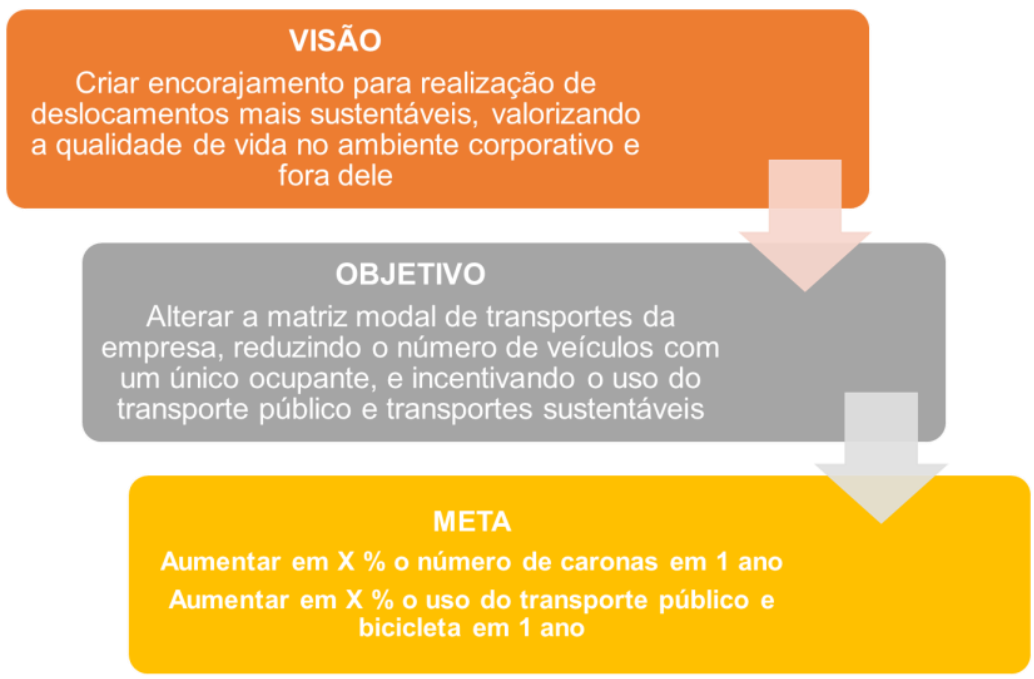

Figura 10: Visão, Objetivo e Meta

Fonte: Elaboração própria

Para a comunicação de forma clara e efetiva, diversas ferramentas podem ser utilizadas, visando o engajamento de toda a organização ao plano Criação de banners e newsletters, parcerias, publicação na intranet e redes sociais, utilização de aplicativos, além de incentivo e reconhecimento aos funcionários engajados, realização de eventos com foco na mobilidade sustentável e criação de uma marca, a qual cria um vínculo com o funcionário. Esta comunicação deve ter linguagem adequada ao público-alvo, com foco no atingimento das metas. 


\subsection{Diagnóstico}

Conforme já exposto no item 2.3 desta Dissertação, o diagnóstico prevê as políticas a serem adotadas pela organização e que podem influenciar no plano. Nele, encontram-se a caracterização do perfil dos funcionários com suas formas de deslocamento, a avaliação das condições de acesso e oferta de transporte local, as políticas já adotadas pela organização e seus custos.

Para este estudo de caso, as políticas e perfil atual da empresa, além da sua localização e oferta de transportes e acesso, foram apresentadas no capítulo 3. É válido também ressaltar que o capítulo 3 demonstra os resultados do inventário corporativo desta empresa em 2017, e será utilizado como banco de informações da empresa e modo de deslocamento global.

A pesquisa de padrão de deslocamento é peça fundamental para elaboração do plano de mobilidade corporativa, e é o foco desta Dissertação. Esta pesquisa de Origem-Destino foi realizada neste estudo de caso com o intuito de traçar o perfil de determinado grupo de funcionários de forma mais detalhada, e, por meio da criação de cenários, avaliar as alternativas e propostas de deslocamento já na fase de elaboração do plano.

\subsubsection{Elaboração do questionário e divulgação}

Como procedimento para coleta de dados quantitativos e qualitativos, optou-se pela elaboração de questionário eletrônico (Ver APÊNDICE F).

Este questionário foi enviado por e-mail corporativo em dois momentos, com o objetivo de reforçar a coleta de dados, pois este método possui algumas desvantagens como redução da interface entre 0 entrevistador e 0 respondente, além de outros fatores que influenciam a taxa de retorno a estes questionários, como: Interesse pelo assunto, nível de instrução e disponibilidade emocional para participar.

As perguntas do questionário objetivavam saber a localidade de origem, pois o destino foi definido como a empresa estudada, e a percepção de mobilidade do funcionário respondente sobre seu percurso. Perguntas como: Se possuíam bens (carro, moto e outros), e qual combustível utilizavam caso 
tivessem algum veículo, foram incluídas no formulário para identificação do perfil do consumidor de veículo motorizado. Além disso, o questionário pergunta se o funcionário possui algum tipo de benefício da empresa como vale transporte ou combustível, se possui vaga própria de estacionamento, ou se poderiam trabalhar remotamente, para assim identificar como a empresa fomenta e incentiva a mobilidade de seus funcionários.

Perguntou-se também, quais alternativas utilizariam caso não tivessem estacionamento próximo e se ofereceriam carona, para identificação de novas possibilidades de deslocamento além da motorização e/ou redução de um único ocupante em um veículo.

Para explorar o fluxo de veículos no entorno da empresa estudada e propor soluções para redução, foi perguntado também, qual horário de chegada e saída do local de trabalho, além da duração das viagens casa-trabalho-casa e de que modo o funcionário se deslocava diariamente (meio de transporte e frequência de uso).

A partir daí, foi traçado o perfil de determinado grupo de funcionários desta empresa, e identificadas oportunidades na mobilidade, a serem exploradas em cenários alternativos e propostas.

\subsubsection{Resultados da pesquisa}

Dos 112 questionários recebidos, foram preenchidos corretamente 110, representando $14 \%$ do número de funcionários da empresa (Ver APÊNDICE B). A amostra poderia ser maior, caso a pesquisa fosse formalizada na empresa estudada, e houvesse algum interesse no uso dos resultados finais e recomendações, o que vem a ser um dos grandes desafios desta dissertação: Demonstrar como a empresa pode contribuir para o desenvolvimento sustentável por meio de ações conjuntas, iniciando com a realização de diagnóstico do próprio corpo de funcionários.

Dos 110 respondentes, $48 \%$ eram mulheres e $52 \%$ homens, todos entre 25 e 40 anos, o que configura a empresa em estudo por funcionários jovens e até meia idade. Destes $110,35 \%$ recebem o auxílio de vale transporte, $2 \%$ recebem vale combustível e os demais não usufruem de benefício com transporte, sendo o valor do vale transporte descontado do funcionário de $6 \%$ 
do salário mensal, e o vale combustível custeado pela empresa é baseado no valor de um tanque cheio por mês. No entanto, como mencionado na seção 2.2, o desconto do vale transporte pode ser reduzido pela empresa, fazendo com que mais funcionários optem por este benefício.

Quanto a localização, referente a bairros, no município do Rio de Janeiro, os funcionários respondentes do questionário são distribuídos da seguinte forma:

\section{Tabela 3: Distribuição de funcionários - Questionário}

\begin{tabular}{|l|c|}
\hline \multicolumn{1}{|c|}{ Zona } & Quant \\
\hline Centro & 8 \\
\hline Zona Norte & 36 \\
\hline Zona Oeste & 19 \\
\hline Zona Sul & 38 \\
\hline Outras (fora cidade) & 9 \\
\hline Total Geral & $\mathbf{1 1 0}$ \\
\hline
\end{tabular}

Fonte: Elaboração própria

Ou seja, 35\% dos funcionários mora na zona sul do Rio de Janeiro, onde o Índice de Desenvolvimento Humano (IDH) segundo o IBGE é o mais alto em relação as demais regiões da cidade. Outros 33\% residem na zona norte, $17 \%$ na zona oeste, $7 \%$ no centro da cidade, e os demais funcionários moram fora do município.

Em relação as distâncias médias, apenas do trecho de ida, tem-se a seguinte distribuição:

Tabela 4: Distribuição de funcionários por distância - Questionário

\begin{tabular}{|l|c|}
\hline Distâncias - Um trecho & Quant.Func \\
\hline Até $5 \mathrm{Km}$ & 7 \\
De 5 à $8 \mathrm{Km}$ & 4 \\
De 8 à $10 \mathrm{Km}$ & 25 \\
De 10 à $15 \mathrm{Km}$ & 39 \\
De 15 à $20 \mathrm{Km}$ & 8 \\
Mais de $20 \mathrm{Km}$ & 27 \\
\hline Total Geral & $\mathbf{1 1 0}$ \\
\hline
\end{tabular}

Fonte: Elaboração própria 
Quando perguntados se possuíam carro ou moto, 70 funcionários responderam que sim, e desses, apenas 9 não possuem vaga de estacionamento no local de trabalho (Figura 11). Desses mesmos 70 funcionários, 61 tem a gasolina como combustível mais utilizado, e 9 se dividem entre GNV e Etanol. Vale ressaltar que o uso dos biocombustíveis vem crescendo no país, e é cada vez mais comum a utilização do GNV e etanol no lugar da gasolina. Segundo a projeção do estudo 'Revolução Energética', divulgado no final de agosto de 2018 pelo Greenpeace e o Conselho Internacional de Energia Eólica, o uso de etanol e biodiesel deve crescer e atingir 30\% do consumo de combustíveis do país em 2050 (GREENPEACE, 2013).

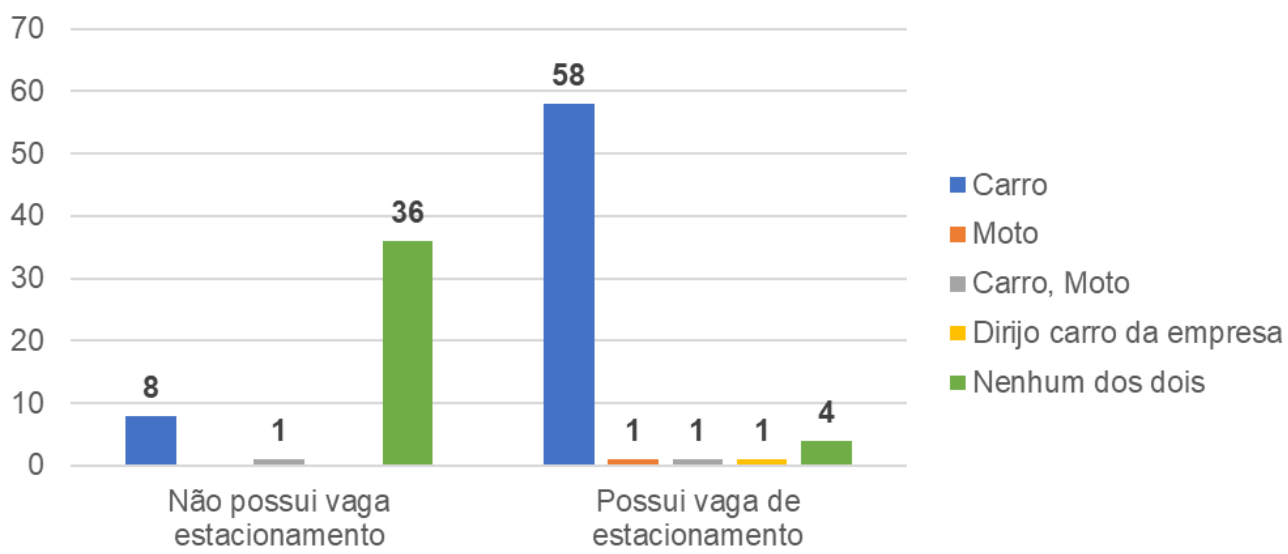

Figura 11: Vagas de estacionamento por funcionário

Fonte: Elaboração própria

Sobre o modo de transporte que utilizam para chegar e sair do local de trabalho, um número expressivo de 44 funcionários, correspondente a $40 \%$ do total, respondeu utilizar o carro próprio todos os dias, porém, todos estão dispostos a oferecer carona. Além disso, aos funcionários que utilizam o carro próprio todos os dias, foi perguntado se, caso a empresa não possuísse estacionamento e o local mais próximo para estacionar fosse a 2 quilômetros de distância, qual modal utilizariam: 14\% responderam que continuariam utilizando o carro, $39 \%$ utilizariam o metrô, $23 \%$ o ônibus, $2 \%$ o trem, e os demais $23 \%$ não responderam. Correlacionando as respostas sobre potenciais 
modos de transporte com as distâncias percorridas em um trecho por cada funcionário, observa-se na Figura 12 o seguinte cenário:

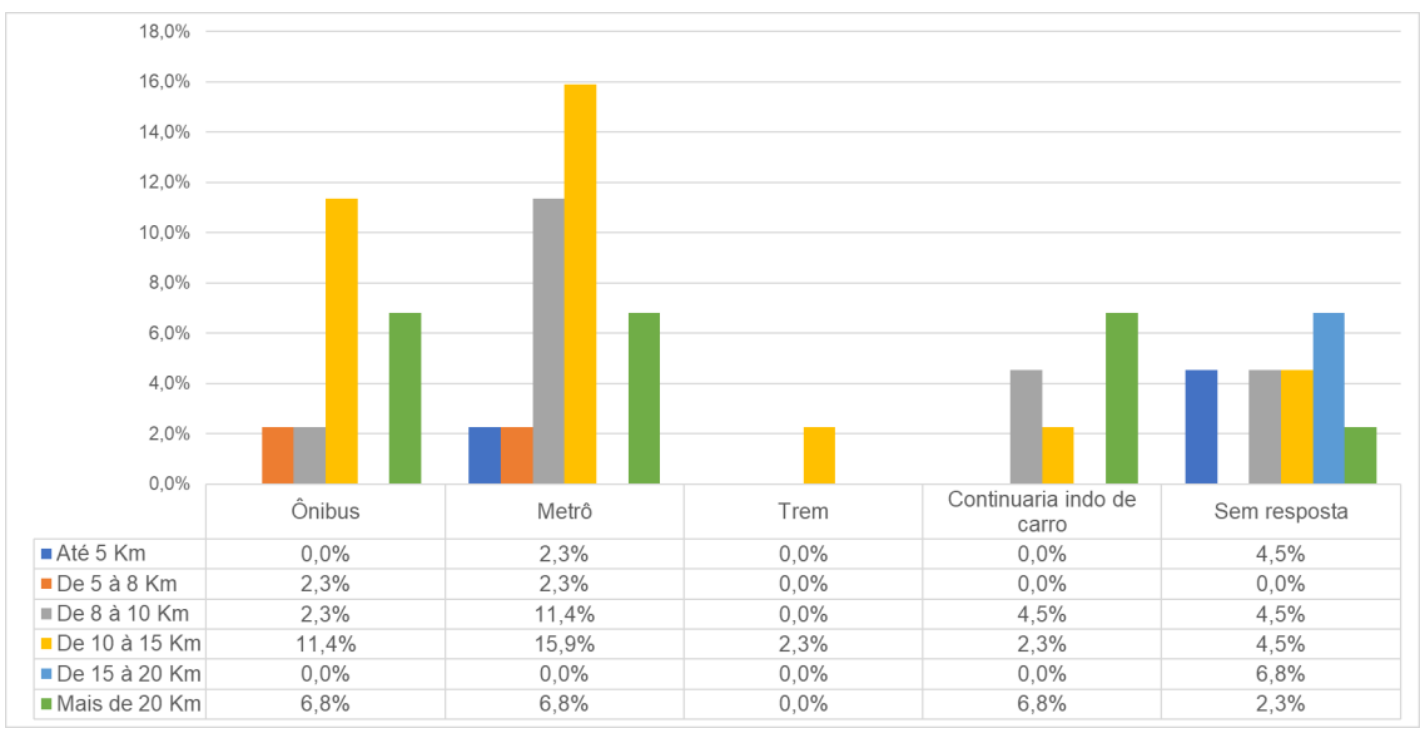

Figura 12: Potencial modal de transporte versus distância percorrida em um trecho

Fonte: Elaboração própria

Quanto aos horários de entrada no local de trabalho, 25\% dos funcionários chega entre 6 e 8 horas da manhã, a maior parcela, 62\%, chega entre 8 e 9 horas, e os demais $13 \%$ após as 9 horas da manhã. $\mathrm{Na}$ saída, $7 \%$ dos funcionários saem entre 15 e 17 horas, a grande maioria, 44\%, sai entre 17 e 18 horas, 37\% entre 18 e 19 horas, e o restante após às 19 horas da noite. Nota-se que o horário de pico fica no intervalo de 8 e 9 horas da manhã na chegada ao trabalho, e 17 e 19 horas na saída. Esta divisão, proporciona a possibilidade de escalonamento de horário de entrada e saída, o que melhoraria o fluxo de veículos no local (estacionamento) e entorno.

A Figura 13 ilustra a distribuição no uso dos modais para chegada ao trabalho, em quantidade de funcionários por frequência, levando em conta que o mesmo funcionário pode diversificar o uso do modal durante a semana. 


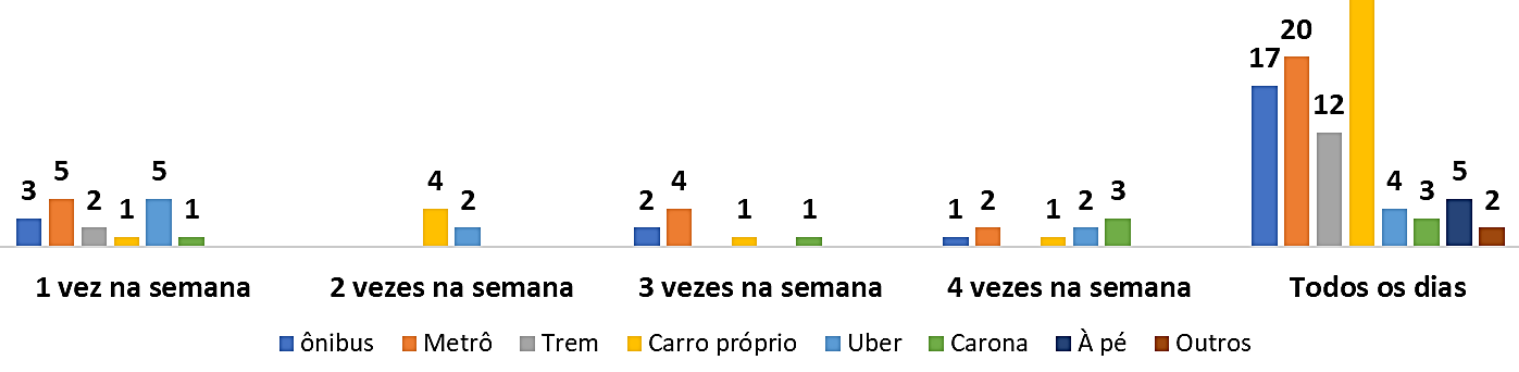

Figura 13: Distribuição modal dos respondentes - Chegada

Fonte: Elaboração própria

A Figura 14 ilustra a distribuição no uso dos modais na saída do local de trabalho. Nota-se a quantidade de usuários que utilizam o carro todos os dias versus as caronas utilizadas, que não condizem com o relato dos mesmos que possuem carro e dizem que podem oferecer carona. Neste caso, a carona é uma alternativa a ser explorada, visto que reduz o número de carros com um único ocupante.

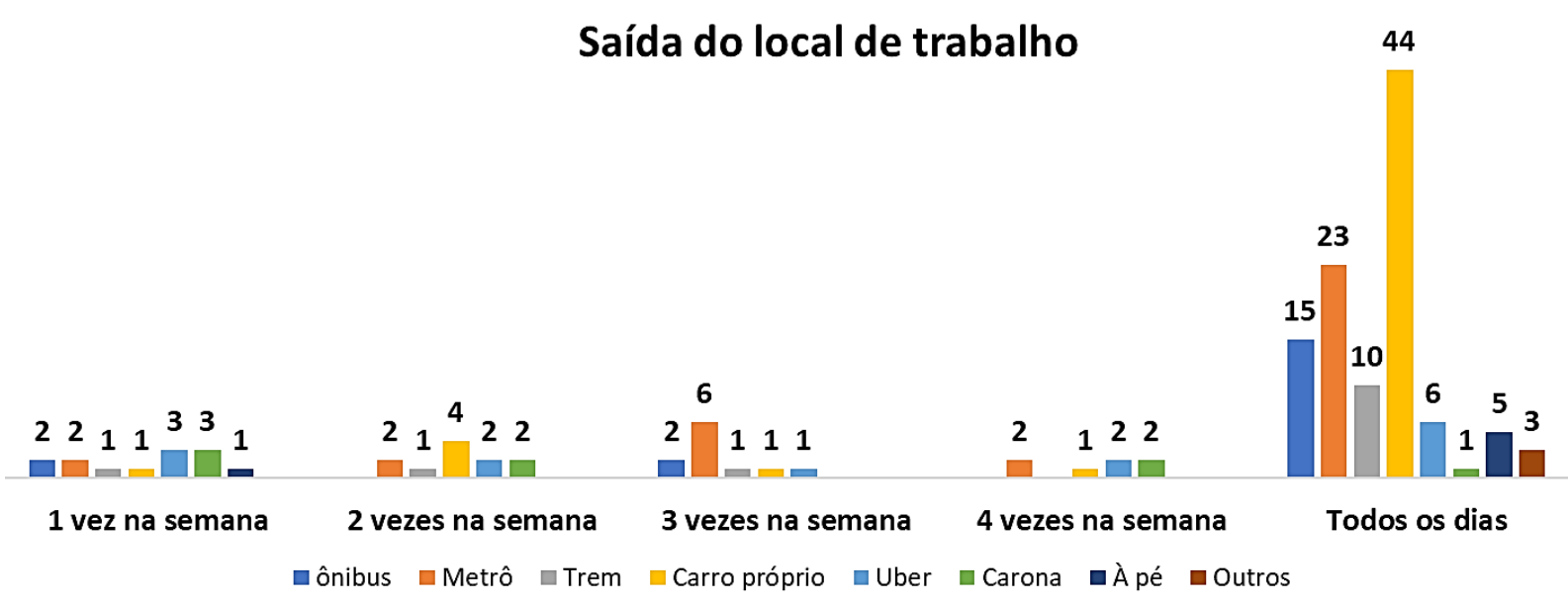

Figura 14: Distribuição modal dos respondentes - Saída

Fonte: Elaboração própria

Pode se verificar o intenso uso do carro próprio todos os dias da semana, e identificar o gap no uso dos transportes públicos, pois os mesmos encontramse disponíveis a curtas distâncias da localidade da empresa. 
Percebe-se também que o deslocamento utilizando a bicicleta não foi mencionado nas respostas de chegada nem de saída do trabalho, mesmo com a recente promoção do uso de bicicletas e patinetes na cidade do Rio de Janeiro. Dos 110 respondentes do questionário, 11 poderiam se deslocar com a bicicleta, por realizarem um percurso inferior a 8 quilômetros, distância dita ótima para este modo de transporte, porém, não o fazem (ITDP, 2017).

Ainda sobre a diversificação modal, as Figuras 15 e 16 ilustram a quantidade de funcionários que utilizam mais de um modal de transporte na semana, na chegada e na saída do trabalho:

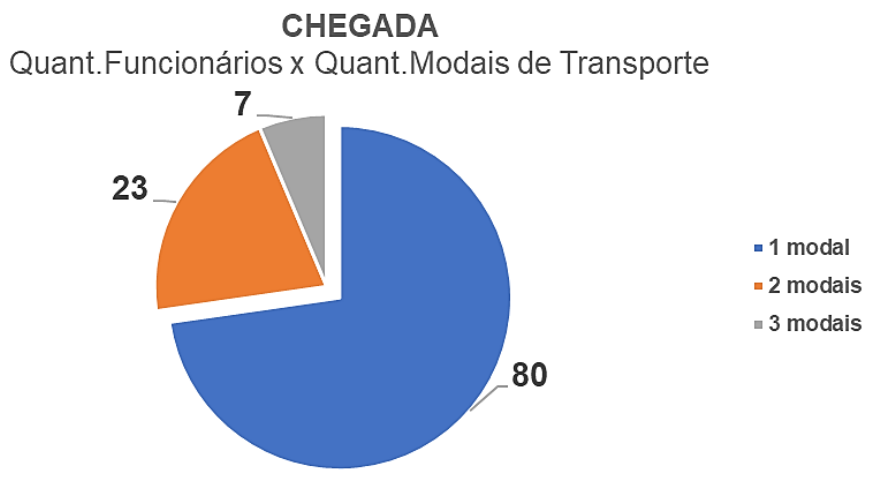

Figura 15: Quantidade de funcionários por Quantidade de modais - Chegada

Fonte: Elaboração própria

SAÍDA

Quant.Funcionários x Quant.Modais de Transporte

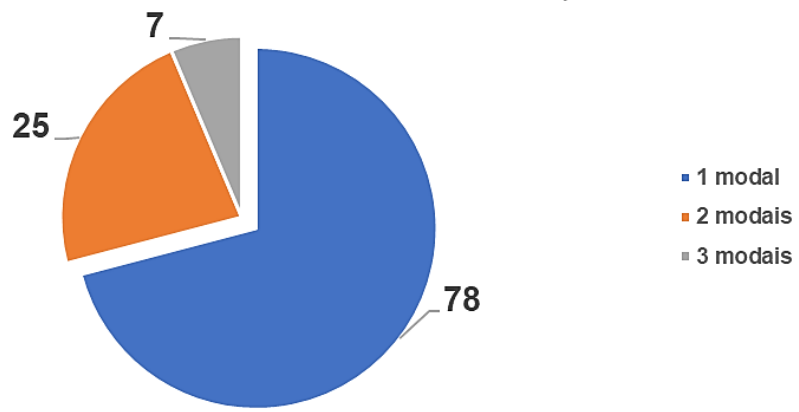

Figura 16: Quantidade de funcionários por Quantidade de modais - Saída

Fonte: Elaboração própria

Quanto à duração no percurso casa-trabalho, 51,8\% dos funcionários levam até 30 minutos, $30 \%$ têm este percurso realizado entre 30 minutos e 1 hora, 15,5\% entre 1 hora e 1 hora e meia, e 2,7\% leva mais de 1 hora e meia para chegar ao local de trabalho. Quanto ao percurso trabalho-casa, 50,9\% 
levam até 30 minutos, 31,8\% entre 30 minutos e 1 hora, 13,6\% entre 1 hora e 1 hora e meia, e 3,6\% mais de 1 hora e meia para chegar em sua moradia após o trabalho. Correlacionando a duração das viagens de ida e volta do trabalho com as distâncias percorridas em um trecho, tem-se as Figura 17 e 18:

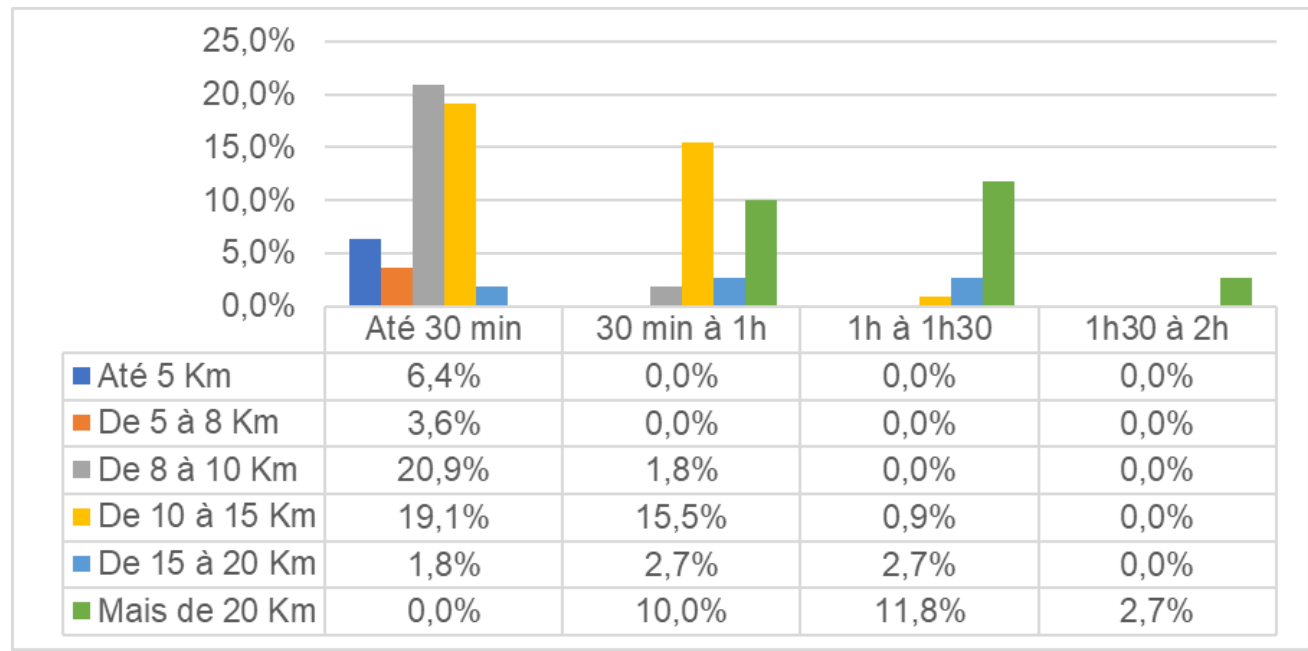

Figura 17: Duração viagem de ida versus distância percorrida em um trecho

Fonte: Elaboração própria

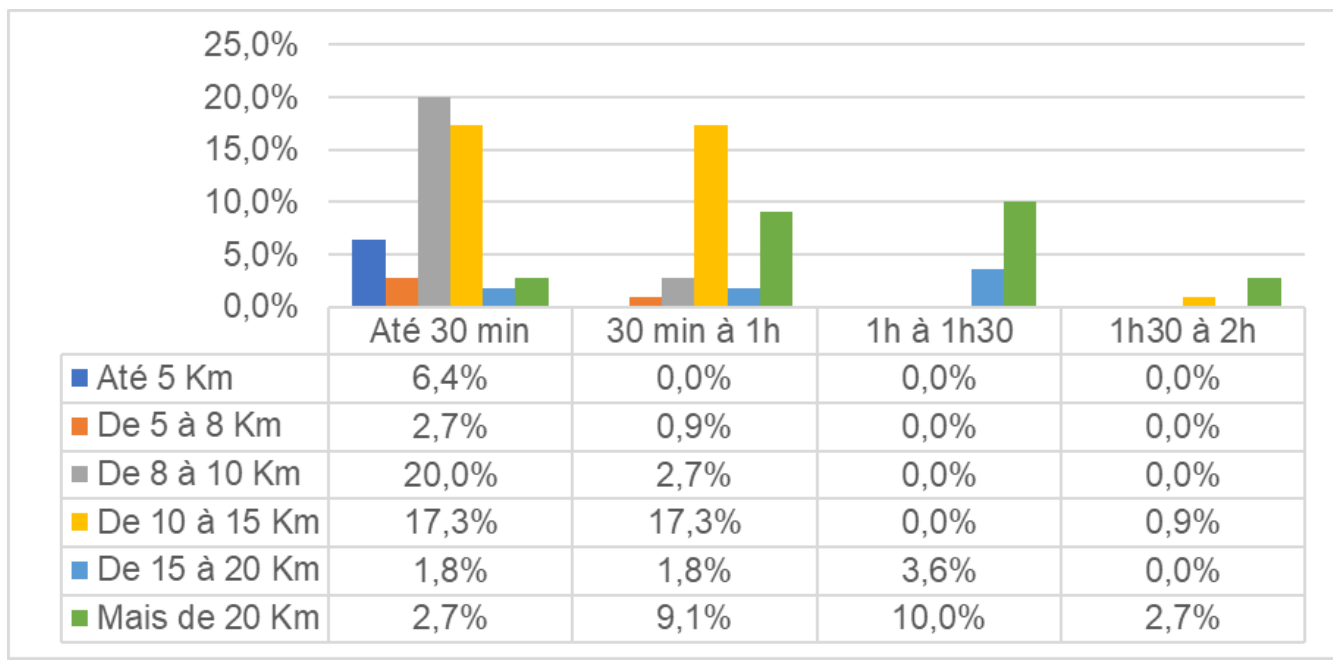

Figura 18: Duração viagem de volta versus distância percorrida em um trecho

Fonte: Elaboração própria

Visto o cenário no deslocamento dos 110 respondentes, é válido ressaltar que, também foi perguntado sobre a possibilidade de trabalho remoto, e apenas 3 funcionários indicaram possuir esta alternativa. Como já dito no capítulo 2.2, o home-office pode ser uma alternativa para que a empresa reduza custos, 
reduzindo o tempo de deslocamento dos funcionários e mitigando efeitos da poluição, com aumento da qualidade de vida.

Após a análise dos dados do questionário no desenvolvimento supracitado, é importante a divulgação do diagnóstico, por meio de newsletters ou intranet, reforçando a necessidade de mudança de comportamento das partes envolvidas e as tornando parte integrante do plano.

\subsection{Elaboração}

Com a conclusão do diagnóstico, é necessário primeiramente reavaliar as metas e definir os indicadores. As informações obtidas no levantamento das respostas do questionário, e atual política corporativa devem servir de norte para ajuste e validação das metas. Por exemplo, se no diagnóstico a quantidade de funcionários que responderam aderir ao transporte público for maior que o inicialmente estimado, a meta precisa ser reajustada. Com relação aos indicadores de desempenho, estes serão mensurados de forma qualitativa, por meio do engajamento e comentário dos funcionários, e quantitativa, por meio do monitoramento da divisão modal da organização. Por exemplo, a quantidade de bicicletas estacionadas diariamente ou número de acessos de entrada e saída por horário de pico.

Após a etapa de validação das metas e indicadores, é necessário determinar o orçamento disponível para implementação do plano. Para isso, é fundamental a consolidação de parcerias, e alocação de recursos financeiros destinados ao plano de mobilidade antes da definição das estratégias, para que as ações e estratégias se enquadrem na verba disponível.

Os maiores custos, são associados a implementação de infraestrutura como bicicletários, vestiários e salas de videoconferência, por exemplo, e que são necessários para a promoção do plano. No entanto, medidas como cobrança pelo estacionamento, redução do auxílio-combustível, ou parceria com aplicativos de mobilidade pelo celular/intranet, também podem gerar receita ou economia (EMBARQUE Brasil, 2014).

Um estudo realizado pelo Conselho Empresarial Brasileiro para o Desenvolvimento Sustentável (CEBDS) em 2016, intitulado Mobilidade 
Corporativa - Potencial econômico de sua implementação, demonstra potenciais ganhos ou economia com a introdução de algumas medidas de mobilidade corporativa em cinco empresas. A publicação também traz uma análise do perfil de custos das empresas associados ao transporte de funcionários, e subdivide em: Incentivos relacionados ao transporte individual motorizado que engloba o taxi, vaga de estacionamento e auxílio-combustível, e Benefícios relacionados ao uso de transportes sustentáveis, como vale transporte, fretamento de ônibus, vans, teletrabalho e home-office. A conclusão é de pelo menos $55 \%$ dos custos das empresas avaliadas estão relacionados a incentivos ao transporte motorizado individual, podendo chegar a $79 \%$ quando acrescentados gastos com taxi em viagens. (CEBDS, 2016).

A próxima etapa, refere-se à definição das estratégias a serem adotadas pela organização. Para tanto, a criação de cenários através do resultado do questionário, direciona quais são as melhores medidas a serem adotadas em prol do deslocamento sustentável.

Assim, utilizando condicionantes das 110 respostas dadas no questionário eletrônico, e, extrapolando para os 2.286 colaboradores respondentes para a elaboração do Inventário de 2017, tem-se alguns cenários alternativos de mitigação e redução de custo e impactos dos gases de efeito estufa.

As respostas do questionário foram desmembradas e utilizadas na ferramenta do Programa Brasileiro GHG Protocol. O Programa Brasileiro tem por objetivo estimular a cultura corporativa para elaboração e publicação de inventários de emissão de gases de efeito estufa (GEE), e a ferramenta utilizada, GHG Protocol ${ }^{14}$, permite quantificar e gerenciar essas emissões. Originalmente, esta ferramenta foi desenvolvida nos Estados Unidos, e adaptada ao contexto nacional em 2008, quando desde então, são organizados grupos de trabalho junto as empresas participantes para aperfeiçoamento e desenvolvimento de novas ferramentas associados a realidade brasileira (GHG Protocol, 2019).

A metodologia do GHG Protocol estabelece diretrizes para a elaboração de um Inventário, identificando os gases de efeito estufa a serem mensurados

14 The Green House Gas Protocol - Protocolo de Gases de Efeito Estufa, foi lançado em 1998 pela World Resources Institute (WRI) em associação a World Business Council for Sustainable Development (WBCSD). 
e reportados. Além disso, estabelece limites organizacionais: Controle operacional e participação societária. Empresas que publicam seu inventário com base na participação societária devem incluir as fontes que estas possuem, de acordo com a participação em cada fonte. No controle operacional, os inventariados devem incluir $100 \%$ das emissões de fontes que estejam sob seu controle, e não incluir fontes que não estejam, independente de sua participação societária na fonte.

Para que as empresas gerenciem as emissões de forma mais eficiente, as fontes identificadas dentro dos limites estabelecidos, devem ser classificadas como diretas e indiretas. Para isso, foram criados os conceitos de escopo 1, 2 e $3^{15}$, explicados anteriormente, no capítulo 3.

Para análise dos resultados do questionário na ferramenta, utilizou-se o ano base de 2017, visto que se tem insumo para comparação com o Inventario elaborado pela mesma empresa deste estudo de caso com os 2.286 colaboradores em 2017. Assim, para o cálculo das emissões de GEE inerente ao objetivo desta dissertação, foi preenchida a categoria "Emissões por Deslocamento Casa - Trabalho" referente ao escopo 3 da ferramenta. Esta categoria contabiliza emissões ocasionadas pelo deslocamento dos funcionários entre suas casas e locais de trabalho nos diferentes modais de transporte, particulares e públicos, não operados nem pertencentes à organização inventariante.

Para uso das tabelas pertencentes a categoria "Emissões por Deslocamento Casa - Trabalho" foi considerada para efeito de cálculo e simplificação, apenas as respostas de chegada ao trabalho, a distância percorrida por trecho de ida e volta, e no item de dias trabalhados por ano, quando não se obteve esta informação, o Programa Brasileiro GHG Protocol sugere 230 dias úteis por ano, cerca de 20 dias úteis por mês. Além disso, os fatores de emissão para cálculo final do inventário, são baseados na literatura, como dados do Intergovernmental Panel on Climate Change (IPCC), United States Environmental Protection Agency (US-EPA), Department for 
Environment Food \& Rural Affairs (DEFRA), dentre outros fatores default, quando o fator de emissão não é conhecido.

$\mathrm{Na}$ tabela referente ao transporte público, foram calculadas as emissões de GEE no uso de trem e metrô, extrapoladas para os dias em que eram utilizados, de acordo com as respostas do questionário. Foram 45 funcionários respondentes no uso deste meio de transporte em algum ou todos os dias da semana, resultando em 1,87 t $\mathrm{CO}_{2}$ eq.

Para o uso do ônibus comum, municipal ou de viagem, foram 23 funcionários respondentes, que resultaram em 17,8 t $\mathrm{CO}_{2} \mathrm{eq}$, e 1,39 t de $\mathrm{CO}_{2}$ biogênico ${ }^{16}$, este, derivado de biomassa, e não de combustíveis fósseis.

Nos demais casos, foram contabilizadas 64 respostas de uso de veículos individuais motorizados (carro próprio ou uber, desconsiderando os usuários de carona) em algum dia da semana, o que resultou em 56,80 t $\mathrm{CO}_{2}$ eq, e 12,13 t de $\mathrm{CO}_{2}$ biogênico.

No somatório das emissões totais no deslocamento casa-trabalho-casa, obteve-se 77,50 t $\mathrm{CO}_{2}$ eq, e 12,13 t de $\mathrm{CO}_{2}$ biogênico totais em um ano.

Ainda sobre o questionário, foram levantados os custos associados ao deslocamento dos 110 funcionários. Estes custos foram calculados por meio da contagem da frequência com que cada funcionário utiliza determinado modal, multiplicado pelo custo com gasolina ou passagem de transporte público, ilustrado na Tabela 5 (Ver APÊNDICE E).

Tabela 5: Custo diário do deslocamento segundo questionário

\begin{tabular}{|ccrrr|}
\hline Meio de Transporte & Somatório de gasto semanal & Somatório da média gasto diário \\
\hline Ônibus & $\mathrm{R} \$$ & 793,80 & $\mathrm{R} \$$ & 158,76 \\
Metrô & $\mathrm{R} \$$ & $1.075,00$ & $\mathrm{R} \$$ & 215,00 \\
Trem & $\mathrm{R} \$$ & 570,40 & $\mathrm{R} \$$ & 114,08 \\
Carro (próprio/uber) & $\mathrm{R} \$$ & $3.455,91$ & $\mathrm{R} \$$ & 691,18 \\
Total: & $\mathbf{R} \$$ & $\mathbf{5 . 8 9 5 , 1 1}$ & $\mathbf{R} \$$ & $\mathbf{1 . 1 7 9 , 0 2}$
\end{tabular}

${ }_{16} \mathrm{CO}_{2}$ derivado da transformação de estoques biológicos de carbono (vegetais, animais, algas, entre outros). O carbono presente em tais estoques biológicos foi removido da atmosfera através da fotossíntese, portanto, não possuem impacto adicional na concentração deste GEE na atmosfera. As emissões de $\mathrm{CO}_{2}$ biogênico devem ser contabilizadas de maneira separada em relação às outras emissões de GEE, pois estas possuem impacto adicional nas concentrações de GEE na atmosfera (GHG PROTOCOL, 2019). 
Além dos custos do funcionário, foi contabilizado o custo de oportunidade para a empresa em questão, onde não existe cobrança pela vaga de estacionamento. Ou seja, o custo de oportunidade, representa o montante/valor potencial que se perde/deixa de receber em função de uma determinada escolha em detrimento de outra, que, no estudo de caso, optou-se por oferecer vaga gratuita de estacionamento em detrimento ao ganho de receita com a mensalidade ou diária de aluguel do espaço.

Para o cálculo do custo de oportunidade, foi considerado o preço de compra de um imóvel na região de São Cristóvão na faixa de $R \$ 300.000,00$. Com isso, o preço médio de compra de vaga de garagem representa $10 \%$ do valor do imóvel, cerca de $R \$ 30.000,00$, sendo o preço do aluguel representado por $1 \%$ do valor da vaga, conforme práticas de mercado, $\mathrm{R} \$ 300,00$ por mês.

Considerando que a empresa em questão possui 300 vagas rotativas, tem-se um custo de oportunidade no valor de $R \$ 90.000,00$ por mês. Ou seja, a empresa está deixando de ganhar receita no valor citado anteriormente.

Para a construção dos cenários, algumas premissas e tendências mencionadas ao longo desta dissertação foram consideradas.

\subsubsection{Uso da bicicleta}

A bicicleta é um veículo movido à propulsão humana, e eficiente no consumo de energia. É o modo de transporte mais apropriado para distâncias curtas, de 5 a 8 quilômetros, tem baixíssimo custo operacional, de aquisição e manutenção, e requer pouco espaço para circular e estacionar. Portanto, funcionários com distância média até $8 \mathrm{~km}$ passariam a utilizar a bicicleta como meio de locomoção (ITDP, 2017).

No questionário, para os funcionários que têm a distância (trajeto de ida) de sua moradia para o local de trabalho menor que 8 quilômetros, foi substituído o uso do modal informado pela bicicleta, e assim, contabilizado o consumo energético final. No total, o modal de 9 funcionários foi alterado para o uso da bicicleta. 


\subsubsection{Utilização de carona}

Segundo o questionário eletrônico, todos os colaboradores informaram que aceitariam oferecer carona. Deste modo, entende-se que é possível reduzir em até $20 \%$ o número de veículos com apenas um ocupante.

Após a mudança na utilização da bicicleta para aqueles com distância inferior a 8 quilômetros, dos 56 funcionários que utilizam carro próprio/uber, os 11 com as menores distâncias foram alterados para uso da carona, a fim de reduzir o número de veículos com apenas um ocupante.

\subsubsection{Utilização de transporte público}

No questionário, os funcionários responderam que modal utilizariam, caso não possuíssem estacionamento, e o local mais próximo para estacionar fosse a 2 quilômetros de distância. Assim, foram alteradas todas as respostas dos funcionários que responderam utilizar o carro próprio todos os dias, para suas respectivas respostas referentes ao modal alternativo, em um total de 22.

\subsection{Análise Comparativa e estratégias do Plano}

Após alteração dos meios de deslocamento dos funcionários e/ou frequência de uso, de acordo com as condicionantes estabelecidas nas perguntas do questionário, obteve-se a seguinte curva de emissões de GEE, calculadas também na ferramenta do Programa Brasileiro GHG Protocol:

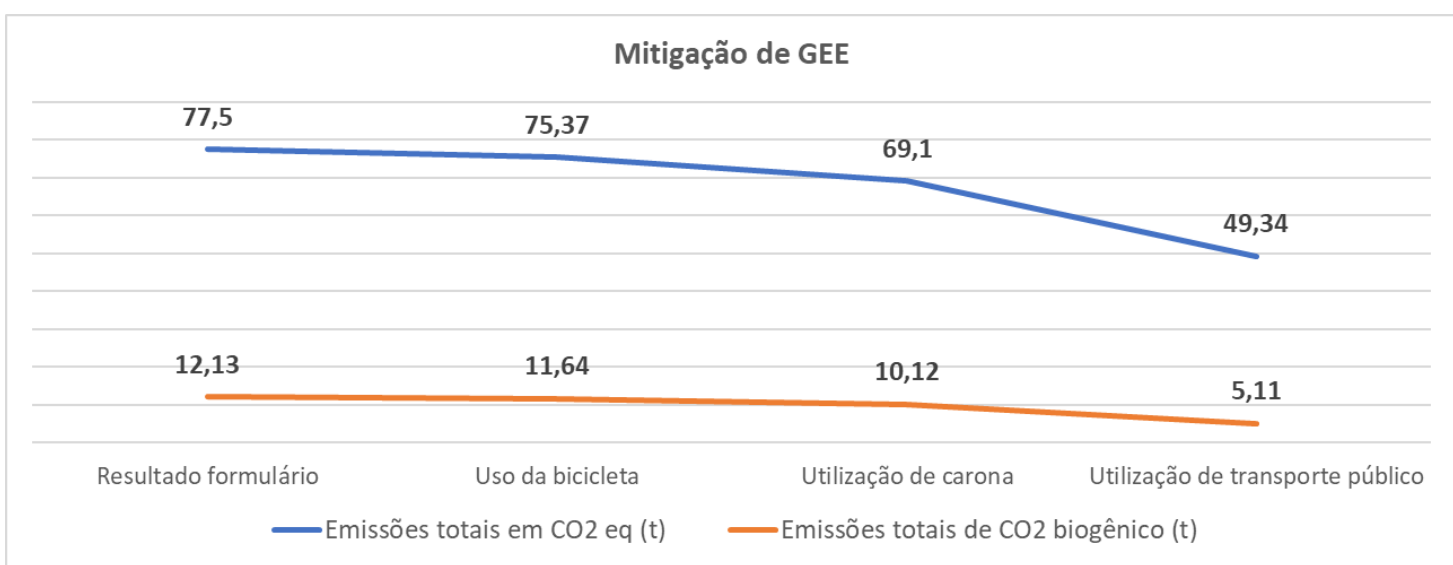


Com relação aos custos associados a utilização dos modais, obteve-se a redução de $R \$ 273,42$ no somatório da média de gastos diários dos funcionários com deslocamento, o que representa cerca de $R \$ 70.000,00$ a menos no ano:

\section{Custo diário com transporte}

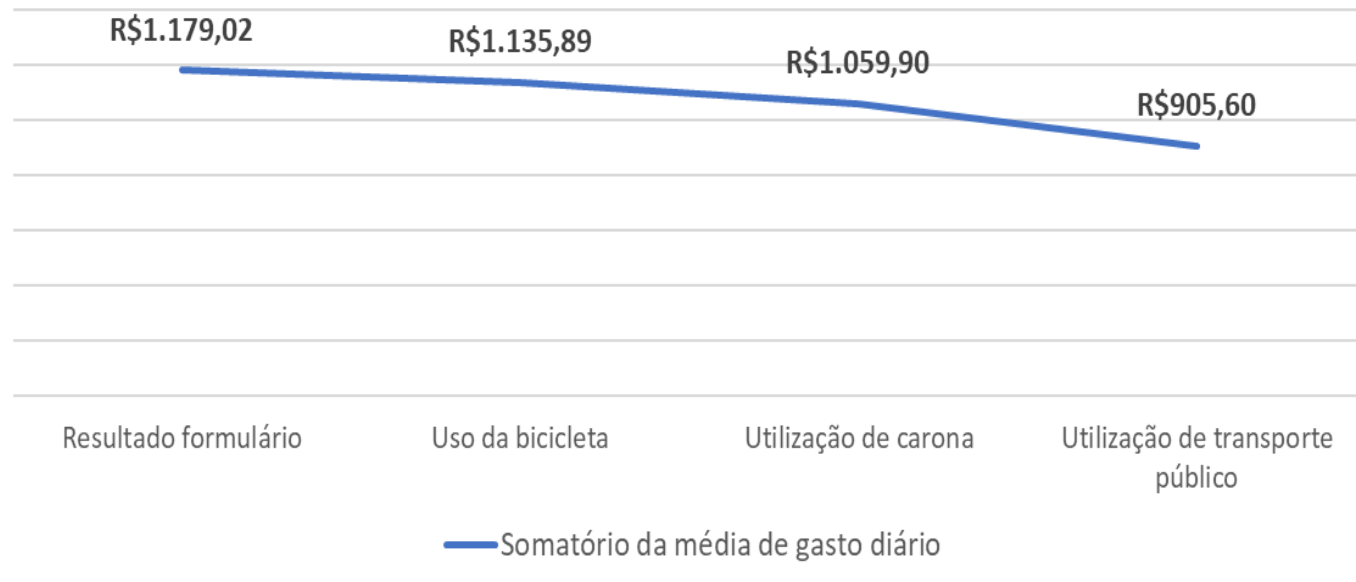

Considerando que 61 funcionários responderam no questionário que possuem vagas de estacionamento, haveria um custo de oportunidade no valor de $R \$ 18.300,00$ caso fosse cobrado mensalmente $R \$ 300,00$, ou $R \$$ $14.030,00$ mensais, caso fosse cobrado diariamente uma tarifa de $R \$ 10,00$ por dia, considerando 23 dias úteis.

Percebe-se por meio da análise comparativa, que as estratégias do Plano, definidas para o grupo selecionado no questionário geram economia e redução de GEE significativos.

As estratégias para incentivo ao uso da bicicleta, da carona e do transporte público, devem ser estudadas e monitoradas. Como exemplo de estratégias a serem adotadas no Plano de Mobilidade Corporativa deste estudo de caso, tem-se: Melhorias na infraestrutura da empresa, com a construção de bicicletário, hoje inexistente; Possíveis pontuações ou benefícios/prioridade de vaga de estacionamento para aqueles que oferecem carona; Criação de parcerias com aplicativos de mobilidade, desburocratizando processos e tornando os preços mais atraentes; Utilização do plano de comunicação para valorizar o uso do transporte público, seja por meio de newsletters ou notícias sobre benefícios de custo/tempo destes meios de locomoção; 
Após a definição do plano de mobilidade, busca-se aprovar as ações a serem tomadas e divulgar o plano. As próximas etapas, são a implementação, promoção, monitoramento e revisão, cujos escopos não é o foco desta Dissertação. 


\section{CONCLUSÕES, LIMITAÇÕES E FUTUROS ESTUDOS}

Este último capítulo apresenta as principais conclusões encontradas no estudo, bem como discute algumas limitações e sugere propostas de futuros estudos, conforme seções a seguir.

\subsection{Principais conclusões}

A demanda por veículos motorizados no país ainda é excessiva, e verificase nesta dissertação que as empresas têm um papel fundamental na reconstrução da matriz de transportes brasileira, no momento em que priorizam e gerenciam o deslocamento de seus funcionários com elaboração de estratégias de gerenciamento da mobilidade, a partir de Planos de Mobilidade. Neste estudo de caso, priorizou-se as estratégias de construção de bicicletário, possíveis pontuações ou benefícios/prioridade de vaga de estacionamento para aqueles que oferecem carona, criação de parcerias com aplicativos de mobilidade, e utilização do plano de comunicação para valorizar o uso do transporte público, além, de escalonamento dos horários de entrada e saída de funcionários.

Estas estratégias objetivam a redução dos impactos ambientais, sociais e econômicos da região de abrangência a serem aplicadas. Visam a racionalização das viagens com apenas um ocupante, acessibilidade, uso consciente de recursos naturais e urbanos, aumento da eficiência energética frente aos meios de locomoção, e a inserção de novas políticas públicas e privadas voltadas à mobilidade urbana. Além disso, estas estratégias podem ser utilizadas não só na gestão do deslocamento pendular dos funcionários, maior contribuinte dos chamados congestionamentos recorrentes, mas também em viagens a negócios, gestão de frotas externas e/ou distribuição, que de fato, a empresa do estudo de caso poderia gerenciar.

Neste contexto, estudos sobre Planos de Mobilidade Corporativa no Brasil ainda são escassos, e foi preciso recorrer à literatura internacional, destacando boas práticas e resultados expressivos, afim de fundamentar 0 real impacto e benefícios das estratégias de gerenciamento da mobilidade, como: redução dos gases de efeito estufa; redução de custos de infraestrutura, 
tarifários e estacionamento; melhoria da acessibilidade; otimização de processos e serviços; melhoria das condições de saúde física e psicológica, com redução principalmente dos níveis de estresse; aumento da produtividade, entre outros benefícios mencionados no decorrer desta dissertação.

A partir deste estudo de caso, verificou-se o padrão original das viagens casa-trabalho-casa dos funcionários da empresa, e foi possível comprovar as possibilidades de mudança do modo de deslocamento, e seus impactos. É importante salientar que a empresa se constitui em sua maioria por jovens, com expressivo número da denominada geração $\mathrm{Y}$, que segundo algumas pesquisas, estão cada vez mais inseridos no contexto do uso consciente de recursos em prol do Desenvolvimento Sustentável.

As respostas dadas no questionário, além dos impactos em termos de geração de GEE e custos associados, servem de insumo para a elaboração de um Plano de Mobilidade Corporativa, onde seria realizado um diagnóstico mais apurado, e abrangente a toda a empresa, e verificadas as melhores estratégias cabíveis ao perfil de funcionários e condições/disponibilidade da empresa, que conforme mencionado anteriormente tem como limitante tratar de negócios envolvendo distribuição de combustíveis e fomento do automóvel.

Nesta dissertação, por meio de cases, e principalmente do estudo de caso apresentado, entende-se que a intervenção racional e sustentável das empresas sobre a demanda por transportes, contribui de forma positiva na implementação de novas políticas orientadas a mobilidade sustentável e gestão ambiental.

\subsection{Limitações do estudo}

O questionário utilizado no diagnóstico foi enviado por e-mail corporativo, no entanto, este método possui algumas desvantagens como redução da interface entre o entrevistador e o respondente, o que limitou a taxa de retorno das respostas. Além disso, o envio do questionário não contou com uma formalização da empresa estudada, o que limitou a quantidade de respostas. 
Para a elaboração e aplicação do Plano de Mobilidade, é necessário o interesse e intervenção principalmente dos Stakeholders e apoio da Diretoria, no entanto, o produto chave da empresa é a distribuição de combustíveis, o que dificulta uma mudança radical do uso do automóvel, visto que os funcionários ainda são incentivados ao uso. Com relação a casos de sucesso, não foram encontrados muitas aplicações nacionais de Políticas e Planos de mobilidade corporativa. A maioria dos estudos e orientações foram publicadas em material e bibliografia internacional.

\subsection{Recomendações para futuros estudos}

Espera-se que este trabalho contribua para o melhor entendimento da importância das empresas na mudança do padrão da mobilidade e comportamento de seus funcionários em prol da sustentabilidade, e sirva de referência para novas pesquisas sobre o tema, visando a implementação na prática e monitoramento das estratégias mencionadas nesta dissertação. Além disso, que os resultados obtidos no estudo de caso, possam ser utilizados para fomentar a elaboração do Plano de Mobilidade Corporativa da empresa local.

Com relação à empresa deste estudo de caso, por ser uma comercializadora de combustíveis, é válido ressaltar que ela se encaixa na atual Política do Renovabio, onde o Programa estabelece metas compulsórias anuais de redução de emissões de gases de efeito estufa que se desmembram em metas individuais dos distribuidores, proporcionalmente a sua participação no mercado de combustíveis fósseis do ano anterior. Além disso, as metas individuais serão quantificadas por unidades de Crédito de Descarbonização, $\mathrm{CBIO}$, emitidos pelos produtores de biocombustíveis, e a distribuidora poderá negociá-los na Bolsa de Valores, caracterizando um novo nicho no mercado financeiro e de combustíveis.

Dito isso, há de se considerar que o Renovabio, avançando em território nacional, impacta diretamente a matriz energética do país e o consumidor final, mesmo que questões tributárias e de precificação ainda não estejam definidas. Assim, fica claro o papel estratégico dos biocombustíveis, e as inúmeras 
possibilidades de trabalhos futuros sobre o tema, simulando cenários com maior valorização dos biocombustíveis.

Para novos trabalhos, também é possível elaborar questionários mais abrangentes, inserindo perguntas pontuais como qualidade do serviço público de transporte e percepção do usuário, além de poder explorar a realização de viagens a negócios pelos funcionários, o uso do uber/taxi corporativo e sua influência, visto que existe uma tendência das empresas se associarem a este tipo de serviço, e as frotas de caminhão utilizadas pela empresa, o que geraria novas avaliações e estratégias para um novo plano. Para os cálculos, podese também utilizar outras ferramentas, como o LEAP (Long-range Energy Alternatives Planning System), plataforma de modelagem e ferramenta gerencial que possibilita o cálculo do consumo energético e respectivas emissões, além de criação de cenários de mitigação. 


\section{REFERÊNCIAS BIBLIOGRÁFICAS}

ALEXANDRE, M.O.L. Potencial de gestão da mobilidade para empregadores da cidade de Resende. 2008. 137p. Dissertação de Mestrado em engenharia de transporte. COPPE/UFRJ, Rio de Janeiro, 2008.

ANFAVEA. Anfavea revela balanço de 2018 e projeções para esse ano 2019. Disponível em <http://www.anfavea.com.br/docs/ 07.01.19_Press_Resultados_2018_V2.pdf>. Acesso em Março de 2019.

ANTP. Associação Nacional de Transporte Público (BRASIL). Relatório Comparativo 2013-2014 - Sistema de Informações da Mobilidade Urbana da ANTP - Julho/2016. Disponível em: <http://www.antp.org.br/sistema-deinformacoes-da-mobilidade>. Acesso em Janeiro de 2018.

ANP, 2017. Série histórica do levantamento de preços e de margens de comercialização de combustíveis. Disponível em: < http://www.anp.gov.br/precos-e-defesa/234-precos/levantamento-de-precos/868serie-historica-do-levantamento-de-precos-e-de-margens-de-comercializacao-decombustiveis>. Acesso em Março de 2019.

BCSD Portugal - Conselho Empresarial para Desenvolvimento Sustentável de Portugal. Mobilidade Urbana Sustentável: 0 impacto das empresas e seus trabalhadores. Lisboa: BCSD Portugal, 2005.

BERTOLINI, I.; LE CLERQ, F. Urban Transportation Planning in transition. World TransitResearch, $2008 . \quad$ Disponível em: <http://www.sciencedirect.com/science/ article/pii/S0967070X07001072>. Acesso em Janeiro de 2017.

BRACKNELL FOREST COUNCIL. Travel Choice for Business: a local guide to workplace travel plan. Bracknell Forest, United Kingdom, 2011.

CASTRO, M.A.G. Gerenciamento da Mobilidade: uma contribuição metodológica para a definição de uma política integrada dos transportes no Brasil. 2006. 391p. Dissertação de Doutorado em engenharia de transporte. COPPE/UFRJ, Rio de Janeiro, 2006.

CEBDS, 2016. Mobilidade Corporativa - Potencial econômico de sua implementação. Disponível em: < https://cebds.org/publicacoes/mobilidade- 
corporativa-potencial-economico-de-sua-implementacao/\#.XRmTcfZFzSE >. Acesso em Agosto de 2018.

CINTRA, M. Os custos dos congestionamentos na cidade de São Paulo. Texto para Discussão, 356. São Paulo: FGV, 2014. Disponível em: $<$ http://www.eesp.fgv.br>

CINTRA, M. Os custos do congestionamento na capital paulista. Revista Conjuntura Econômica. Junho de 2008.

DECASTRO, J. Caracterização e Análise do Deslocamento Casa-TrabalhoCasa em Empresas Localizadas na Barra da Tijuca. Dissertação de Mestrado - Programa de Pós-graduação em Engenharia de Transportes, Universidade Federal do Rio de Janeiro, Rio de Janeiro, 2014.

DOWNS, A. Still stuck in traffic: Coping with peak-hour traffic congestion. Brookings Institution Press: Washington, D.C, 2004.

DUANY, A; SPECK, J; LYDON, M. The Smart growth manual. Nova York: McGraw Hill, 2010.

EMBARQ BRASIL. Passo a Passo para a Construção de um Plano de Mobilidade Urbana. Porto Alegre, Brasil, 2014. Disponível em: <http://d.pr/f/1eLcr>. Acesso em Maio de 2017.

EMBARQ BRASIL. Estratégias de mobilidade urbana para organizações. Porto Alegre, Brasil, 2017. Disponível em: < http://wricidades.org/research/publication>. Acesso em Maio de 2018.

EPOMM. European Platform on mobility management. Disponível em: <http:// epomm.org>, Acesso em Maio de 2018.

FINANCE DIRECTOR. Model of propriety: corporate mobility integration, 2017. Disponível em: <http://www.the-financedirector.com/features/ featurefinance-director-europe-mobility-integration-martyn-briggs/>. Acesso em Maio de 2017

FIRJAN - Federação das Indústrias do Estado do Rio de Janeiro. O custo dos deslocamentos nas principais áreas urbanas do Brasil. Rio de Janeiro: FIRJAN, 2015. 
FRANZ, G.; MAIER, G.; SCHRÖCK, P. Urban sprawl: how useful is this concept? Viena, 2006.

GREENPEACE, 2013. [R]evolução energética. A caminho do desenvolvimento limpo. São Paulo: Greenpeace, 2013. Disponível em: < http://www.unica.com.br/noticia/ 38156175920337887669/uso-debiocombustiveis-deve-aumentar-ate-2050-por-cento2C-diz-relatorio-dogreenpeace/>. Acesso em Março de 2019.

INCT. Institutos Nacionais de Ciência e Tecnologias - Observatório das Metrópoles. Estado da motorização individual no Brasil - 2015. Disponível em: <http://www.observatoriodasmetropoles.net/download/automoveis_e_motos2015 .pdf>. Acesso em Novembro de 2017.

INRIX. Inrix Global Traffic Scorecard, 2017.INRIX: Disponível em $<$ http://inrix.com/resources/inrix-2016-global-traffic-scorecard/>. Acessado em: 20 mai. 2017

INVENTÁRIO 2017. Disponível em: < http://www.ultra.com.br/Ultra/relatorio/2017/ pt/gestao-ambiental.html> e <https://www.registropublicodeemissoes.com.br/ participantes/1126>. Acesso em Março de 2019.

IPEA - Instituto de Pesquisa Econômica Aplicada. Tempo de deslocamento casa-trabalho no Brasil (1992-2009): diferenças entre regiões metropolitanas, níveis de renda e sexo. Texto para Discussão, 1813. Brasília: IPEA, 2013.

IRELAND. National Transport Authority. Workplace Travel Plans: a guide for implementers. Dublin, Ireland, 2011. Disponível em: < https:// www.smartertravelworkplaces.ie/ >. Acesso em Maio de 2018.

ISP, 2018. Segurança Pública em números 2018. Evolução dos principais indicadores de criminalidade e atividade policial no estado do Rio de Janeiro de $2003 \quad$ a 2018. Disponível em: < http://www.ispdados.rj.gov.br/Sitelsp/SegurancaEmNumeros2018.pdf> . Acesso em Março de 2019.

ITDP, 2017. Guia de Planejamento Cicloinclusivo < http://itdpbrasil.org.br/wpcontent/uploads/2017/09/guia-cicloinclusivo-ITDP-Brasil-setembro-2017.pdf>. Acesso em Março de 2019. 
JUSBRASIL. Disponível em: <https://trt3.jusbrasil.com.br/noticias/210879008/desconto-de-6-pelo-vale-transporte-incideapenas-sobre-o-salario-basico>. Acesso em Março de 2019.

KNEIB, E. C. Caracterização de empreendimentos geradores de viagens: contribuição conceitual à análise de seus impactos no uso, ocupação e valorização do solo urbano. Dissertação de mestrado em Transportes, Universidade de Brasília, 2004.

LITMAN, T. Guide to calculating mobility management benefits. Vitoria Transport Policy Institute, March, 2011.

McGROARTY, J. 2010. Recurring and Non-Recurring Congestion: Causes, Impacts, and Solutions. Neihoff Urban Studio - W10. Disponível em: <https://www.uc.edu/>. Acesso em Maio de 2018.

MENEZES, F.S.S.e BALASSIANO, R. Participação das empresas na política de gerenciamento da demanda por transportes. In: III RIO DE TRANSPORTES, 2005, Rio de Janeiro. Disponível em: <http://www.riodetransportes.org>, acesso em Setembro de 2017.

METRO-SP, 2007. Pesquisa O/D. Disponível em: < https://www.nossasaopaulo.org.br/portal/files/sintese_od_2007.pdf>. Acesso em Agosto de 2018.

MIHESSEN, V.; MACHADO, D. C.; PERO, V.; Mobilidade urbana e mercado de trabalho na região metropolitana do Rio de Janeiro. In: $42^{\circ}$ Encontro Nacional de Economia, 2014, Natal. Anais do 42ํㅡㄹ Encontro Nacional de Economia. Niterói: ANPEC, 2014. v. 1. p. 1-20.

MINISTÉRIO DAS CIDADES. 2015. PlanMob: caderno de referência para elaboração de plano de mobilidade urbana. Brasília: Ministério das Cidades. Disponível em: <http://www.cidades.gov.br/images/stories/ArquivosSE/planmob. pdf>. Acesso em Janeiro de 2017.

MINISTÉRIO DAS CIDADES, 2013. Política Nacional de Mobilidade Urbana. 2013. 5 p. 
MME - MINISTÉRIO DE MINAS E ENERGIA. Balanço Energético Nacional 2018, 2018. Disponível em: < https://ben.epe.gov.br/ >. Acesso em Março de 2019.

NZ TRANSPORT AGENCY. Workplace Travel Plan Guidelines: general travel planning know-how with a focus on travel to and from work. New Zealand, 2011.

Observatório das metrópoles (2015). Estado de motorização individual no Brasil Relatório 2015. Disponível em: < http://www.observatoriodasmetropoles.net>. Acesso em Março de 2018

OLIVEIRA, Riley Rodrigues de. Mobilidade urbana na cidade do Rio de Janeiro: Impactos de longo prazo dos projetos da Copa do Mundo de 2014 e dos Jogos Olímpicos de 2016. Rio de Janeiro, 2013.

PEREIRA, R. H. M.; SCWANEN, T. Tempo de Deslocamento Casa-Trabalho no Brasil (1992-2009): diferenças entre regiões metropolitanas, níveis de renda e sexo. Instituto de Pesquisa Econômica Aplicada, Brasilia/DF, Brasil, 2013.

PERTH. Department of Environment and Conservation. Department of Transport. TraveISmart Workplace Fact Sheet: Promoting walking. Perth, Australia, 2013. Disponível em: <https://healthierworkplacewa.com.au/media/2297/promotingwalking.pdf>. Acesso em Maio de 2018.

PETZHOLD, G. S.; LINDAU, L. A. O Papel das Corporações na Busca da Melhoria das Condições de Mobilidade Urbana nas Cidades. In: Anais XXIX Congresso de Pesquisa e Ensino em Transportes, ANPET, Ouro Preto, 2015.

PETZHOLD, G. S.; LINDAU, L. A. Planos de Mobilidade Corporativa: Análise e Proposta de Método para sua Elaboração. In: Anais XXIX Congresso de Pesquisa e Ensino em Transportes, ANPET, Ouro Preto, 2015.

PORTUGAL, L.S. e GOLDNER, L.G. Estudo de Pólos Geradores de Tráfego e de seus Impactos nos Sistemas Viários e de Transportes. Editora Edgard Blucher, 2003

REDPGV. Rede Íbero-Americana de Estudo em Polos Geradores de Viagens. Disponível em: <http://redpgv.coppe.ufrj.br/index.php/pt-BR/conceitos/o-que-eum-pgv>. Acesso em Maio de 2018. 
ROSA, M.; BRANCO, M.L.G. C; FIRKOWSKI, O.L.C de F. Movimento pendular e perspectivas de pesquisas em aglomerados urbanos. São Paulo em Perspectiva, V.19, N.4, p.121-133, 2005.

ROSS, S. L.; YINGER, John. Timing equilibria in an urban model with congestion. Journal of Urban Economics, v. 47, n. 3, p. 390-413, May 2000. Department of Economics, University of Connecticut, Connecticut.

Salas, D. C., G. Darido, S. Mehndiratta e A. Leal; A Commuter-Based Traffic Demand Management Approach for Latin America: Results from Voluntary Corporate Mobility Pilots in Sao Paulo and Mexico City. In 94th Transportation Research Board Annual Meeting. Washington D. C., United States, 2015.

SANTOS, L. Mudanças Climáticas e Mobilidade Urbana: análise de políticas públicas para o setor de transporte de passageiros no Brasil. Projeto de tese de Doutorado - Programa de Planejamento energético, Universidade Federal do Rio de Janeiro, Rio de Janeiro, 2013.

SISTEMA FIRJAN (2015). O custo dos deslocamentos nas principais áreas urbanas do Brasil. Disponível em: <http://www.firjan.com.br/publicacoes/ publicacoes-de-economia/o-custo-dos-deslocamentosnas-principais-areasurbanas-do-brasil>. Acesso em abril de 2018.

UNITED KINGDOM. Department for Transport. The Essential Guide to Travel Planning. London, United Kingdom, 2008. Disponível em: < http://www.pcal.nsw.gov.au/>. Acesso em Maio de 2018.

VAN MALDEREN, L.; JOURQUIN, B.; THOMAS, I.; VANOUTRIVE, T.; VERHETSEL, A; WITLOX, F. On the mobility policies of companies: What are the good practices? The Belgian case. In: Transport Policy, v. 21, p 10-19. 2012 WRI BRASIL. Estudo mostra como organizações podem mudar políticas de transporte de funcionários, 2016. Disponível em: <http://wricidades.org >. Acesso em Dezembro de 2017.

YOUNG, C.; AGUIAR, C.; POSSAS, E. Custo econômico do tempo de deslocamento para o trabalho na Região Metropolitana do Rio de Janeiro, 2013. Disponível em: <http://www.ie.ufrj.br/>. Acesso em Abril de 2018. 
GHG PROTOCOL, 2019. Disponível em:

$<$ https://www.ghgprotocolbrasil.com.br/o-programa-brasileiro-ghg-

protocol? locale=pt-br>. Acesso em Maio de 2019. 


\section{APÊNDICE A - DADOS DO INVENTÁRIO 2017}

\begin{tabular}{|c|c|c|c|c|c|}
\hline Ordem & Bairro & Municipio & UF & Usuário VT & $\begin{array}{l}\text { Distância } \\
\text { média até } \\
\text { São } \\
\text { Cristóvão } \\
\text { (km) }\end{array}$ \\
\hline 1 & RAMOS & RIO DE JANEIRO & RJ & SIM & 11 \\
\hline 2 & SANTA ROSA & NITERÓI & RJ & NÃO & 21 \\
\hline 3 & SANTA ROSA & NITERÓI & RJ & NÃO & 21 \\
\hline 4 & PECHINCHA & RIO DE JANEIRO & RJ & SIM & 20,6 \\
\hline 5 & CATETE & RIO DE JANEIRO & RJ & NÃO & 9,9 \\
\hline 6 & JARDIM CARIOCA & RIO DE JANEIRO & RJ & NÃO & 15,1 \\
\hline 7 & SANTA ROSA & NITERÓI & RJ & NÃO & 21 \\
\hline 8 & QUINTANDINHA & PETRÓPOLIS & RJ & SIM & 60,6 \\
\hline 9 & CENTRO & BELFORD ROXO & RJ & SIM & 30,7 \\
\hline 10 & BOTAFOGO & RIO DE JANEIRO & RJ & NÃO & 11,9 \\
\hline 11 & IPANEMA & RIO DE JANEIRO & RJ & NÃO & 13,6 \\
\hline 12 & ANIL & RIO DE JANEIRO & RJ & NÃO & 25,1 \\
\hline 13 & PENDOTIBA & NITERÓI & RJ & NÃO & 25,2 \\
\hline 14 & VILA DA PENHA & RIO DE JANEIRO & RJ & SIM & 18,5 \\
\hline 15 & SÃO CRISTÓVÃO & RIO DE JANEIRO & RJ & NÃO & 1 \\
\hline 16 & CACHAMBI & RIO DE JANEIRO & RJ & NÃO & 11,9 \\
\hline 17 & COQUEIRAL & ARARUAMA & RJ & NÃO & 118 \\
\hline 18 & ANDARAÍ & RIO DE JANEIRO & RJ & NÃO & 7,3 \\
\hline 19 & FLAMENGO & RIO DE JANEIRO & RJ & NÃO & 9,9 \\
\hline
\end{tabular}




\begin{tabular}{|c|c|c|c|c|c|}
\hline 20 & BARRA DA TIJUCA & RIO DE JANEIRO & RJ & NÃO & 28,4 \\
\hline 21 & PARQUE LAFAIETE & DUQUE DE CAXIAS & RJ & NÃO & 20,9 \\
\hline 22 & ANDARAÍ & RIO DE JANEIRO & RJ & NÃO & 7,3 \\
\hline 23 & ENGENHO NOVO & RIO DE JANEIRO & RJ & NÃO & 6,3 \\
\hline 24 & SANTA TERESA & RIO DE JANEIRO & RJ & NÃO & 7,3 \\
\hline 25 & $\begin{array}{l}\text { ENGENHO DE } \\
\text { DENTRO }\end{array}$ & RIO DE JANEIRO & RJ & NÃO & 13,5 \\
\hline 26 & ANDARAÍ & RIO DE JANEIRO & RJ & SIM & 7,3 \\
\hline 27 & HIGIENOPOLIS & RIO DE JANEIRO & RJ & NÃO & 9,4 \\
\hline 28 & RIBEIRA & RIO DE JANEIRO & RJ & NÃO & 18,6 \\
\hline 29 & FLAMENGO & RIO DE JANEIRO & RJ & NÃO & 9,9 \\
\hline 30 & CENTRO & RIO DE JANEIRO & RJ & NÃO & 6,9 \\
\hline 31 & COPACABANA & RIO DE JANEIRO & RJ & SIM & 13,8 \\
\hline 32 & TIJUCA & RIO DE JANEIRO & RJ & NÃO & 8,6 \\
\hline 33 & SANTA TERESA & RIO DE JANEIRO & RJ & NÃO & 7,3 \\
\hline 34 & CAVALCANTI & RIO DE JANEIRO & RJ & NÃO & 14,7 \\
\hline 35 & FREGUESIA & RIO DE JANEIRO & RJ & NÃO & 20,3 \\
\hline 36 & JACAREPAGUÁ & RIO DE JANEIRO & RJ & SIM & 32,2 \\
\hline 37 & FLAMENGO & RIO DE JANEIRO & RJ & NÃO & 9,9 \\
\hline 38 & BARRA DA TIJUCA & RIO DE JANEIRO & RJ & NÃO & 28,4 \\
\hline 39 & PRAÇA SECA & RIO DE JANEIRO & RJ & NÃO & 21,5 \\
\hline 40 & TIJUCA & RIO DE JANEIRO & RJ & NÃO & 8,6 \\
\hline 41 & COPACABANA & RIO DE JANEIRO & RJ & NÃO & 13,8 \\
\hline 42 & COPACABANA & RIO DE JANEIRO & RJ & NÃO & 13,8 \\
\hline 43 & TIJUCA & RIO DE JANEIRO & RJ & NÃO & 8,6 \\
\hline
\end{tabular}




\begin{tabular}{|c|c|c|c|c|c|}
\hline 44 & MEIER & RIO DE JANEIRO & RJ & NÃO & 7,9 \\
\hline 45 & VILA SANTA ALICE & DUQUE DE CAXIAS & RJ & NÃO & 44,6 \\
\hline 46 & RAMOS & RIO DE JANEIRO & RJ & SIM & 11 \\
\hline 47 & REALENGO & RIO DE JANEIRO & RJ & NÃO & 33,6 \\
\hline 48 & JACAREPAGUÁ & RIO DE JANEIRO & RJ & SIM & 32,2 \\
\hline 49 & SAPE & NITERÓI & RJ & SIM & 25,3 \\
\hline 50 & MEIER & RIO DE JANEIRO & RJ & SIM & 7,9 \\
\hline 51 & ANDARAÍ & RIO DE JANEIRO & RJ & NÃO & 7,3 \\
\hline 52 & PITANGUEIRAS & RIO DE JANEIRO & RJ & NÃO & 17,1 \\
\hline 53 & TIJUCA & RIO DE JANEIRO & RJ & NÃO & 8,6 \\
\hline 54 & $\begin{array}{l}\text { BARRA DE } \\
\text { GUARATIBA }\end{array}$ & RIO DE JANEIRO & RJ & NÃO & 51,5 \\
\hline 55 & ANDARAÍ & RIO DE JANEIRO & RJ & NÃO & 7,3 \\
\hline 56 & BENTO RIBEIRO & RIO DE JANEIRO & RJ & NÃO & 22,9 \\
\hline 57 & LEBLON & RIO DE JANEIRO & RJ & NÃO & 13,3 \\
\hline 58 & FREGUESIA & RIO DE JANEIRO & RJ & NÃO & 20,3 \\
\hline 59 & MÉIER & RIO DE JANEIRO & RJ & NÃO & 7,9 \\
\hline 60 & COPACABANA & RIO DE JANEIRO & RJ & NÃO & 13,8 \\
\hline 61 & BOTAFOGO & RIO DE JANEIRO & RJ & NÃO & 11,9 \\
\hline 62 & VILA VALQUEIRE & RIO DE JANEIRO & RJ & NÃO & 22,3 \\
\hline 63 & INGA & NITERÓI & RJ & NÃO & 20,2 \\
\hline 64 & CAMPO GRANDE & RIO DE JANEIRO & RJ & NÃO & 49,7 \\
\hline 65 & FREGUESIA & RIO DE JANEIRO & RJ & NÃO & 20,3 \\
\hline 66 & JARDIM BOTÂNICO & RIO DE JANEIRO & RJ & NÃO & 11,6 \\
\hline 67 & TIJUCA & RIO DE JANEIRO & RJ & NÃO & 8,6 \\
\hline
\end{tabular}




\begin{tabular}{|c|c|c|c|c|c|}
\hline 68 & COPACABANA & RIO DE JANEIRO & RJ & NÃO & 13,8 \\
\hline 69 & $\begin{array}{l}\text { LINS DE } \\
\text { VASCONCELOS }\end{array}$ & RIO DE JANEIRO & RJ & NÃO & 8,6 \\
\hline 70 & GRAJAÚ & RIO DE JANEIRO & RJ & NÃO & 8,9 \\
\hline 71 & IRAJÁ & RIO DE JANEIRO & RJ & SIM & 21,8 \\
\hline 72 & COPACABANA & RIO DE JANEIRO & RJ & NÃO & 13,8 \\
\hline 73 & FLAMENGO & RIO DE JANEIRO & RJ & NÃO & 9,9 \\
\hline 74 & GRAJAÚ & RIO DE JANEIRO & RJ & NÃO & 8,9 \\
\hline 75 & TIJUCA & RIO DE JANEIRO & RJ & NÃO & 8,6 \\
\hline 76 & BENTO RIBEIRO & RIO DE JANEIRO & RJ & SIM & 22,9 \\
\hline 77 & FONSECA & NITERÓI & RJ & NÃO & 19,1 \\
\hline 78 & IPANEMA & RIO DE JANEIRO & RJ & NÃO & 13,6 \\
\hline 79 & PRATA & BELFORD ROXO & RJ & NÃO & 31,9 \\
\hline 80 & SÃO CRISTÓVÃO & RIO DE JANEIRO & RJ & NÃO & 1 \\
\hline 81 & COPACABANA & RIO DE JANEIRO & RJ & NÃO & 13,8 \\
\hline 82 & PECHINCHA & RIO DE JANEIRO & RJ & SIM & 20,6 \\
\hline 83 & TIJUCA & RIO DE JANEIRO & RJ & NÃO & 8,6 \\
\hline 84 & RIACHUELO & RIO DE JANEIRO & RJ & NÃO & 4,8 \\
\hline 85 & IPANEMA & RIO DE JANEIRO & RJ & NÃO & 13,6 \\
\hline 86 & CAMPO GRANDE & RIO DE JANEIRO & RJ & NÃO & 49,7 \\
\hline 87 & TIJUCA & RIO DE JANEIRO & RJ & NÃO & 8,6 \\
\hline 88 & ANDARAÍ & RIO DE JANEIRO & RJ & NÃO & 7,3 \\
\hline 89 & $\begin{array}{l}\text { ENGENHO DE } \\
\text { DENTRO }\end{array}$ & RIO DE JANEIRO & RJ & NÃO & 13,5 \\
\hline 90 & LARANJEIRAS & RIO DE JANEIRO & RJ & SIM & 9,9 \\
\hline
\end{tabular}




\begin{tabular}{|c|c|c|c|c|c|}
\hline 91 & BANGU & RIO DE JANEIRO & RJ & SIM & 37,3 \\
\hline 92 & VILA DA PENHA & RIO DE JANEIRO & RJ & SIM & 18,5 \\
\hline 93 & PENHA CIRCULAR & RIO DE JANEIRO & RJ & SIM & 13,9 \\
\hline 94 & ZUMBI & RIO DE JANEIRO & RJ & SIM & 17,6 \\
\hline 95 & COLUBANDE & SÃO GONÇALO & RJ & SIM & 29,7 \\
\hline 96 & $\begin{array}{l}\text { RECREIO DOS } \\
\text { BANDEIRANTES }\end{array}$ & RIO DE JANEIRO & RJ & SIM & 38,6 \\
\hline 97 & ENGENHO NOVO & RIO DE JANEIRO & RJ & NÃO & 6,3 \\
\hline 98 & ICARAÍ & NITERÓI & RJ & SIM & 19,6 \\
\hline 99 & VILA ISABEL & RIO DE JANEIRO & RJ & SIM & 7,2 \\
\hline 100 & OLINDA & NILÓPOLIS & RJ & SIM & 29,5 \\
\hline 101 & COLUBANDE & SÃO GONÇALO & RJ & SIM & 29,7 \\
\hline 102 & FLAMENGO & RIO DE JANEIRO & RJ & NÃO & 9,9 \\
\hline 103 & HUMAITÁ & RIO DE JANEIRO & RJ & NÃO & 10 \\
\hline 104 & SÃO CRISTÓVÃO & RIO DE JANEIRO & RJ & SIM & 1 \\
\hline 105 & BRÁS DE PINA & RIO DE JANEIRO & RJ & SIM & 22,5 \\
\hline 106 & VILA ISABEL & RIO DE JANEIRO & RJ & NÃO & 7,2 \\
\hline 107 & BARRA DA TIJUCA & RIO DE JANEIRO & RJ & NÃO & 28,4 \\
\hline 108 & MADUREIRA & RIO DE JANEIRO & RJ & NÃO & 19,4 \\
\hline 109 & VILA BELA VISTA & DUQUE DE CAXIAS & RJ & SIM & 20,5 \\
\hline 110 & VILA DA PENHA & RIO DE JANEIRO & RJ & NÃO & 18,5 \\
\hline 111 & $\begin{array}{l}\text { CONDADO DE } \\
\text { MARICA }\end{array}$ & MARICA & RJ & NÃO & 58 \\
\hline 112 & JACAREPAGUÁ & RIO DE JANEIRO & RJ & NÃO & 32,2 \\
\hline 113 & OLARIA & RIO DE JANEIRO & RJ & NÃO & 11 \\
\hline
\end{tabular}




\begin{tabular}{|c|c|c|c|c|c|}
\hline 114 & RAMOS & RIO DE JANEIRO & RJ & NÃO & 11 \\
\hline 115 & ITANHANGÁ & RIO DE JANEIRO & RJ & NÃO & 26 \\
\hline 116 & ALTO & TERESÓPOLIS & RJ & SIM & 88,9 \\
\hline 117 & CENTRO & PARACAMBI & RJ & SIM & 79,8 \\
\hline 118 & RAMOS & RIO DE JANEIRO & RJ & NÃO & 11 \\
\hline 119 & $\begin{array}{l}\text { LINS DE } \\
\text { VASCONCELOS }\end{array}$ & RIO DE JANEIRO & RJ & NÃO & 8,6 \\
\hline 120 & IRAJÁ & RIO DE JANEIRO & RJ & NÃO & 21,8 \\
\hline 121 & PRAÇA SECA & RIO DE JANEIRO & RJ & SIM & 21,5 \\
\hline 122 & PENDOTIBA & NITERÓI & RJ & NÃO & 25,2 \\
\hline 123 & RIO COMPRIDO & RIO DE JANEIRO & RJ & NÃO & 5,9 \\
\hline 124 & PRAÇA SECA & RIO DE JANEIRO & RJ & SIM & 21,5 \\
\hline 125 & TIJUCA & RIO DE JANEIRO & RJ & NÃO & 8,6 \\
\hline 126 & $\begin{array}{l}\text { JARDIM OLAVO } \\
\text { BILAC }\end{array}$ & $\begin{array}{l}\text { SÃO JOÃO DE } \\
\text { MERITI }\end{array}$ & RJ & NÃO & 24 \\
\hline 127 & PITA & SÃO GONÇALO & RJ & NÃO & 23 \\
\hline 128 & MARACANÃ & RIO DE JANEIRO & RJ & NÃO & 7 \\
\hline 129 & BOA ESPERANÇA & SEROPÉDICA & RJ & SIM & 66,5 \\
\hline 130 & FREGUESIA & RIO DE JANEIRO & RJ & SIM & 20,3 \\
\hline 131 & SÃO CRISTÓVÃO & RIO DE JANEIRO & RJ & NÃO & 1 \\
\hline 132 & VILA NORMA & MESQUITA & RJ & NÃO & 29,4 \\
\hline 133 & $\begin{array}{l}\text { VICENTE DE } \\
\text { CARVALHO }\end{array}$ & RIO DE JANEIRO & RJ & SIM & 15,7 \\
\hline 134 & SANTA ROSA & NITERÓI & RJ & SIM & 21 \\
\hline 135 & ICARAÍ & NITERÓI & RJ & SIM & 19,6 \\
\hline
\end{tabular}




\begin{tabular}{|c|c|c|c|c|c|}
\hline 136 & $\begin{array}{l}\text { ENGENHO DE } \\
\text { DENTRO }\end{array}$ & RIO DE JANEIRO & RJ & NÃO & 13,5 \\
\hline 137 & PRAÇA SECA & RIO DE JANEIRO & $\mathbf{R J}$ & SIM & 21,5 \\
\hline 138 & CASCADURA & RIO DE JANEIRO & RJ & SIM & 17,4 \\
\hline 139 & $\begin{array}{l}\text { RECREIO DOS } \\
\text { BANDEIRANTES }\end{array}$ & RIO DE JANEIRO & RJ & NÃO & 38,6 \\
\hline 140 & SÃO CRISTÓVÃO & RIO DE JANEIRO & RJ & NÃO & 1 \\
\hline 141 & ÁGUA SANTA & RIO DE JANEIRO & RJ & SIM & 15,9 \\
\hline 142 & COSMOS & RIO DE JANEIRO & RJ & SIM & 58,1 \\
\hline 143 & CATETE & RIO DE JANEIRO & RJ & SIM & 9,9 \\
\hline 144 & TIJUCA & RIO DE JANEIRO & RJ & SIM & 8,6 \\
\hline 145 & HUMAITÁ & RIO DE JANEIRO & RJ & SIM & 10 \\
\hline 146 & TRINDADE & SÃO GONÇALO & RJ & NÃO & 32,9 \\
\hline 147 & TIJUCA & RIO DE JANEIRO & RJ & NÃO & 8,6 \\
\hline 148 & TAQUARA & RIO DE JANEIRO & RJ & NÃO & 23 \\
\hline 149 & ANDARAÍ & RIO DE JANEIRO & RJ & NÃO & 7,3 \\
\hline 150 & VILA ISABEL & RIO DE JANEIRO & RJ & NÃO & 7,2 \\
\hline 151 & BARRA DA TIJUCA & RIO DE JANEIRO & RJ & NÃO & 28,4 \\
\hline 152 & JACAREPAGUÁ & RIO DE JANEIRO & RJ & NÃO & 32,2 \\
\hline 153 & JACAREPAGUÁ & RIO DE JANEIRO & RJ & NÃO & 32,2 \\
\hline 154 & PAVUNA & RIO DE JANEIRO & RJ & SIM & 25,1 \\
\hline 155 & PARQUE TIETE & $\begin{array}{l}\text { SÃO JOÃO DE } \\
\text { MERITI }\end{array}$ & $\mathbf{R J}$ & NÃO & 21,7 \\
\hline 156 & JARDIM CATARINA & SÃO GONÇALO & RJ & NÃO & 34,9 \\
\hline 157 & CAMPO GRANDE & RIO DE JANEIRO & $\mathbf{R J}$ & NÃO & 49,7 \\
\hline
\end{tabular}




\begin{tabular}{|c|c|c|c|c|c|}
\hline 158 & $\begin{array}{l}\text { COMENDADOR } \\
\text { SOARES }\end{array}$ & NOVA IGUAÇU & RJ & SIM & 38,4 \\
\hline 159 & CUBANGO & NITERÓI & RJ & SIM & 19,1 \\
\hline 160 & TIJUCA & RIO DE JANEIRO & RJ & SIM & 8,6 \\
\hline 161 & TIJUCA & RIO DE JANEIRO & RJ & NÃO & 8,6 \\
\hline 162 & RIO COMPRIDO & RIO DE JANEIRO & RJ & NÃO & 5,9 \\
\hline 163 & NOVA BELÉM & JAPERI & RJ & SIM & 72,7 \\
\hline 164 & $\begin{array}{l}\text { PARQUE SÃO } \\
\text { VICENTE }\end{array}$ & BELFORD ROXO & RJ & SIM & 37,8 \\
\hline 165 & FREGUESIA & RIO DE JANEIRO & RJ & NÃO & 20,3 \\
\hline 166 & BARRA DA TIJUCA & RIO DE JANEIRO & RJ & NÃO & 28,4 \\
\hline 167 & ICARAÍ & NITERÓI & RJ & NÃO & 19,6 \\
\hline 168 & PARQUE XERÉM & DUQUE DE CAXIAS & RJ & NÃO & 43 \\
\hline 169 & LEME & RIO DE JANEIRO & RJ & NÃO & 13,8 \\
\hline 170 & VILA INHOM & MAGÉ & RJ & SIM & 47,2 \\
\hline 171 & PARQUE SAXÔNIA & BELFORD ROXO & RJ & SIM & 34,4 \\
\hline 172 & $\begin{array}{l}\text { SÃO JOSE DE } \\
\text { IMBASSAI }\end{array}$ & MARICA & RJ & NÃO & 54,3 \\
\hline 173 & PRAÇA SECA & RIO DE JANEIRO & RJ & NÃO & 21,5 \\
\hline 174 & $\begin{array}{l}\text { ANDRADE DE } \\
\text { ARAUJO }\end{array}$ & BELFORD ROXO & RJ & NÃO & 33,6 \\
\hline 175 & PORTUGUESA & RIO DE JANEIRO & RJ & NÃO & 15,2 \\
\hline 176 & SÃO BENTO & DUQUE DE CAXIAS & RJ & SIM & 26 \\
\hline 177 & TIJUCA & RIO DE JANEIRO & RJ & NÃO & 8,6 \\
\hline 178 & VILA JOLAR & BELFORD ROXO & RJ & SIM & 35,9 \\
\hline 179 & JACAREPAGUÁ & RIO DE JANEIRO & RJ & NÃO & 32,2 \\
\hline
\end{tabular}




\begin{tabular}{|c|c|c|c|c|c|}
\hline 180 & TIJUCA & RIO DE JANEIRO & RJ & SIM & 8,6 \\
\hline 181 & FREGUESIA & RIO DE JANEIRO & RJ & NÃO & 20,3 \\
\hline 182 & FLAMENGO & RIO DE JANEIRO & RJ & NÃO & 9,9 \\
\hline 183 & $\begin{array}{l}\text { RECREIO } \\
\text { BANDEIRANTES }\end{array}$ & RIO DE JANEIRO & RJ & NÃO & 38,6 \\
\hline 184 & INGA & NITERÓI & RJ & NÃO & 20,2 \\
\hline 185 & ITAIPUAÇU & MARICA & RJ & NÃO & 49,2 \\
\hline 186 & JACAREPAGUÁ & RIO DE JANEIRO & RJ & NÃO & 32,2 \\
\hline 187 & SÃO DOMINGOS & NITERÓI & RJ & NÃO & 20 \\
\hline 188 & TIJUCA & RIO DE JANEIRO & RJ & NÃO & 8,6 \\
\hline 189 & FREGUESIA & RIO DE JANEIRO & RJ & NÃO & 20,3 \\
\hline 190 & COPACABANA & RIO DE JANEIRO & RJ & NÃO & 13,8 \\
\hline 191 & PIRATININGA & NITERÓI & RJ & NÃO & 31,1 \\
\hline 192 & GRAJAÚ & RIO DE JANEIRO & RJ & NÃO & 8,9 \\
\hline 193 & TIJUCA & RIO DE JANEIRO & RJ & NÃO & 8,6 \\
\hline 194 & MARACANÃ & RIO DE JANEIRO & RJ & NÃO & 7 \\
\hline 195 & ICARAÍ & NITERÓI & RJ & NÃO & 19,6 \\
\hline 196 & ANIL & RIO DE JANEIRO & RJ & NÃO & 25,1 \\
\hline 197 & CENTRO & RIO DE JANEIRO & RJ & NÃO & 6,9 \\
\hline 198 & COPACABANA & RIO DE JANEIRO & RJ & NÃO & 13,8 \\
\hline 199 & $\begin{array}{l}\text { ILHA DO } \\
\text { GOVERNADOR }\end{array}$ & RIO DE JANEIRO & RJ & NÃO & 14,6 \\
\hline 200 & FONSECA & NITERÓI & RJ & NÃO & 19,1 \\
\hline 201 & VILLAGE SÃO ROQUE & MIGUEL PEREIRA & RJ & NÃO & 114 \\
\hline 202 & TIJUCA & RIO DE JANEIRO & RJ & NÃO & 8,6 \\
\hline
\end{tabular}




\begin{tabular}{|c|c|c|c|c|c|}
\hline 203 & BOTAFOGO & RIO DE JANEIRO & RJ & NÃO & 11,9 \\
\hline 204 & LEME & RIO DE JANEIRO & RJ & NÃO & 13,8 \\
\hline 205 & BADU & NITERÓI & RJ & NÃO & 31 \\
\hline 206 & COPACABANA & RIO DE JANEIRO & RJ & NÃO & 13,8 \\
\hline 207 & JACAREPAGUÁ & RIO DE JANEIRO & RJ & NÃO & 32,2 \\
\hline 208 & HUMAITÁ & RIO DE JANEIRO & RJ & NÃO & 10 \\
\hline 209 & TIJUCA & RIO DE JANEIRO & RJ & NÃO & 8,6 \\
\hline 210 & ICARAÍ & NITERÓI & RJ & NÃO & 19,6 \\
\hline 211 & LARANJEIRAS & RIO DE JANEIRO & RJ & NÃO & 9,9 \\
\hline 212 & IRAJÁ & RIO DE JANEIRO & RJ & NÃO & 21,8 \\
\hline 213 & JOCKEY CLUB & SÃO GONÇALO & RJ & NÃO & 31,7 \\
\hline 214 & CACHAMBI & RIO DE JANEIRO & RJ & SIM & 11,9 \\
\hline 215 & ITANHANGÁ & RIO DE JANEIRO & RJ & SIM & 26 \\
\hline 216 & SÃO CRISTÓVÃO & RIO DE JANEIRO & RJ & NÃO & 1 \\
\hline 217 & JARDIM ALVORADA & NOVA IGUAÇU & RJ & NÃO & 42,5 \\
\hline 218 & VÁRZEA DAS MOCAS & NITERÓI & RJ & NÃO & 38,2 \\
\hline 219 & ICARAÍ & NITERÓI & RJ & NÃO & 19,6 \\
\hline 220 & COPACABANA & RIO DE JANEIRO & RJ & NÃO & 13,8 \\
\hline 221 & BARRA DA TIJUCA & RIO DE JANEIRO & RJ & NÃO & 28,4 \\
\hline 222 & LARANJEIRAS & RIO DE JANEIRO & RJ & NÃO & 9,9 \\
\hline 223 & BARRA DA TIJUCA & RIO DE JANEIRO & RJ & NÃO & 28,4 \\
\hline 224 & HUMAITÁ & RIO DE JANEIRO & RJ & NÃO & 10 \\
\hline 225 & CATETE & RIO DE JANEIRO & RJ & NÃO & 9,9 \\
\hline 226 & GÁVEA & RIO DE JANEIRO & RJ & NÃO & 13,9 \\
\hline
\end{tabular}




\begin{tabular}{|c|c|c|c|c|c|}
\hline 227 & FLAMENGO & RIO DE JANEIRO & RJ & SIM & 9,9 \\
\hline 228 & ANDARAÍ & RIO DE JANEIRO & RJ & NÃO & 7,3 \\
\hline 229 & IPANEMA & RIO DE JANEIRO & RJ & NÃO & 13,6 \\
\hline 230 & TURIACU & RIO DE JANEIRO & RJ & NÃO & 19,7 \\
\hline 231 & RIO COMPRIDO & RIO DE JANEIRO & RJ & NÃO & 5,9 \\
\hline 232 & OLARIA & RIO DE JANEIRO & RJ & NÃO & 11 \\
\hline 233 & INGA & NITERÓI & RJ & SIM & 20,2 \\
\hline 234 & TIJUCA & RIO DE JANEIRO & RJ & NÃO & 8,6 \\
\hline 235 & BARRA DA TIJUCA & RIO DE JANEIRO & RJ & NÃO & 28,4 \\
\hline 236 & TIJUCA & RIO DE JANEIRO & RJ & NÃO & 8,6 \\
\hline 237 & SANTA LUCIA & DUQUE DE CAXIAS & RJ & SIM & 39,9 \\
\hline 238 & PRATA & BELFORD ROXO & RJ & SIM & 31,9 \\
\hline 239 & IPIRANGA & NOVA IGUAÇU & RJ & SIM & 52,3 \\
\hline 240 & PARQUE VENEZA & BELFORD ROXO & RJ & SIM & 32,8 \\
\hline 241 & $\begin{array}{l}\text { SANTO ANTONIO DA } \\
\text { PRATA }\end{array}$ & BELFORD ROXO & $\mathbf{R J}$ & SIM & 33,1 \\
\hline 242 & PACHECO & SÃO GONÇALO & RJ & SIM & 35,1 \\
\hline 243 & AGOSTINHO PORTO & $\begin{array}{l}\text { SÃO JOÃO DE } \\
\text { MERITI }\end{array}$ & RJ & SIM & 26,3 \\
\hline 244 & $\begin{array}{l}\text { JARDIM OLAVO } \\
\text { BILAC }\end{array}$ & DUQUE DE CAXIAS & RJ & SIM & 23,9 \\
\hline 245 & COPACABANA & RIO DE JANEIRO & RJ & SIM & 13,8 \\
\hline 246 & ANDARAÍ & RIO DE JANEIRO & RJ & NÃO & 7,3 \\
\hline 247 & $\begin{array}{l}\text { RECREIO DOS } \\
\text { BANDEIRANTES }\end{array}$ & RIO DE JANEIRO & RJ & NÃO & 38,6 \\
\hline 248 & ICARAÍ & NITERÓI & RJ & NÃO & 19,6 \\
\hline
\end{tabular}




\begin{tabular}{|c|c|c|c|c|c|}
\hline 249 & $\begin{array}{l}\text { PARQUE SANTA } \\
\text { MARTA }\end{array}$ & DUQUE DE CAXIAS & RJ & NÃO & 16,5 \\
\hline 250 & TRINDADE & SÃO GONÇALO & RJ & SIM & 32,9 \\
\hline 251 & CAMPO GRANDE & RIO DE JANEIRO & RJ & SIM & 49,7 \\
\hline 252 & SÃO CRISTÓVÃO & RIO DE JANEIRO & RJ & NÃO & 1 \\
\hline 253 & $\begin{array}{l}\text { RECREIO DOS } \\
\text { BANDEIRANTES }\end{array}$ & RIO DE JANEIRO & RJ & NÃO & 38,6 \\
\hline 254 & IRAJÁ & RIO DE JANEIRO & RJ & NÃO & 21,8 \\
\hline 255 & VILA ISABEL & RIO DE JANEIRO & $\mathbf{R J}$ & NÃO & 7,2 \\
\hline 256 & ANDARAÍ & RIO DE JANEIRO & RJ & NÃO & 7,3 \\
\hline 257 & MESQUITA & NOVA IGUAÇU & RJ & NÃO & 33,9 \\
\hline 258 & ACARI & RIO DE JANEIRO & RJ & NÃO & 22,5 \\
\hline 259 & VIGÁRIO GERAL & RIO DE JANEIRO & RJ & NÃO & 19,4 \\
\hline 260 & CIDADE NOVA & RIO DE JANEIRO & RJ & NÃO & 6 \\
\hline 261 & PECHINCHA & RIO DE JANEIRO & RJ & NÃO & 20,6 \\
\hline 262 & VILA ISABEL & RIO DE JANEIRO & RJ & NÃO & 7,2 \\
\hline 263 & MARACANÃ & RIO DE JANEIRO & RJ & NÃO & 7 \\
\hline 264 & REALENGO & RIO DE JANEIRO & RJ & NÃO & 33,6 \\
\hline 265 & PARAÍSO & NOVA IGUAÇU & RJ & NÃO & 56,5 \\
\hline 266 & HONÓRIO GURGEL & RIO DE JANEIRO & RJ & SIM & 25 \\
\hline 267 & SÃO CRISTÓVÃO & RIO DE JANEIRO & RJ & NÃO & 1 \\
\hline 268 & BANGU & RIO DE JANEIRO & RJ & NÃO & 37,3 \\
\hline 269 & MARACANÃ & RIO DE JANEIRO & RJ & NÃO & 7 \\
\hline 270 & TODOS OS SANTOS & RIO DE JANEIRO & RJ & NÃO & 14,8 \\
\hline 271 & PIRATININGA & NITERÓI & RJ & NÃO & 31,1 \\
\hline
\end{tabular}




\begin{tabular}{|c|c|c|c|c|c|}
\hline 272 & LARANJEIRAS & RIO DE JANEIRO & RJ & NÃO & 9,9 \\
\hline 273 & VILA SÃO LUIS & DUQUE DE CAXIAS & RJ & NÃO & 20,5 \\
\hline 274 & VILA ISABEL & RIO DE JANEIRO & RJ & NÃO & 7,2 \\
\hline 275 & GRAJAÚ & RIO DE JANEIRO & RJ & NÃO & 8,9 \\
\hline 276 & BARRA DA TIJUCA & RIO DE JANEIRO & RJ & NÃO & 28,4 \\
\hline 277 & DEL CASTILHO & RIO DE JANEIRO & RJ & NÃO & $\overline{10,4}$ \\
\hline 278 & $\begin{array}{l}\text { LINS DE } \\
\text { VASCONCELOS }\end{array}$ & RIO DE JANEIRO & RJ & NÃO & 8,6 \\
\hline 279 & PECHINCHA & RIO DE JANEIRO & RJ & NÃO & 20,6 \\
\hline 280 & JACAREPAGUÁ & RIO DE JANEIRO & RJ & NÃO & 32,2 \\
\hline 281 & BANGU & RIO DE JANEIRO & RJ & NÃO & 37,3 \\
\hline 282 & FREGUESIA & RIO DE JANEIRO & RJ & NÃO & 20,3 \\
\hline 283 & ANDARAÍ & RIO DE JANEIRO & RJ & NÃO & 7,3 \\
\hline 284 & CALIFÓRNIA & NOVA IGUAÇU & RJ & NÃO & 32,6 \\
\hline 285 & ANDARAÍ & RIO DE JANEIRO & RJ & NÃO & 7,3 \\
\hline 286 & FLAMENGO & RIO DE JANEIRO & RJ & NÃO & 9,9 \\
\hline 287 & CARMARI & NOVA IGUAÇU & RJ & NÃO & 37,9 \\
\hline 288 & BARRA DA TIJUCA & RIO DE JANEIRO & RJ & NÃO & 28,4 \\
\hline 289 & FLAMENGO & RIO DE JANEIRO & RJ & NÃO & 9,9 \\
\hline 290 & $\begin{array}{l}\text { RECREIO DOS } \\
\text { BANDEIRANTES }\end{array}$ & RIO DE JANEIRO & RJ & NÃO & 38,6 \\
\hline 291 & $\begin{array}{l}\text { VICENTE DE } \\
\text { CARVALHO }\end{array}$ & RIO DE JANEIRO & RJ & NÃO & 15,7 \\
\hline 292 & BOTAFOGO & RIO DE JANEIRO & RJ & NÃO & 11,9 \\
\hline 293 & MARIA PAULA & SÃO GONÇALO & RJ & NÃO & 27,2 \\
\hline 294 & TODOS OS SANTOS & RIO DE JANEIRO & RJ & NÃO & 14,8 \\
\hline
\end{tabular}




\begin{tabular}{|c|c|c|c|c|c|}
\hline 295 & CACHAMBI & RIO DE JANEIRO & RJ & NÃO & 11,9 \\
\hline 296 & MÉIER & RIO DE JANEIRO & RJ & NÃO & 7,9 \\
\hline 297 & MARIA PAULA & SÃO GONÇALO & RJ & NÃO & 27,2 \\
\hline 298 & IPANEMA & RIO DE JANEIRO & RJ & NÃO & 13,6 \\
\hline 299 & COPACABANA & RIO DE JANEIRO & RJ & NÃO & 13,8 \\
\hline 300 & SÃO CRISTÓVÃO & RIO DE JANEIRO & RJ & NÃO & 1 \\
\hline 301 & COPACABANA & RIO DE JANEIRO & RJ & NÃO & 13,8 \\
\hline 302 & MADUREIRA & RIO DE JANEIRO & RJ & NÃO & $\overline{19,4}$ \\
\hline 303 & COPACABANA & RIO DE JANEIRO & RJ & NÃO & 13,8 \\
\hline 304 & FLAMENGO & RIO DE JANEIRO & RJ & NÃO & 9,9 \\
\hline 305 & COPACABANA & RIO DE JANEIRO & RJ & SIM & 13,8 \\
\hline 306 & CACHAMBI & RIO DE JANEIRO & RJ & NÃO & 11,9 \\
\hline 307 & TIJUCA & RIO DE JANEIRO & RJ & NÃO & 8,6 \\
\hline 308 & $\begin{array}{l}\text { ENGENHO DE } \\
\text { DENTRO }\end{array}$ & RIO DE JANEIRO & RJ & NÃO & 13,5 \\
\hline 309 & VÁRZEA DAS MOÇAS & NITERÓI & RJ & NÃO & 38,2 \\
\hline 310 & LARANJEIRAS & RIO DE JANEIRO & RJ & NÃO & 9,9 \\
\hline 311 & HUMAITÁ & RIO DE JANEIRO & RJ & NÃO & 10 \\
\hline 312 & TAQUARA & RIO DE JANEIRO & RJ & NÃO & 23 \\
\hline 313 & COPACABANA & RIO DE JANEIRO & RJ & SIM & 13,8 \\
\hline 314 & CENTRO & RIO DE JANEIRO & RJ & SIM & 6,9 \\
\hline 315 & LARANJEIRAS & RIO DE JANEIRO & RJ & NÃO & 9,9 \\
\hline 316 & BARRA DA TIJUCA & RIO DE JANEIRO & RJ & NÃO & 28,4 \\
\hline 317 & TIJUCA & RIO DE JANEIRO & RJ & NÃO & 8,6 \\
\hline 318 & VILA ISABEL & RIO DE JANEIRO & RJ & NÃO & 7,2 \\
\hline
\end{tabular}




\begin{tabular}{|c|c|c|c|c|c|}
\hline 319 & BARRA DA TIJUCA & RIO DE JANEIRO & RJ & NÃO & 28,4 \\
\hline 320 & JACAREPAGUÁ & RIO DE JANEIRO & RJ & NÃO & 32,2 \\
\hline 321 & $\begin{array}{l}\text { RECREIO DOS } \\
\text { BANDEIRANTES }\end{array}$ & RIO DE JANEIRO & RJ & NÃO & 38,6 \\
\hline 322 & SANTA ROSA & NITERÓI & RJ & NÃO & 21 \\
\hline 323 & COPACABANA & RIO DE JANEIRO & RJ & NÃO & 13,8 \\
\hline 324 & TAQUARA & RIO DE JANEIRO & RJ & NÃO & 23 \\
\hline 325 & BARRA DA TIJUCA & RIO DE JANEIRO & RJ & NÃO & 28,4 \\
\hline 326 & JACAREPAGUÁ & RIO DE JANEIRO & RJ & NÃO & 32,2 \\
\hline 327 & PIRATININGA & NITERÓI & RJ & NÃO & 31,1 \\
\hline 328 & IPANEMA & RIO DE JANEIRO & RJ & NÃO & 13,6 \\
\hline 329 & ICARAÍ & NITERÓI & RJ & NÃO & 19,6 \\
\hline 330 & LAGOA & RIO DE JANEIRO & RJ & NÃO & 11,2 \\
\hline 331 & HUMAITÁ & RIO DE JANEIRO & RJ & NÃO & 10 \\
\hline 332 & BARRA DA TIJUCA & RIO DE JANEIRO & RJ & NÃO & 28,4 \\
\hline 333 & RECREIO & RIO DE JANEIRO & RJ & NÃO & 38,6 \\
\hline 334 & $\begin{array}{l}\text { COMENDADOR } \\
\text { SOARES }\end{array}$ & NOVA IGUAÇU & RJ & SIM & 38,4 \\
\hline 335 & ÁGUA SANTA & RIO DE JANEIRO & RJ & SIM & 15,9 \\
\hline 336 & PRATA & BELFORD ROXO & RJ & SIM & 31,9 \\
\hline 337 & TIJUCA & RIO DE JANEIRO & RJ & NÃO & 8,6 \\
\hline 338 & BARRA DA TIJUCA & RIO DE JANEIRO & RJ & NÃO & 28,4 \\
\hline 339 & CENTRO & RIO DE JANEIRO & RJ & NÃO & 6,9 \\
\hline 340 & MARACANÃ & RIO DE JANEIRO & RJ & NÃO & 7 \\
\hline 341 & HUMAITÁ & RIO DE JANEIRO & RJ & NÃO & 10 \\
\hline
\end{tabular}




\begin{tabular}{|c|c|c|c|c|c|}
\hline 342 & TIJUCA & RIO DE JANEIRO & RJ & NÃO & 8,6 \\
\hline 343 & TIJUCA & RIO DE JANEIRO & $\mathbf{R J}$ & NÃO & 8,6 \\
\hline 344 & TIJUCA & RIO DE JANEIRO & RJ & NÃO & 8,6 \\
\hline 345 & ITAIPU & NITERÓI & RJ & NÃO & 32,6 \\
\hline 346 & JARDIM LEAL & DUQUE DE CAXIAS & RJ & SIM & 23,8 \\
\hline 347 & SANTA CRUZ SERRA & DUQUE DE CAXIAS & RJ & NÃO & 35,3 \\
\hline 348 & TIJUCA & RIO DE JANEIRO & RJ & NÃO & 8,6 \\
\hline 349 & VILA SARAPUI & DUQUE DE CAXIAS & RJ & SIM & 22,2 \\
\hline 350 & LEBLON & RIO DE JANEIRO & RJ & NÃO & 13,3 \\
\hline 351 & $\begin{array}{l}\text { RECREIO DOS } \\
\text { BANDEIRA }\end{array}$ & RIO DE JANEIRO & $\mathbf{R J}$ & NÃO & 40,6 \\
\hline 352 & ANDARAÍ & RIO DE JANEIRO & RJ & NÃO & 7,3 \\
\hline 353 & RECREIO & RIO DE JANEIRO & RJ & NÄO & 38,6 \\
\hline 354 & TIJUCA & RIO DE JANEIRO & RJ & NÃO & 8,6 \\
\hline 355 & ITAIPU & NITERÓI & RJ & SIM & 32,6 \\
\hline 356 & $\begin{array}{l}\text { PARQUE SÃO } \\
\text { BERNARDO }\end{array}$ & BELFORD ROXO & $\mathbf{R J}$ & SIM & 35,4 \\
\hline 357 & ANDRADE ARAUJO & BELFORD ROXO & RJ & SIM & 33,6 \\
\hline 358 & ENGENHO NOVO & RIO DE JANEIRO & RJ & SIM & 6,3 \\
\hline 359 & REALENGO & RIO DE JANEIRO & RJ & SIM & 33,6 \\
\hline 360 & VILA ISABEL & RIO DE JANEIRO & RJ & SIM & 7,2 \\
\hline 361 & LARANJEIRAS & RIO DE JANEIRO & RJ & NÃO & 9,9 \\
\hline 362 & TAQUARA & RIO DE JANEIRO & RJ & NÃO & 23 \\
\hline 363 & CENTRO & RIO DE JANEIRO & RJ & NÃO & 6,9 \\
\hline 364 & MARECHAL HERMES & RIO DE JANEIRO & RJ & NÃO & 27,3 \\
\hline
\end{tabular}




\begin{tabular}{|c|c|c|c|c|c|}
\hline 365 & ICARAÍ & NITERÓI & RJ & NÃO & 19,6 \\
\hline 366 & BOTAFOGO & RIO DE JANEIRO & RJ & NÃO & 11,9 \\
\hline 367 & ENGENHO DO MATO & NITERÓI & RJ & SIM & 35,4 \\
\hline 368 & BOTAFOGO & RIO DE JANEIRO & RJ & SIM & 11,9 \\
\hline 369 & TIJUCA & RIO DE JANEIRO & RJ & NÃO & 8,6 \\
\hline 370 & CAMPO GRANDE & RIO DE JANEIRO & RJ & SIM & 49,7 \\
\hline 371 & INGA & NITERÓI & RJ & NÃO & 20,2 \\
\hline 372 & SANTA CRUZ & RIO DE JANEIRO & RJ & NÃO & 62 \\
\hline 373 & JARDIM SULACAP & RIO DE JANEIRO & RJ & SIM & 34,9 \\
\hline 374 & PORTUGUESA & RIO DE JANEIRO & RJ & NÃO & 15,2 \\
\hline 375 & COPACABANA & RIO DE JANEIRO & RJ & NÃO & 13,8 \\
\hline 376 & DEL CASTILHO & RIO DE JANEIRO & RJ & NÃO & 10,4 \\
\hline 377 & TIJUCA & RIO DE JANEIRO & RJ & NÃO & 8,6 \\
\hline 378 & LAGOA & RIO DE JANEIRO & RJ & NÃO & 11,2 \\
\hline 379 & ANCHIETA & RIO DE JANEIRO & RJ & SIM & 28,1 \\
\hline 380 & FREGUESIA & RIO DE JANEIRO & RJ & NÃO & 20,3 \\
\hline 381 & LEBLON & RIO DE JANEIRO & RJ & NÃO & 13,3 \\
\hline 382 & FLAMENGO & RIO DE JANEIRO & RJ & NÃO & 9,9 \\
\hline 383 & FREGUESIA & RIO DE JANEIRO & RJ & NÃO & 20,3 \\
\hline 384 & LEME & RIO DE JANEIRO & RJ & SIM & 13,8 \\
\hline 385 & TIJUCA & RIO DE JANEIRO & RJ & NÃO & 8,6 \\
\hline 386 & CENTRO & NILÓPOLIS & RJ & NÃO & 31 \\
\hline 387 & TIJUCA & RIO DE JANEIRO & RJ & NÃO & 8,6 \\
\hline 388 & COPACABANA & RIO DE JANEIRO & RJ & NÃO & 13,8 \\
\hline
\end{tabular}




\begin{tabular}{|c|c|c|c|c|c|}
\hline 389 & TIJUCA & RIO DE JANEIRO & RJ & NÃO & 8,6 \\
\hline 390 & JARDIM GUANABARA & RIO DE JANEIRO & RJ & NÃO & 13,7 \\
\hline 391 & TIJUCA & RIO DE JANEIRO & RJ & NÃO & 8,6 \\
\hline 392 & $\begin{array}{l}\text { RECREIO DOS } \\
\text { BANDEIRANTES }\end{array}$ & RIO DE JANEIRO & RJ & NÃO & 38,6 \\
\hline 393 & VILA ISABEL & RIO DE JANEIRO & RJ & NÃO & 7,2 \\
\hline 394 & ICARAÍ & NITERÓI & RJ & NÃO & 19,6 \\
\hline 395 & $\begin{array}{l}\text { LINS DE } \\
\text { VASCONCELOS }\end{array}$ & RIO DE JANEIRO & RJ & NÃO & 8,6 \\
\hline 396 & COPACABANA & RIO DE JANEIRO & RJ & NÃO & 13,8 \\
\hline 397 & NILÓPOLIS & RIO DE JANEIRO & RJ & SIM & 32,4 \\
\hline 398 & TIJUCA & RIO DE JANEIRO & RJ & NÃO & 8,6 \\
\hline 399 & PADRE MIGUEL & RIO DE JANEIRO & RJ & NÃO & 35,2 \\
\hline 400 & VILA ISABEL & RIO DE JANEIRO & RJ & NÃO & 7,2 \\
\hline 401 & CAMPINHO & RIO DE JANEIRO & RJ & NÃO & 20,8 \\
\hline 402 & $\begin{array}{l}\text { ILHA DO } \\
\text { GOVERNADOR }\end{array}$ & RIO DE JANEIRO & RJ & NÃO & 14,6 \\
\hline 403 & ENCANTADO & RIO DE JANEIRO & RJ & NÃO & $\overline{14,4}$ \\
\hline 404 & INHAÚMA & RIO DE JANEIRO & RJ & SIM & 10,8 \\
\hline 405 & LARANJAL & SÃO GONÇALO & RJ & SIM & 33,6 \\
\hline 406 & HIGIENOPOLIS & RIO DE JANEIRO & RJ & NÃO & 9,4 \\
\hline 407 & VILA DA PENHA & RIO DE JANEIRO & RJ & NÃO & 18,5 \\
\hline 408 & COLÉGIO & RIO DE JANEIRO & RJ & SIM & 17,9 \\
\hline 409 & TIJUCA & RIO DE JANEIRO & RJ & NÃO & 8,6 \\
\hline 410 & RIACHUELO & RIO DE JANEIRO & RJ & NÃO & 4,8 \\
\hline 411 & BADU & NITERÓI & RJ & NÃO & 31 \\
\hline
\end{tabular}




\begin{tabular}{|c|c|c|c|c|c|}
\hline 412 & MEIER & RIO DE JANEIRO & RJ & NÃO & 7,9 \\
\hline 413 & PECHINCHA & RIO DE JANEIRO & RJ & NÃO & 20,6 \\
\hline 414 & $\begin{array}{l}\text { ENGENHO DE } \\
\text { DENTRO }\end{array}$ & RIO DE JANEIRO & $\mathbf{R J}$ & NÃO & 13,5 \\
\hline 415 & CENTRO & NITERÓI & $\mathbf{R J}$ & NÃO & 18,2 \\
\hline 416 & ITAÚNA & SÃO GONÇALO & RJ & NÃO & 30,5 \\
\hline 417 & $\begin{array}{l}\text { JARDIM BARRO } \\
\text { BRANCO }\end{array}$ & DUQUE DE CAXIAS & RJ & NÃO & 37,9 \\
\hline 418 & OLARIA & RIO DE JANEIRO & RJ & NÃO & 11 \\
\hline 419 & VILA ISABEL & RIO DE JANEIRO & RJ & NÃO & 7,2 \\
\hline 420 & TIJUCA & RIO DE JANEIRO & RJ & NÃO & 8,6 \\
\hline 421 & JACAREPAGUÁ & RIO DE JANEIRO & $\mathbf{R J}$ & NÃO & 32,2 \\
\hline 422 & SENADOR CAMARÁ & RIO DE JANEIRO & RJ & SIM & 42 \\
\hline 423 & SÃO CRISTÓVÃO & RIO DE JANEIRO & RJ & NÃO & 1 \\
\hline 424 & COPACABANA & RIO DE JANEIRO & RJ & NÃO & 13,8 \\
\hline 425 & $\begin{array}{l}\text { ILHA DO } \\
\text { GOVERNADOR }\end{array}$ & RIO DE JANEIRO & $\mathbf{R J}$ & NÃO & 14,6 \\
\hline 426 & JACAREPAGUÁ & RIO DE JANEIRO & RJ & NÃO & 32,2 \\
\hline 427 & HUMAITÁ & RIO DE JANEIRO & $\mathbf{R J}$ & NÃO & 10 \\
\hline 428 & PIEDADE & RIO DE JANEIRO & RJ & NÃO & 16,1 \\
\hline 429 & MEIER & RIO DE JANEIRO & RJ & NÃO & 7,9 \\
\hline 430 & PRAÇA SECA & RIO DE JANEIRO & RJ & NÃO & 21,5 \\
\hline 431 & SÃO CRISTÓVÃO & RIO DE JANEIRO & RJ & NÃO & 1 \\
\hline 432 & PIRATININGA & NITERÓI & $\mathbf{R J}$ & NÃO & 31,1 \\
\hline 433 & RIBEIRA & RIO DE JANEIRO & RJ & NÃO & 18,6 \\
\hline 434 & PILARES & RIO DE JANEIRO & RJ & NÃO & 13,1 \\
\hline
\end{tabular}




\begin{tabular}{|c|c|c|c|c|c|}
\hline 435 & BARRA DA TIJUCA & RIO DE JANEIRO & RJ & NÃO & 28,4 \\
\hline 436 & SÃO FRANCISCO & NITERÓI & RJ & NÃO & 21,9 \\
\hline 437 & BARRA DA TIJUCA & RIO DE JANEIRO & RJ & NÃO & 28,4 \\
\hline 438 & $\begin{array}{l}\text { ILHA DO } \\
\text { GOVERNADOR }\end{array}$ & RIO DE JANEIRO & RJ & NÃO & 14,6 \\
\hline 439 & LAGOA & RIO DE JANEIRO & RJ & NÃO & 11,2 \\
\hline 440 & $\begin{array}{l}\text { GALEÃO } \\
\text { PORTUGUESA }\end{array}$ & RIO DE JANEIRO & RJ & NÃO & 15,2 \\
\hline 441 & JACAREPAGUÁ & RIO DE JANEIRO & RJ & NÃO & 32,2 \\
\hline 442 & SÃO CRISTÓVÃO & RIO DE JANEIRO & RJ & NÃO & 1 \\
\hline 443 & CENTRO & NITERÓI & RJ & NÃO & 18,2 \\
\hline 444 & JACAREPAGUÁ & RIO DE JANEIRO & RJ & NÃO & 32,2 \\
\hline 445 & COPACABANA & RIO DE JANEIRO & RJ & NÃO & 13,8 \\
\hline 446 & BARRA DA TIJUCA & RIO DE JANEIRO & RJ & NÃO & 28,4 \\
\hline 447 & TIJUCA & RIO DE JANEIRO & RJ & NÃO & 8,6 \\
\hline 448 & FREGUESIA & RIO DE JANEIRO & RJ & NÃO & 20,3 \\
\hline 449 & ROCHA MIRANDA & RIO DE JANEIRO & RJ & NÃO & 19,5 \\
\hline 450 & FREGUESIA & RIO DE JANEIRO & RJ & NÃO & 20,3 \\
\hline 451 & RAMOS & RIO DE JANEIRO & RJ & NÃO & 11 \\
\hline 452 & CAMPO GRANDE & RIO DE JANEIRO & RJ & NÃO & 49,7 \\
\hline 453 & VILA ISABEL & RIO DE JANEIRO & RJ & NÃO & 7,2 \\
\hline 454 & CENTRO & RIO DE JANEIRO & RJ & NÃO & 6,9 \\
\hline 455 & CACHAMBI & RIO DE JANEIRO & RJ & NÃO & 11,9 \\
\hline 456 & COSMOS & RIO DE JANEIRO & RJ & NÃO & 58,1 \\
\hline 457 & SÃO FRANCISCO & NITERÓI & RJ & SIM & 21,9 \\
\hline
\end{tabular}




\begin{tabular}{|c|c|c|c|c|c|}
\hline 458 & BRÁS DE PINA & RIO DE JANEIRO & RJ & SIM & 22,5 \\
\hline 459 & MARACANÃ & RIO DE JANEIRO & RJ & NÃO & 7 \\
\hline 460 & GRAJAÚ & RIO DE JANEIRO & RJ & NÃO & 8,9 \\
\hline 461 & TIJUCA & RIO DE JANEIRO & RJ & NÃO & 8,6 \\
\hline 462 & TIJUCA & RIO DE JANEIRO & RJ & NÃO & 8,6 \\
\hline 463 & $\begin{array}{l}\text { LINS DE } \\
\text { VASCONCELOS }\end{array}$ & RIO DE JANEIRO & RJ & NÃO & 8,6 \\
\hline 464 & MEIER & RIO DE JANEIRO & RJ & NÃO & 7,9 \\
\hline 465 & REALENGO & RIO DE JANEIRO & RJ & NÃO & 33,6 \\
\hline 466 & HUMAITÁ & RIO DE JANEIRO & RJ & NÃO & 10 \\
\hline 467 & FLAMENGO & RIO DE JANEIRO & RJ & NÃO & 9,9 \\
\hline 468 & TODOS OS SANTOS & RIO DE JANEIRO & RJ & NÃO & 14,8 \\
\hline 469 & TIJUCA & RIO DE JANEIRO & RJ & NÃO & 8,6 \\
\hline 470 & VILA ISABEL & RIO DE JANEIRO & RJ & NÃO & 7,2 \\
\hline 471 & $\begin{array}{l}\text { RECREIO DOS } \\
\text { BANDEIRANTES }\end{array}$ & RIO DE JANEIRO & RJ & SIM & 38,6 \\
\hline 472 & HUMAITÁ & RIO DE JANEIRO & RJ & NÃO & 10 \\
\hline 473 & CENTRO & NILÓPOLIS & RJ & NÃO & 31 \\
\hline 474 & FLAMENGO & RIO DE JANEIRO & RJ & NÃO & 9,9 \\
\hline 475 & FREGUESIA & RIO DE JANEIRO & RJ & NÃO & 20,3 \\
\hline 476 & GRAJAÚ & RIO DE JANEIRO & RJ & NÃO & 8,9 \\
\hline 477 & FREGUESIA & RIO DE JANEIRO & RJ & NÃO & 20,3 \\
\hline 478 & TIJUCA & RIO DE JANEIRO & RJ & NÃO & 8,6 \\
\hline 479 & DOUTOR LAUREANO & DUQUE DE CAXIAS & RJ & SIM & 21,3 \\
\hline 480 & TRÊS CORAÇÕES & NOVA IGUAÇU & RJ & SIM & 39 \\
\hline
\end{tabular}




\begin{tabular}{|c|c|c|c|c|c|}
\hline 481 & VILA DO TINGUÁ & QUEIMADOS & RJ & SIM & 49,3 \\
\hline 482 & FONSECA & NITERÓI & RJ & SIM & 19,1 \\
\hline 483 & SERRA GRANDE & NITERÓI & RJ & NÃO & 33,2 \\
\hline 484 & BANGU & RIO DE JANEIRO & RJ & SIM & 37,3 \\
\hline 485 & VILA SÃO JOÃO & $\begin{array}{l}\text { SÃO JOÃO DE } \\
\text { MERITI }\end{array}$ & RJ & NÃO & 27,8 \\
\hline 486 & COPACABANA & RIO DE JANEIRO & RJ & NÃO & 13,8 \\
\hline 487 & DEL CASTILHO & RIO DE JANEIRO & RJ & NÃO & 10,4 \\
\hline 488 & CAMPO GRANDE & RIO DE JANEIRO & RJ & SIM & 49,7 \\
\hline 489 & PENHA & RIO DE JANEIRO & RJ & NÃO & 10,9 \\
\hline 490 & FREGUESIA & RIO DE JANEIRO & RJ & NÃO & 20,3 \\
\hline 491 & FLAMENGO & RIO DE JANEIRO & RJ & NÃO & 9,9 \\
\hline 492 & $\begin{array}{l}\text { RECREIO DOS } \\
\text { BANDEIRANTES }\end{array}$ & RIO DE JANEIRO & RJ & NÃO & 38,6 \\
\hline 493 & TIJUCA & RIO DE JANEIRO & RJ & NÃO & 8,6 \\
\hline 494 & JARDIM CATARINA & SÃO GONÇALO & RJ & SIM & 34,9 \\
\hline 495 & GRAJAÚ & RIO DE JANEIRO & RJ & NÃO & 8,9 \\
\hline 496 & TIJUCA & RIO DE JANEIRO & RJ & NÃO & 8,6 \\
\hline 497 & GLORIA & RIO DE JANEIRO & RJ & NÃO & $\overline{11,4}$ \\
\hline 498 & TIJUCA & RIO DE JANEIRO & RJ & NÃO & 8,6 \\
\hline 499 & TIJUCA & RIO DE JANEIRO & RJ & NÃO & 8,6 \\
\hline 500 & LARANJEIRAS & RIO DE JANEIRO & RJ & NÃO & 9,9 \\
\hline 501 & COPACABANA & RIO DE JANEIRO & RJ & NÃO & 13,8 \\
\hline 502 & ICARAÍ & NITERÓI & RJ & NÃO & 19,6 \\
\hline 503 & TIJUCA & RIO DE JANEIRO & RJ & NÃO & 8,6 \\
\hline
\end{tabular}




\begin{tabular}{|c|c|c|c|c|c|}
\hline 504 & VILA ISABEL & RIO DE JANEIRO & RJ & NÃO & 7,2 \\
\hline 505 & ICARAÍ & NITERÓI & $\mathbf{R J}$ & NÃO & 19,6 \\
\hline 506 & JACAREPAGUÁ & RIO DE JANEIRO & RJ & NÃO & 32,2 \\
\hline 507 & FLAMENGO & RIO DE JANEIRO & RJ & SIM & 9,9 \\
\hline 508 & TIJUCA & RIO DE JANEIRO & RJ & NÃO & 8,6 \\
\hline 509 & COPACABANA & RIO DE JANEIRO & RJ & NÃO & 13,8 \\
\hline 510 & SANTA ROSA & NITERÓI & RJ & NÃO & 21 \\
\hline 511 & FLAMENGO & RIO DE JANEIRO & RJ & NÃO & 9,9 \\
\hline 512 & TIJUCA & RIO DE JANEIRO & RJ & NÃO & 8,6 \\
\hline 513 & TIJUCA & RIO DE JANEIRO & RJ & NÃO & 8,6 \\
\hline 514 & MARIA PAULA & SÃO GONÇALO & RJ & NÃO & 27,2 \\
\hline 515 & TODOS OS SANTOS & RIO DE JANEIRO & RJ & NÃO & 14,8 \\
\hline 516 & MARIA PAULA & SÃO GONÇALO & RJ & NÃO & 27,2 \\
\hline 517 & PRAÇA DA BANDEIRA & RIO DE JANEIRO & RJ & NÃO & 2,9 \\
\hline 518 & MARACANÃ & RIO DE JANEIRO & RJ & NÃO & 7 \\
\hline 519 & PADRE MIGUEL & RIO DE JANEIRO & RJ & NÃO & 35,2 \\
\hline 520 & TIJUCA & RIO DE JANEIRO & $\mathbf{R J}$ & NÃO & 8,6 \\
\hline 521 & SÃO CONRADO & RIO DE JANEIRO & RJ & NÃO & 18,7 \\
\hline 522 & BOTAFOGO & RIO DE JANEIRO & RJ & NÃO & 11,9 \\
\hline 523 & SAMPAIO & RIO DE JANEIRO & RJ & NÃO & 5,5 \\
\hline 524 & MADUREIRA & RIO DE JANEIRO & RJ & SIM & 19,4 \\
\hline 525 & JACAREPAGUÁ & RIO DE JANEIRO & RJ & NÃO & 32,2 \\
\hline 526 & VILA DA PENHA & RIO DE JANEIRO & RJ & SIM & 18,5 \\
\hline 527 & ENCANTADO & RIO DE JANEIRO & RJ & SIM & 14,4 \\
\hline
\end{tabular}




\begin{tabular}{|c|c|c|c|c|c|}
\hline 528 & BRÁS DE PINA & RIO DE JANEIRO & RJ & NÃO & 22,5 \\
\hline 529 & ENGENHO & ITAGUAÍ & RJ & SIM & 71,5 \\
\hline 530 & $\begin{array}{l}\text { ENGENHO DE } \\
\text { DENTRO }\end{array}$ & RIO DE JANEIRO & RJ & SIM & 13,5 \\
\hline 531 & CAMPO GRANDE & RIO DE JANEIRO & RJ & SIM & 49,7 \\
\hline 532 & CENTRO & NILÓPOLIS & RJ & SIM & 31 \\
\hline 533 & $\begin{array}{l}\text { RECREIO } \\
\text { BANDEIRANTES }\end{array}$ & RIO DE JANEIRO & RJ & NÃO & 38,6 \\
\hline 534 & BARRA DA TIJUCA & RIO DE JANEIRO & RJ & NÃO & 28,4 \\
\hline 535 & MONERO & RIO DE JANEIRO & RJ & NÃO & 15,5 \\
\hline 536 & TIJUCA & RIO DE JANEIRO & RJ & NÃO & 8,6 \\
\hline 537 & NOVA CAMPINAS & DUQUE DE CAXIAS & RJ & NÃO & 36,9 \\
\hline 538 & JARDIM GUANABARA & RIO DE JANEIRO & RJ & NÃO & 13,7 \\
\hline 539 & BARRA DA TIJUCA & RIO DE JANEIRO & RJ & NÃO & 28,4 \\
\hline 540 & TIJUCA & RIO DE JANEIRO & RJ & NÃO & 8,6 \\
\hline 541 & LARANJEIRAS & RIO DE JANEIRO & RJ & NÃO & 9,9 \\
\hline 542 & VILA ISABEL & RIO DE JANEIRO & $\mathbf{R J}$ & NÃO & 7,2 \\
\hline 543 & $\begin{array}{l}\text { RECREIO DOS } \\
\text { BANDEIRANTES }\end{array}$ & RIO DE JANEIRO & RJ & NÃO & 38,6 \\
\hline 544 & BARRA DA TIJUCA & RIO DE JANEIRO & RJ & NÃO & 28,4 \\
\hline 545 & COPACABANA & RIO DE JANEIRO & RJ & NÃO & 13,8 \\
\hline 546 & ANIL & RIO DE JANEIRO & RJ & NÃO & 25,1 \\
\hline 547 & GÁVEA & RIO DE JANEIRO & RJ & NÃO & 13,9 \\
\hline 548 & PILARES & RIO DE JANEIRO & RJ & NÃO & 13,1 \\
\hline 549 & IPANEMA & RIO DE JANEIRO & RJ & NÃO & 13,6 \\
\hline 550 & HUMAITÁ & RIO DE JANEIRO & RJ & NÃO & 10 \\
\hline
\end{tabular}




\begin{tabular}{|c|c|c|c|c|c|}
\hline 551 & BARRA DA TIJUCA & RIO DE JANEIRO & RJ & NÃO & 28,4 \\
\hline 552 & TIJUCA & RIO DE JANEIRO & RJ & NÃO & 8,6 \\
\hline 553 & JARDIM GUANABARA & RIO DE JANEIRO & RJ & NÃO & 13,7 \\
\hline 554 & VILA ISABEL & RIO DE JANEIRO & RJ & NÃO & 7,2 \\
\hline 555 & VILA ISABEL & RIO DE JANEIRO & RJ & NÃO & 7,2 \\
\hline 556 & LEBLON & RIO DE JANEIRO & RJ & NÃO & 13,3 \\
\hline 557 & TIJUCA & RIO DE JANEIRO & RJ & NÃO & 8,6 \\
\hline 558 & TIJUCA & RIO DE JANEIRO & RJ & NÃO & 8,6 \\
\hline 559 & GRAJAÚ & RIO DE JANEIRO & RJ & NÃO & 8,9 \\
\hline 560 & TIJUCA & RIO DE JANEIRO & RJ & NÃO & 8,6 \\
\hline 561 & COPACABANA & RIO DE JANEIRO & RJ & NÃO & 13,8 \\
\hline 562 & COPACABANA & RIO DE JANEIRO & RJ & NÃO & 13,8 \\
\hline 563 & VILA AMERICANA & VOLTA REDONDA & RJ & NÃO & 131 \\
\hline 564 & GRAJAÚ & RIO DE JANEIRO & RJ & NÃO & 8,9 \\
\hline 565 & SANTA ROSA & NITERÓl & RJ & NÃO & 21 \\
\hline 566 & BARRA DA TIJUCA & RIO DE JANEIRO & $\mathbf{R J}$ & NÃO & 28,4 \\
\hline 567 & BARRA DA TIJUCA & RIO DE JANEIRO & RJ & NÃO & 28,4 \\
\hline 568 & TIJUCA & RIO DE JANEIRO & RJ & NÃO & 8,6 \\
\hline 569 & GRAJAÚ & RIO DE JANEIRO & RJ & NÃO & 8,9 \\
\hline 570 & ICARAÍ & NITERÓI & RJ & NÃO & 19,6 \\
\hline 571 & BARRA DA TIJUCA & RIO DE JANEIRO & RJ & NÃO & 28,4 \\
\hline 572 & COPACABANA & RIO DE JANEIRO & RJ & NÃO & 13,8 \\
\hline 573 & GRAJAÚ & RIO DE JANEIRO & RJ & NÃO & 8,9 \\
\hline 574 & VILA ISABEL & RIO DE JANEIRO & RJ & NÃO & 7,2 \\
\hline
\end{tabular}




\begin{tabular}{|c|c|c|c|c|c|}
\hline 575 & LEME & RIO DE JANEIRO & RJ & NÃO & 13,8 \\
\hline 576 & TIJUCA & RIO DE JANEIRO & RJ & NÃO & 8,6 \\
\hline 577 & BOTAFOGO & RIO DE JANEIRO & RJ & NÃO & 11,9 \\
\hline 578 & ENGENHO DENTRO & RIO DE JANEIRO & RJ & SIM & 13,5 \\
\hline 579 & TAQUARA & RIO DE JANEIRO & RJ & NÃO & 23 \\
\hline 580 & JARDIM PIEDADE & BELFORD ROXO & RJ & SIM & 28 \\
\hline 581 & PIABETA & MAGÉ & RJ & SIM & 47,3 \\
\hline 582 & BOTAFOGO & RIO DE JANEIRO & RJ & NÃO & 11,9 \\
\hline 583 & AREIA BRANCA & BELFORD ROXO & RJ & NÃO & 34,3 \\
\hline 584 & BARRA DA TIJUCA & RIO DE JANEIRO & RJ & NÃO & 28,4 \\
\hline 585 & ICARAÍ & NITERÓI & RJ & NÃO & 19,6 \\
\hline 586 & FLAMENGO & RIO DE JANEIRO & RJ & NÃO & 9,9 \\
\hline 587 & TIJUCA & RIO DE JANEIRO & RJ & NÃO & 8,6 \\
\hline 588 & FLAMENGO & RIO DE JANEIRO & RJ & NÃO & 9,9 \\
\hline 589 & SÃO CRISTÓVÃO & RIO DE JANEIRO & RJ & NÃO & 1 \\
\hline 590 & $\begin{array}{l}\text { RECREIO DOS } \\
\text { BANDEIRANTES }\end{array}$ & RIO DE JANEIRO & RJ & NÃO & 38,6 \\
\hline 591 & ICARAÍ & NITERÓI & RJ & NÃO & 19,6 \\
\hline 592 & ANDARAÍ & RIO DE JANEIRO & RJ & NÃO & 7,3 \\
\hline 593 & BARRA DA TIJUCA & RIO DE JANEIRO & RJ & NÃO & 28,4 \\
\hline 594 & $\begin{array}{l}\text { ILHA DO } \\
\text { GOVERNADOR }\end{array}$ & RIO DE JANEIRO & RJ & NÃO & 14,6 \\
\hline 595 & BONSUCESSO & RIO DE JANEIRO & RJ & NÃO & 9,5 \\
\hline 596 & MARACANÃ & RIO DE JANEIRO & RJ & NÃO & 7 \\
\hline 597 & TIJUCA & RIO DE JANEIRO & RJ & NÃO & 8,6 \\
\hline
\end{tabular}




\begin{tabular}{|c|c|c|c|c|c|}
\hline 598 & FREGUESIA & RIO DE JANEIRO & RJ & NÃO & 20,3 \\
\hline 599 & RIACHUELO & RIO DE JANEIRO & $\mathbf{R J}$ & NÃO & 4,8 \\
\hline 600 & GRAJAÚ & RIO DE JANEIRO & RJ & NÃO & 8,9 \\
\hline 601 & TIJUCA & RIO DE JANEIRO & RJ & NÃO & 8,6 \\
\hline 602 & ANDARAÍ & RIO DE JANEIRO & RJ & NÃO & 7,3 \\
\hline 603 & NITERÓI & RIO DE JANEIRO & RJ & NÃO & 18,5 \\
\hline 604 & MARACANÃ & RIO DE JANEIRO & RJ & NÃO & 7 \\
\hline 605 & BOTAFOGO & RIO DE JANEIRO & RJ & NÃO & 11,9 \\
\hline 606 & BOTAFOGO & RIO DE JANEIRO & RJ & NÃO & 11,9 \\
\hline 607 & TIJUCA & RIO DE JANEIRO & RJ & NÃO & 8,6 \\
\hline 608 & FLAMENGO & RIO DE JANEIRO & RJ & NÃO & 9,9 \\
\hline 609 & CACHAMBI & RIO DE JANEIRO & RJ & NÃO & 11,9 \\
\hline 610 & MARIA DA GRAÇA & RIO DE JANEIRO & RJ & NÃO & 10,8 \\
\hline 611 & HUMAITÁ & RIO DE JANEIRO & RJ & NÃO & 10 \\
\hline 612 & COLUMBANDE & SÃO GONÇALO & RJ & SIM & 29,7 \\
\hline 613 & $\begin{array}{l}\text { COMENDADOR } \\
\text { SOARES }\end{array}$ & NOVA IGUAÇU & RJ & SIM & 38,4 \\
\hline 614 & CAMPOS ELISEOS & DUQUE DE CAXIAS & RJ & NÃO & 30,5 \\
\hline 615 & PARQUE COLUMBIA & DUQUE DE CAXIAS & RJ & NÃO & 22,5 \\
\hline 616 & ÁGUA SANTA & RIO DE JANEIRO & RJ & SIM & 15,9 \\
\hline 617 & TIJUCA & RIO DE JANEIRO & RJ & NÃO & 8,6 \\
\hline 618 & JARDIM PORANGABA & DUQUE DE CAXIAS & RJ & SIM & 27,2 \\
\hline 619 & VILA VALQUEIRE & RIO DE JANEIRO & RJ & SIM & 22,3 \\
\hline 620 & SANTA ROSA & NITERÓI & RJ & NÃO & 21 \\
\hline 621 & ICARAÍ & NITERÓI & RJ & NÃO & 19,6 \\
\hline
\end{tabular}




\begin{tabular}{|c|c|c|c|c|c|}
\hline 622 & TIJUCA & RIO DE JANEIRO & $\mathbf{R J}$ & NÃO & 8,6 \\
\hline 623 & BARRA DA TIJUCA & RIO DE JANEIRO & RJ & NÃO & 28,4 \\
\hline 624 & LEBLON & RIO DE JANEIRO & RJ & NÃO & 13,3 \\
\hline 625 & BARRA DA TIJUCA & RIO DE JANEIRO & RJ & NÃO & 28,4 \\
\hline 626 & TIJUCA & RIO DE JANEIRO & RJ & NÃO & 8,6 \\
\hline 627 & GLORIA & RIO DE JANEIRO & RJ & NÃO & 11,4 \\
\hline 628 & FLAMENGO & RIO DE JANEIRO & RJ & NÃO & 9,9 \\
\hline 629 & ABOLIÇÃO & RIO DE JANEIRO & RJ & NÃO & 13,5 \\
\hline 630 & GLORIA & RIO DE JANEIRO & RJ & NÃO & 11,4 \\
\hline 631 & VILA ISABEL & RIO DE JANEIRO & RJ & SIM & 7,2 \\
\hline 632 & TIJUCA & RIO DE JANEIRO & RJ & NÃO & 8,6 \\
\hline 633 & COPACABANA & RIO DE JANEIRO & RJ & NÃO & 13,8 \\
\hline 634 & TAQUARA & RIO DE JANEIRO & RJ & NÃO & 23 \\
\hline 635 & PRAÇA SECA & RIO DE JANEIRO & RJ & NÃO & 21,5 \\
\hline 636 & ALCÂNTARA & SÃO GONÇALO & RJ & SIM & 32,5 \\
\hline 637 & INHAÚMA & RIO DE JANEIRO & RJ & SIM & 10,8 \\
\hline 638 & VILA DA PENHA & RIO DE JANEIRO & RJ & NÃO & 18,5 \\
\hline 639 & GAMBOA & RIO DE JANEIRO & $\mathbf{R J}$ & SIM & 5,7 \\
\hline 640 & TIJUCA & RIO DE JANEIRO & RJ & SIM & 8,6 \\
\hline 641 & PECHINCHA & RIO DE JANEIRO & RJ & SIM & 20,6 \\
\hline 642 & VIDIGAL & RIO DE JANEIRO & RJ & SIM & 15,6 \\
\hline 643 & CAVALCANTI & RIO DE JANEIRO & $\mathbf{R J}$ & SIM & 14,7 \\
\hline 644 & BARRA DA TIJUCA & RIO DE JANEIRO & RJ & NÃO & 28,4 \\
\hline 645 & SÃO CRISTÓVÃO & RIO DE JANEIRO & RJ & NÃO & 1 \\
\hline
\end{tabular}




\begin{tabular}{|c|c|c|c|c|c|}
\hline 646 & JARDIM BOTÂNICO & RIO DE JANEIRO & RJ & NÃO & 11,6 \\
\hline 647 & ICARAÍ & NITERÓI & RJ & NÃO & 19,6 \\
\hline 648 & CACHAMBI & RIO DE JANEIRO & RJ & NÃO & 11,9 \\
\hline 649 & TIJUCA & RIO DE JANEIRO & RJ & NÃO & 8,6 \\
\hline 650 & CACHAMBI & RIO DE JANEIRO & RJ & NÃO & 11,9 \\
\hline 651 & JACAREPAGUÁ & RIO DE JANEIRO & RJ & NÃO & 32,2 \\
\hline 652 & LEME & RIO DE JANEIRO & RJ & NÃO & 13,8 \\
\hline 653 & MARACANÃ & RIO DE JANEIRO & RJ & NÃO & 7 \\
\hline 654 & TIJUCA & RIO DE JANEIRO & RJ & NÃO & 8,6 \\
\hline 655 & BOTAFOGO & RIO DE JANEIRO & RJ & NÃO & 11,9 \\
\hline 656 & SANTA ROSA & NITERÓI & RJ & NÃO & 21 \\
\hline 657 & GÁVEA & RIO DE JANEIRO & RJ & NÃO & 13,9 \\
\hline 658 & ARARAS & PETRÓPOLIS & RJ & NÃO & 63,2 \\
\hline 659 & MARACANÃ & RIO DE JANEIRO & RJ & NÃO & 7 \\
\hline 660 & COPACABANA & RIO DE JANEIRO & RJ & NÃO & 13,8 \\
\hline 661 & $\begin{array}{l}\text { RECREIO DOS } \\
\text { BANDEIRANTES }\end{array}$ & RIO DE JANEIRO & RJ & SIM & 38,6 \\
\hline 662 & ICARAÍ & NITERÓI & RJ & NÃO & 19,6 \\
\hline 663 & IRAJÁ & RIO DE JANEIRO & RJ & NÃO & 21,8 \\
\hline 664 & BOTAFOGO & RIO DE JANEIRO & RJ & NÃO & 11,9 \\
\hline 665 & BOTAFOGO & RIO DE JANEIRO & RJ & NÃO & 11,9 \\
\hline 666 & LEBLON & RIO DE JANEIRO & RJ & NÃO & 13,3 \\
\hline 667 & ICARAÍ & NITERÓI & RJ & NÃO & 19,6 \\
\hline 668 & TIJUCA & RIO DE JANEIRO & RJ & NÃO & 8,6 \\
\hline 669 & PORTUGUESA & RIO DE JANEIRO & RJ & NÃO & 15,2 \\
\hline
\end{tabular}




\begin{tabular}{|c|c|c|c|c|c|}
\hline 670 & PILARES & RIO DE JANEIRO & RJ & NÃO & 13,1 \\
\hline 671 & SÃO CRISTÓVÃO & RIO DE JANEIRO & $\mathbf{R J}$ & NÃO & 1 \\
\hline 672 & COPACABANA & RIO DE JANEIRO & RJ & NÃO & 13,8 \\
\hline 673 & TIJUCA & RIO DE JANEIRO & RJ & NÃO & 8,6 \\
\hline 674 & IPANEMA & RIO DE JANEIRO & RJ & NÃO & 13,6 \\
\hline 675 & JACAREPAGUÁ & RIO DE JANEIRO & RJ & NÃO & 32,2 \\
\hline 676 & GLORIA & RIO DE JANEIRO & RJ & SIM & 11,4 \\
\hline 677 & CAMPO GRANDE & RIO DE JANEIRO & RJ & NÃO & 49,7 \\
\hline 678 & ANIL & RIO DE JANEIRO & RJ & NÃO & 25,1 \\
\hline 679 & JARDIM BOTÂNICO & RIO DE JANEIRO & RJ & NÃO & 11,6 \\
\hline 680 & BARRA DA TIJUCA & RIO DE JANEIRO & RJ & NÃO & 28,4 \\
\hline 681 & CAVALCANTI & RIO DE JANEIRO & RJ & NÃO & 14,7 \\
\hline 682 & JARDIM GUANABARA & RIO DE JANEIRO & RJ & SIM & 13,7 \\
\hline 683 & CENTRO & BELFORD ROXO & RJ & NÃO & 30,7 \\
\hline 684 & GUADALUPE & RIO DE JANEIRO & RJ & SIM & 28,3 \\
\hline 685 & BARRA DA TIJUCA & RIO DE JANEIRO & RJ & NÃO & 28,4 \\
\hline 686 & PRAÇA SECA & RIO DE JANEIRO & $\mathbf{R J}$ & NÃO & 21,5 \\
\hline 687 & COPACABANA & RIO DE JANEIRO & RJ & NÃO & 13,8 \\
\hline 688 & ENGENHO DA RAINHA & RIO DE JANEIRO & RJ & NÃO & 12,5 \\
\hline 689 & INHAÚMA & RIO DE JANEIRO & RJ & NÃO & 10,8 \\
\hline 690 & DEL CASTILHO & RIO DE JANEIRO & RJ & SIM & 10,4 \\
\hline 691 & COCOTA & RIO DE JANEIRO & RJ & SIM & 17,2 \\
\hline 692 & COPACABANA & RIO DE JANEIRO & RJ & NÃO & 13,8 \\
\hline 693 & COPACABANA & RIO DE JANEIRO & RJ & NÃO & 13,8 \\
\hline
\end{tabular}




\begin{tabular}{|c|c|c|c|c|c|}
\hline 694 & CIDADE DE DEUS & RIO DE JANEIRO & RJ & NÃO & 25 \\
\hline 695 & ENGENHO NOVO & RIO DE JANEIRO & RJ & NÃO & 6,3 \\
\hline 696 & VILA ISABEL & RIO DE JANEIRO & RJ & SIM & 7,2 \\
\hline 697 & PRAÇA SECA & RIO DE JANEIRO & RJ & SIM & 21,5 \\
\hline 698 & BANGU & RIO DE JANEIRO & RJ & NÃO & 37,3 \\
\hline 699 & RIACHUELO & RIO DE JANEIRO & RJ & SIM & 4,8 \\
\hline 700 & TIJUCA & RIO DE JANEIRO & RJ & SIM & 8,6 \\
\hline 701 & COPACABANA & RIO DE JANEIRO & RJ & NÃO & 13,8 \\
\hline 702 & AUSTIN & NOVA IGUAÇU & RJ & SIM & 44,9 \\
\hline 703 & CAMPO GRANDE & RIO DE JANEIRO & RJ & NÃO & 49,7 \\
\hline 704 & INHAÚMA & RIO DE JANEIRO & RJ & SIM & 10,8 \\
\hline 705 & TODOS OS SANTOS & RIO DE JANEIRO & RJ & NÃO & 14,8 \\
\hline 706 & BARRA DA TIJUCA & RIO DE JANEIRO & RJ & NÃO & 28,4 \\
\hline 707 & ENGENHO DA RAINHA & RIO DE JANEIRO & RJ & NÃO & 12,5 \\
\hline 708 & CENTRO & RIO DE JANEIRO & RJ & NÃO & 6,9 \\
\hline
\end{tabular}




\section{APÊNDICE B - DADOS DO QUESTIONÁRIO}

\begin{tabular}{|c|c|c|c|c|c|c|c|c|c|c|c|c|}
\hline Nome & Gênero & $\begin{array}{l}\text { Faixa } \\
\text { etária }\end{array}$ & Moradia & $\begin{array}{l}\text { Possui carro ou } \\
\text { moto? }\end{array}$ & $\begin{array}{l}\text { Caso possua } \\
\text { carro ou moto, } \\
\text { informe o tipo de } \\
\text { combustivel que } \\
\text { mais utiliza }\end{array}$ & $\begin{array}{l}\text { Quais destes } \\
\text { beneficios você } \\
\text { possui hoje na } \\
\text { empresa? }\end{array}$ & $\begin{array}{l}\text { Caso possua } \\
\text { carro, você } \\
\text { tem vaga de } \\
\text { estacioname } \\
\text { nto no local } \\
\text { to thathn? }\end{array}$ & $\begin{array}{l}\text { Caso sua empresa nao } \\
\text { possua estacionamento, } \\
\text { e o local mais próximo } \\
\text { para estacionar fosse a } 2 \\
\text { km de distância, qual } \\
\text { madl ...tilin.--2 }\end{array}$ & $\begin{array}{l}\text { Caso possua } \\
\text { carro, você } \\
\text { optaria por } \\
\text { oferecer ou } \\
\text { dar carona }\end{array}$ & $\begin{array}{l}\text { Intorme seu } \\
\text { horário de } \\
\text { ENTRADA na } \\
\text { empresa } \\
\text { (horário }\end{array}$ & $\begin{array}{l}\text { Intorme seu } \\
\text { horário de } \\
\text { SAíDA na } \\
\text { empresa } \\
\text { (horário }\end{array}$ & $\begin{array}{l}\text { voce tem a } \\
\text { oppão de } \\
\text { trabalhar } \\
\text { remotament } \\
\text { e DURANTE } \\
\text { Tnnnn }\end{array}$ \\
\hline Carolina Grangeia & Feminino 2 & 26 à 35. & Tijuca & Carro & Gasolina & Vale Transporte & Não & Metrố & Sim & $8 \mathrm{~h}$ às $9 \mathrm{~h}$ & $18 \mathrm{~h}$ às $19 \mathrm{~h}$ & Não \\
\hline Hugo Farelli & Masculino 2 & 26 à 35 & Copacabana & Nenhum dos dois & & Nenhum beneficio & & Metrô & & $8 \mathrm{~h}$ às $9 \mathrm{~h}$ & $17 \mathrm{~h}$ às $18 \mathrm{~h}$ & Não \\
\hline Alecio Rodolfo & Masculino 2 & 26 à 35 & São Cristóvão & Carro & Gasolina & Nenhum beneficio & sim & Metrô & sim & $7 \mathrm{~h}$ às $8 \mathrm{~h}$ & $17 \mathrm{~h}$ as $18 \mathrm{~h}$ & Não \\
\hline Ricardo Meliande & Masculino 2 & 26 a 35 & Andarai & Carro & Gasolina & Nenhum beneficio & sim & Metrô & sim & $7 \mathrm{~h}$ às $8 \mathrm{~h}$ & $17 \mathrm{~h}$ às $18 \mathrm{~h}$ & Não \\
\hline Daniel Pessan & Masculino 3 & 36 à 55 & Copacabana & Carro & Gasolina & Nenhum beneficio & sim & Metrô & sim & $8 \mathrm{~h}$ às $9 \mathrm{~h}$ & $17 \mathrm{~h}$ às $18 \mathrm{~h}$ & Não \\
\hline Danilo de Castro & Masculino 2 & 26 à 35 & Bangu & Carro & Gasolina & Nenhum beneficio & Sim & Metrô & Sim & $7 \mathrm{~h}$ às $8 \mathrm{~h}$ & $17 \mathrm{~h}$ às $18 \mathrm{~h}$ & Não \\
\hline Tayrine de Souza & Feminino 2 & 26 à 35 । & Ipanema & Nenhum dos dois & & Vale Transporte & & & & $9 \mathrm{~h}$ às $10 \mathrm{~h}$ & $15 \mathrm{~h}$ às $16 \mathrm{~h}$ & Não \\
\hline Maria Carmelina & Feminino 3 & 36 à 55 & Copacabana & Carro & Gasolina & Nenhum beneficio & $\operatorname{sim}$ & Ônibus & $\operatorname{sim}$ & $8 \mathrm{~h}$ às $9 \mathrm{~h}$ & $17 \mathrm{~h}$ às $18 \mathrm{~h}$ & Não \\
\hline Andre Martins & Masculino 2 & 26 à 35 & Humaitá & Carro & Gasolina & Nenhum beneficio & sim & Metrô & Sim & $8 \mathrm{~h}$ às $9 \mathrm{~h}$ & $18 \mathrm{~h}$ às $19 \mathrm{~h}$ & Não \\
\hline Victor Esteves & Masculino & Até 25 a & Flamengo & Carro & Gasolina & Nenhum beneficio & sim & Metrô & Sim & $8 \mathrm{~h}$ às $9 \mathrm{~h}$ & $17 \mathrm{~h}$ às $18 \mathrm{~h}$ & Não \\
\hline Angela Medeiros & Feminino 3 & 36 à 55 & Recreio & Carro & Gasolina & Nenhum beneficio & sim & Metrô & $\operatorname{sim}$ & $7 \mathrm{~h}$ às $8 \mathrm{~h}$ & $18 \mathrm{~h}$ às $19 \mathrm{~h}$ & Não \\
\hline Washington Gomes & Masculino 2 & 26 à 35 & Caxias & Carro & GNV & Vale Transporte & Sim & Ônibus & sim & $8 \mathrm{~h}$ as $9 \mathrm{~h}$ & $17 \mathrm{~h}$ às $18 \mathrm{~h}$ & Não \\
\hline Lenina Santiago & Feminino 2 & 26 à 35 & Copacabana & Nenhum dos dois & & Nenhum beneficio & & & & $8 \mathrm{~h}$ às $9 \mathrm{~h}$ & $18 \mathrm{~h}$ às $19 \mathrm{~h}$ & Não \\
\hline Maryliz Habib & Feminino 3 & 36 à 55 & Barra da Tijuca & Carro & Gasolina & Nenhum beneficio & sim & Ônibus & Sim & $8 \mathrm{~h}$ às $9 \mathrm{~h}$ & $17 \mathrm{~h}$ às $18 \mathrm{~h}$ & Não \\
\hline Pedro Pecanha & Masculino & Até 25 a & Recreio & Carro $\quad \mathrm{G}$ & Gasolina & Vale Combustivel & sim & Metrô & sim & $7 \mathrm{~h}$ às $8 \mathrm{~h}$ & $17 \mathrm{~h}$ às $18 \mathrm{~h}$ & Não \\
\hline Leonardo Magalhaes & Masculino 2 & 26 à 35 & Botafogo & Nenhum dos dois & & Nenhum beneficio & & Ônibus & & $7 \mathrm{~h}$ às $8 \mathrm{~h}$ & $18 \mathrm{~h}$ às $19 \mathrm{~h}$ & Não \\
\hline Fernanda Nunes & Feminino 2 & 26 à 35 & Barra da Tijuca & Nenhum dos dois & & Vale Transporte & & & & $8 \mathrm{~h}$ às $9 \mathrm{~h}$ & $17 \mathrm{~h}$ às $18 \mathrm{~h}$ & Não \\
\hline Natasha de Mesquita & Feminino 2 & 26 à 35 & Humaitá & Carro $\quad \mathrm{c}$ & Gasolina & Nenhum beneficio & sim & Ônibus & $\operatorname{sim}$ & $7 \mathrm{~h}$ às $8 \mathrm{~h}$ & $18 \mathrm{~h}$ às $19 \mathrm{~h}$ & Não \\
\hline Beatriz Roza & Feminino 2 & 26 à 35 & Tijuca & Carro & Gasolina & Nenhum beneficio & sim & Continuaria indo de carro & Sim & $8 \mathrm{~h}$ às $9 \mathrm{~h}$ & $17 \mathrm{~h}$ às $18 \mathrm{~h}$ & Não \\
\hline Roberto Freitas & Masculino 2 & 26 à 35 & Campo Grande & Carro & Gasolina & Vale Transporte & Não & Ônibus & Sim & $7 \mathrm{~h}$ às $8 \mathrm{~h}$ & $17 \mathrm{~h}$ às $18 \mathrm{~h}$ & Não \\
\hline Jorge Allan & Masculino 2 & 26 à $35 \mathrm{~s}$ & Santa Rosa - Nitel C & Carro & Gasolina & Nenhum beneficio & sim & Ônibus & sim & $7 \mathrm{~h}$ às $8 \mathrm{~h}$ & $17 \mathrm{~h}$ às $18 \mathrm{~h}$ & Não \\
\hline Bruna Coelho & Feminino 2 & 26 a 35 & Barra da Tijuca & Carro & Etanol (Älcool), GI & I Nenhum beneficio & sim & Metrô & Sim & $7 \mathrm{~h}$ às $8 \mathrm{~h}$ & $18 \mathrm{~h}$ às $19 \mathrm{~h}$ & Não \\
\hline Ana Carolina Correa & Feminino 2 & 26 à 35 & Tijuca & Carro $\quad \mathrm{G}$ & Gasolina & Nenhum beneficio & sim & Continuaria indo de carro & Sim & $8 \mathrm{~h}$ às $9 \mathrm{~h}$ & Após as 19h & Não \\
\hline João Caldas & Masculino 2 & 26 à 35 । & Icarai - Niterói & Nenhum dos dois & & Nenhum beneficio & & & & $8 \mathrm{~h}$ às $9 \mathrm{~h}$ & $17 \mathrm{~h}$ às $18 \mathrm{~h}$ & Não \\
\hline Mariana Gaio & Feminino 3 & 36 a 55 & Jacarepaguá & Carro $\quad \mathrm{G}$ & Gasolina & Vale Transporte & sim & & Sim & $8 \mathrm{~h}$ às $9 \mathrm{~h}$ & $18 \mathrm{~h}$ às $19 \mathrm{~h}$ & Não \\
\hline Andre Luiz Chagas & Masculino 2 & 26 à 35 & Méier & Carro & Gasolina & Vale Transporte & sim & Trem & Sim & $7 \mathrm{~h}$ às $8 \mathrm{~h}$ & $17 \mathrm{~h}$ às $18 \mathrm{~h}$ & Não \\
\hline Paula Nogueira & Feminino 3 & 36 à 55 & Botafogo & Carro & Gasolina & Nenhum beneficio & sim & Metró & sim & $8 \mathrm{~h}$ às $9 \mathrm{~h}$ & $18 \mathrm{~h}$ às $19 \mathrm{~h}$ & Não \\
\hline Marinus Visser & Masculino & Atê 25 a & Tijuca & Carro, Moto & Gasolina & Nenhum beneficio & Näo & Metró & Sim & $8 \mathrm{~h}$ às $9 \mathrm{~h}$ & $17 \mathrm{~h}$ às $18 \mathrm{~h}$ & sim \\
\hline William Santos & Masculino 2 & 26 à 35 & Parada de Lucas $N$ & Nenhum dos dois & & Nenhum beneficio & & Trem & & $9 \mathrm{~h}$ às $10 \mathrm{~h}$ & $18 \mathrm{~h}$ às $19 \mathrm{~h}$ & Não \\
\hline Leonardo Silva Pires & Masculino 2 & 26 à 35 & Vista Alegre & Carro & Gasolina & Vale Transporte & Näo & Metrô & sim & $12 \mathrm{~h} 40$ & $21 \mathrm{~h}$ & Não \\
\hline Eduardo Rodrigues & Masculino 2 & 26 a 35 & Engenho de Dentr C & Carro $\quad \mathrm{G}$ & Gasolina & Vale Transporte & Não & Trem & sim & $12 \mathrm{~h} 40$ & $21 \mathrm{~h}$ & Não \\
\hline Teissa de Pinho & Feminino 2 & 26 à 35 & Jacarepaguá $N$ & Nenhum dos dois & & Nenhum beneficio & Não & Ônibus & Sim & $9 \mathrm{~h}$ às $10 \mathrm{~h}$ & $18 \mathrm{~h}$ às $19 \mathrm{~h}$ & Não \\
\hline Priscila Lourinho & Feminino 2 & 26 a 35 . & Tijuca & Nenhum dos dois & & Vale Transpotte & Sim & Metrô & & $8 \mathrm{~h}$ às $9 \mathrm{~h}$ & $18 \mathrm{~h}$ às $19 \mathrm{~h}$ & Não \\
\hline Flavia Sipres & Feminino $A$ & Atế 25 a J & Jardim Botảnico & Carro $\mathrm{G}$ & Gasolina & Vale Transporte & Sim & Ônibus & Sim & $7 \mathrm{~h}$ às $8 \mathrm{~h}$ & $17 \mathrm{~h}$ às $18 \mathrm{~h}$ & Sim \\
\hline Vitor Salgado & Masculino 2 & 26 à 35 & Ipanema & Nenhum dos dois & & Nenhum beneficio & & Metrô & sim & $8 \mathrm{~h}$ às $9 \mathrm{~h}$ & $18 \mathrm{~h}$ às $19 \mathrm{~h}$ & Não \\
\hline Fernando Capanema & Masculino 3 & 36 à 55 c & Copacabana & Carro $\quad \mathrm{c}$ & Gasolina & Nenhum beneficio & sim & Metrô & sim & $8 \mathrm{~h}$ às $9 \mathrm{~h}$ & $18 \mathrm{~h}$ as $19 \mathrm{~h}$ & Não \\
\hline Fabiele Luize & Feminino 2 & 26 à 35 E & Engenho da Raint $\mathrm{C}$ & Carro & GNV & Vale Transporte & Não & Metró & sim & $8 \mathrm{~h}$ às $9 \mathrm{~h}$ & $17 \mathrm{~h}$ às $18 \mathrm{~h}$ & Não \\
\hline Marina Grauer & Feminino 2 & 26 à 35 J & Jacarepaguá & Carro $\quad \mathrm{G}$ & Gasolina & Nenhum beneficio & sim & Ônibus & Sim & $8 \mathrm{~h}$ às $9 \mathrm{~h}$ & Após as $19 \mathrm{~h}$ & Não \\
\hline Julio Alberto & Masculino 2 & 26 à 35 B & Botafogo & Nenhum dos dois & & Nenhum beneficio & & & & $8 \mathrm{~h}$ às $9 \mathrm{~h}$ & $17 \mathrm{~h}$ às $18 \mathrm{~h}$ & Não \\
\hline Barbara de Abreu & Feminino & Até 25 a & a Laranjeiras & Nenhum dos dois & & Vale Transporte & & & & $8 \mathrm{n}$ às $9 \mathrm{~h}$ & $17 \mathrm{~h}$ às $18 \mathrm{~h}$ & Não \\
\hline Marcus Vinicius Alves & Masculino & o 26 а 35 & 5 Vila da Penha & Nenhum dos dois & & Vale Transporte & & & & $8 \mathrm{~h}$ às $9 \mathrm{~h}$ & $17 \mathrm{~h}$ às $18 \mathrm{~h}$ & Não \\
\hline Julia Garcia & Feminino & Até 25 a & a Barra da Tjuca & Carro & Gasolina & Vale Transporte & Não & Metró & sim & $9 \mathrm{~h}$ às $10 \mathrm{~h}$ & $16 \mathrm{~h}$ às $17 \mathrm{~h}$ & Não \\
\hline Stefano Palazzi & Masculino & o 26 à 35 & 5. Tijuca & Nenhum dos dois & & Nenhum beneficio & & À pé & sim & $8 \mathrm{~h}$ às $9 \mathrm{~h}$ & $17 \mathrm{~h}$ as $18 \mathrm{~h}$ & Não \\
\hline Flavio do Nascimento & Masculino & o 36 à 55 & 5. Botafogo & Carro & Gasolina & Nenhum beneficio & osim & Metrô & sim & $7 \mathrm{~h}$ às $8 \mathrm{~h}$ & $17 \mathrm{~h}$ às $18 \mathrm{~h}$ & Não \\
\hline Andreas Hasenclever & Masculino & o 36 à 55 & 5 Gávea & Dirijo carro da em! & II Gasolina & Vale Combustivel & $\mathrm{sim}$ & & Sim & $8 \mathrm{~h}$ às $9 \mathrm{~h}$ & $18 \mathrm{~h}$ às $19 \mathrm{~h}$ & Não \\
\hline Flavia Buarque & Feminino & 26 a 35 & 5 Tiuca & Carro 2 & Gasolina & Nenhum beneficio & osim & Metrô & Sim & $8 \mathrm{hàs} 9 \mathrm{~h}$ & $18 \mathrm{~h}$ às $19 \mathrm{~h}$ & Não \\
\hline Luiz AntonioAlves & Masculino & o 36 à 55 & Tijuca & Carro & Gasolina & Nenhum beneficio & osim & Metró & sim & $7 \mathrm{~h}$ às $8 \mathrm{~h}$ & $18 \mathrm{~h}$ às $19 \mathrm{~h}$ & Não \\
\hline Pedro Kinder & Masculino & o 26 à 35 & 5 Jacarepaguá & Carro & Gasolina & Nenhum beneficio & & Continuaria indo de carro & Sim & $8 \mathrm{~h}$ às $9 \mathrm{~h}$ & $17 \mathrm{~h}$ às $18 \mathrm{~h}$ & Não \\
\hline Gisele Saveriano & Feminino & 36 à 55 & 5 Jardim Botânico & Carro & Gasolina & Nenhum beneficio & osim & Ōnibus & Sim & $8 \mathrm{~h}$ às $9 \mathrm{~h}$ & $18 \mathrm{~h}$ às $19 \mathrm{~h}$ & Não \\
\hline Isabela Retumba & Feminino & 36 à 55 & 5. Copacabana & Carro & Gasolina & Nenhum beneficio & o sim & & sim & $8 \mathrm{~h}$ às $9 \mathrm{~h}$ & $18 \mathrm{~h}$ às $19 \mathrm{~h}$ & Não \\
\hline Paula Bessa & Feminino & 26 à 35 & 5. Madureira & Nenhum dos dois & & Vale Transporte & & & & $8 \mathrm{~h}$ às $9 \mathrm{~h}$ & & Não \\
\hline Denise Silva & Feminino & 26 à 35 & 5 Copacabana & Nenhum dos dois & & Vale Transporte & & Metrô & & $8 \mathrm{~h}$ às $9 \mathrm{~h}$ & $18 \mathrm{~h}$ às $19 \mathrm{~h}$ & Não \\
\hline Olivia Wamken & Feminino & 26 a 35 & Tijuca & Carro & Gasolina & Nenhum beneficio & osim & Metrô & Sim & $7 \mathrm{~h}$ às $8 \mathrm{~h}$ & $17 \mathrm{~h}$ às $18 \mathrm{~h}$ & Não \\
\hline Vanessa Aparecida & Feminino & 26 à 35 & Botafogo & Nenhum dos dois & & Vale Transporte & & Metrô & & $8 \mathrm{~h}$ às $9 \mathrm{~h}$ & Após as $19 \mathrm{~h}$ & Não \\
\hline Francine Rossi & Feminino & 36 à 55 & 5 Copacabana & Nenhum dos dois & & Nenhum beneficio & osim & Ônibus & & $8 \mathrm{~h}$ às $9 \mathrm{~h}$ & $17 \mathrm{~h}$ às $18 \mathrm{~h}$ & Não \\
\hline Isabela Pacheco & Feminino & 26 à 35 & Gávea & Carro & Gasolina & Nenhum beneficio & osim & Continuaria indo de carro & Sim & $8 \mathrm{~h}$ às $9 \mathrm{~h}$ & $18 \mathrm{~h}$ às $19 \mathrm{~h}$ & Não \\
\hline Aline Barbara & Feminino & Até 25 a & a Campo Grande & Nenhum dos dois & & Vale Transp & & Önibus & Sim & $8 \mathrm{~h}$ às $9 \mathrm{~h}$ & $17 \mathrm{~h}$ às $18 \mathrm{~h}$ & Não \\
\hline Alvaro Barbosa & Masculino & o Até 25 a & a Innaúma & Nenhum dos dois & & Vale Transporte & $\operatorname{sim}$ & Metró & Sim & $7 \mathrm{~h}$ às $8 \mathrm{~h}$ & $16 \mathrm{~h}$ às $17 \mathrm{~h}$ & Não \\
\hline João Apolonio & Masculino & o 26 à 35 & 5 Méier & Carro & Gasolina & Nenhum beneficio & osim & Ônibus & sim & $7 \mathrm{~h}$ às $8 \mathrm{~h}$ & Após as $19 \mathrm{~h}$ & Não \\
\hline Alexander Pereira & Masculino & o 36 à 55 & Copacabana & Nenhum dos dois & & Nenhum beneficio & & & & $7 \mathrm{~h}$ às $8 \mathrm{~h}$ & $16 \mathrm{~h}$ às $17 \mathrm{~h}$ & Não \\
\hline Diogo Lota & Masculino & o 26 à 35 & 5. Fonseca - Niterói & i Carro & Gasolina & Nenhum beneficio & osim & & Sim & $8 \mathrm{~h}$ às $9 \mathrm{~h}$ & Após as $19 \mathrm{~h}$ & Não \\
\hline Alexandre Paula & Masculino & o 26 à 35 & 5. Humaitá & Nenhum dos dois & & Nenhum benefício & & Metró & sim & $8 \mathrm{~h}$ às $9 \mathrm{~h}$ & $17 \mathrm{~h}$ às $18 \mathrm{~h}$ & Não \\
\hline Jessica Cascareja & Feminino & 26 à 35 & 5 . Iha do Governadc & dc Carro & Etanol (Álcool) & Nenhum beneficio & osim & Ónibus & sim & $8 \mathrm{~h}$ às $9 \mathrm{~h}$ & $17 \mathrm{~h}$ às $18 \mathrm{~h}$ & Não \\
\hline Flavia Cristina & Feminino & 26 à 35 & 5 Säo Cristóväo & Carro & Gasolina & Nenhum beneficio & o sim & & sim & $8 \mathrm{~h}$ às $9 \mathrm{~h}$ & $17 \mathrm{~h}$ às $18 \mathrm{~h}$ & Não \\
\hline Rafael Kesseles & Masculino & ○ 26 à 35 & 5 Engenho de Dentt & to Carro & Gasolina, Etanol & (Vale Transporte & sim & Trem & sim & $9 \mathrm{~h}$ às $10 \mathrm{~h}$ & $18 \mathrm{~h}$ às $19 \mathrm{~h}$ & Não \\
\hline Maria & & 36 à 55 & 5. Ipanema & Nenhum dos dois & & Nenhum beneficio & & & & $8 \mathrm{~h}$ às & Após as $19 \mathrm{~h}$ & Não \\
\hline Bernardo Fanganito & Masculino & o 26 à 35 & Copacabana & Nenhum dos dois & & Vale Transporte & & & & $8 \mathrm{~h}$ às $9 \mathrm{~h}$ & $17 \mathrm{~h}$ às $18 \mathrm{~h}$ & Não \\
\hline Vinicius Manzan & Masculino & o 26 à 35 & Copacabana & Carro & Gasolina & Nenhum beneficio & osim & Metrô & Sim & $8 \mathrm{~h}$ às $9 \mathrm{~h}$ & $18 \mathrm{~h}$ às $19 \mathrm{~h}$ & Não \\
\hline Samara Lamberg & Feminino & 26 à 35 & Copacabana & Carro & Gasolina & Nenhum beneficio & osim & Metrô & sim & $8 \mathrm{~h}$ às $9 \mathrm{~h}$ & $17 \mathrm{~h}$ às $18 \mathrm{~h}$ & Não \\
\hline & Masculino & o 26 à 35 & 5 Copacabana & Can & & & osim & Metrô & sim & & & Não \\
\hline Mariana de Castro & Feminino & 26 à 35 & Tijuca & Carro & Gasolina & Vale Transporte & Sim & & Sim & $8 \mathrm{~h}$ às $9 \mathrm{~h}$ & Após as $19 \mathrm{~h}$ & Não \\
\hline Douglas Dardengo & Masculino & o 26 à 35 & 5 São Cristóvão & Carro & Gasolina & Nenhum beneficio & o sim & & sim & $8 \mathrm{~h}$ às $9 \mathrm{~h}$ & Após as $19 \mathrm{~h}$ & Não \\
\hline Bruno Araujo & Masculino & o 26 à 35 & 5 Jacarepaguá & Carro & GNV & Nenhum beneficio & osim & Continuaria indo de carro & sim & $7 \mathrm{~h}$ às $8 \mathrm{~h}$ & $17 \mathrm{~h}$ às $18 \mathrm{~h}$ & Não \\
\hline
\end{tabular}




\begin{tabular}{|c|c|c|c|c|c|}
\hline & Feminit & 36 à 55 & os dois & & \\
\hline Jean Carlos Dias & Masculino & 26 à 35 Tijuca & Nenhum dos dois & & Vale Transporte \\
\hline Leticia Ferreira & Feminino & Até 25 a Vila da Penha & Nenhum dos dois & & Vale Transporte \\
\hline Felipe da Costa & Masculino & 26 à 35 . Campo Grande & Carro & GNV & Nenhum beneficio Sim \\
\hline Camila Villasboas & Feminino & 26 à 35 Barra da Tiuca & carro & Gasolina & Nenhum beneficio Sim \\
\hline Ina Fabbio & Feminino & Até 25 a Vila da Penha & Carro & GNV & Vale Transporte Sim \\
\hline Breno Baum & Masculino & 26 à 35 Laranjeiras & Carro & Gasolina & Vale Transporte Sim \\
\hline Aline Palmier & Feminino & 26 à 35 Gloria & Nenhum dos dois & & Nenhum beneficio \\
\hline Aldo Delmiro & & & Nenhum dos dois & Prefiro näo respor & \\
\hline mar Silva & Masculino & 26 à 35 Duque de caxias & Carro & Gasolina & Vale Transporte Não \\
\hline Gabriela Aguiar & Feminino & 26 à 35 Tijuca & Carro & Gasolina & Nenhum beneficio Sim \\
\hline & 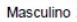 & 26 à 35 Co & Nenhum dos dois & & \\
\hline tonio Jordão & tasculino & 26 à 35 Botafogo & Carro & Gasolina & Nenhum ! \\
\hline Gisele Rosner & Feminino & 36 à 55 Tijuca & Carro & Gasolina & Nenhum beneficio Sim \\
\hline Cleiton Gustavo & Masculino & Até 25 a Jacarepaguá & Carro & Gasolina, Etanol ( & Vale Transporte Sim \\
\hline Adriana Maria & Feminino & 26 à 35 Riachuelo & Nenhum dos dois & & Vale Transporte \\
\hline Jonia Fatima & Feminino & 36 à 55 Copacabana & Carro - & Gasolina & Nenhum beneficio Näo \\
\hline Thais Araujo & minino & 26 à 35 Duque de Caxias & & & \\
\hline Laurita Dias & minino & 36 à 55 Botafogo & Carro & Etanol (Álcool) & Nenhum ber \\
\hline Danilo Fontenele & Masculino & Até 25 a Tjuca & Nenhum dos dois & & Nenhum beneficio \\
\hline Sergio Luiz Cardoso & Masculino & 26 à 35 . Flamengo & Nenhum dos dois & & Nenhum beneficio \\
\hline Gabriella Sivelli & Feminino & 26 à 35 Tijuca & Nenhum dos dois & & Nenhum beneficio \\
\hline iana & eminino & Até 25 a Copacabana & Nenhum dos dois & & Vale Transporte \\
\hline Mylena Pereira & Feminino & 26 a 35 Engenho da Raint & If Carro & Gasolina & Nenhum beneficio Sim \\
\hline Hanna da costa & Feminino & 26 à 35 Guadalupe & Nenhum dos dois & & Vale \\
\hline Marcos Vinicius do Nas & (Masculino & 26 à 35 Jacarepaguá & Carro, Moto & Gasolina & Nenhum beneficio Sim \\
\hline Guilherme Gomes & Masculino & 26 à 35 Duque de Caxias & Carro & Gasolina, GNV & Vale Transporte Sim \\
\hline Gabriel Soriano & Masculino & 36 à 55 Säo Cristóvão & Carro & Gasolina & Nenhum beneficio Sim \\
\hline Marcelo da Costa & Masculino & 26 à 35 Säo Cristóvão & Moto & Gasolina & Nenhum beneficio Sim \\
\hline Thalis: & Feminino & Atế 25 a Tiuca & Nenhum dos dois & & \\
\hline Thiago Carreira & Masculino & 26 à 35 Méier & Carro & & Nenhum : \\
\hline Richard Cardoso & ulino & 36 à 55 tha do Governadd & ¿Carro & Gasolina & Nenhum beneficio Sim \\
\hline Vitoria do Nascimento & Feminino & Atế 25 a Mangueira & Nenhum dos dois & & Vale Transporte \\
\hline Amanda da Silva & Feminino & Até 25 a Jacarepaguá & Nenhum dos dois & & Vale Transporte \\
\hline & & 26 à 35 Niterói & Carro & & Nenhum beneficic \\
\hline Raphael Nunes & & & Nenhum dos dois & & \\
\hline Victor Considera & & 26 à 35 Niterói & Carro & GNV & Nenhum beneficio Sim \\
\hline
\end{tabular}

\begin{tabular}{|c|c|c|c|}
\hline & \multirow{2}{*}{$\begin{array}{l}8 \mathrm{~h} \text { às } 9 h \\
8 \mathrm{~h} \text { à } 9 \mathrm{~h} \\
8 \mathrm{~h} \text { hà } 9 \mathrm{~h}\end{array}$} & \multirow{2}{*}{$\begin{array}{l}18 \mathrm{~h} \text { às } 19 \mathrm{~h} \\
17 \mathrm{~h} \text { as } 18 \mathrm{~h}\end{array}$} \\
\hline Trem & & & \\
\hline Metró & Sim & $7 \mathrm{~h}$ às $8 \mathrm{~h}$ & $17 \mathrm{~h}$ às $18 \mathrm{~h}$ \\
\hline Continuaria indo de carro & Sim & $7 \mathrm{~h}$ às $8 \mathrm{~h}$ & $17 \mathrm{~h}$ às $18 \mathrm{~h}$ \\
\hline & Sim & $8 \mathrm{~h}$ às $9 \mathrm{~h}$ & $17 \mathrm{~h}$ às $18 \mathrm{~h}$ \\
\hline Ônibus & Sim & $8 \mathrm{~h}$ às $9 \mathrm{~h}$ & $17 \mathrm{~h}$ às $18 \mathrm{~h}$ \\
\hline Metrô & Sim & $\begin{array}{l}8 \mathrm{~h} \text { às } 9 \mathrm{~h} \\
6 \mathrm{~h} \text { às } 7 \mathrm{~h}\end{array}$ & $\begin{array}{l}17 \mathrm{~h} \text { às } 18 \mathrm{~h} \\
15 \mathrm{~h} \text { as } 16 \mathrm{~h}\end{array}$ \\
\hline Trem & Sim & $8 \mathrm{~h}$ às $9 \mathrm{~h}$ & $18 \mathrm{~h}$ às $19 \mathrm{~h}$ \\
\hline Metrô & Sim & $\begin{array}{l}8 \mathrm{~h} \text { às } 9 \mathrm{~h} \\
8 \mathrm{~h} \text { às } 9 \mathrm{~h}\end{array}$ & $\begin{array}{l}18 \mathrm{~h} \text { às } 19 \mathrm{~h} \\
17 \mathrm{~h} \text { as } 18 \mathrm{~h}\end{array}$ \\
\hline \multirow[t]{3}{*}{ Metrồ } & Sim & $8 \mathrm{~h}$ às $9 \mathrm{~h}$ & $18 \mathrm{~h}$ às $19 \mathrm{~h}$ \\
\hline & Sim & $8 \mathrm{~h}$ às $9 \mathrm{~h}$ & $18 \mathrm{~h}$ às $19 \mathrm{~h}$ \\
\hline & Sim & $\begin{array}{l}8 \mathrm{~h} \text { às } 9 \mathrm{~h} \\
12 \mathrm{~h}\end{array}$ & $\begin{array}{l}18 \mathrm{~h} \text { as } 19 \mathrm{~h} \\
21 \mathrm{~h}\end{array}$ \\
\hline Ônibus & Não & $8 \mathrm{~h}$ às $9 \mathrm{~h}$ & $18 \mathrm{~h}$ às $19 \mathrm{~h}$ \\
\hline Metrồ & sim & $9 \mathrm{~h}$ às $10 \mathrm{~h}$ & $18 \mathrm{~h}$ às $19 \mathrm{~h}$ \\
\hline Metrố & sim & $9 \mathrm{~h}$ às $10 \mathrm{~h}$ & $18 \mathrm{~h}$ à $19 \mathrm{~h}$ \\
\hline Metrồ & Sim & $9 \mathrm{~h}$ às $10 \mathrm{~h}$ & $18 \mathrm{~h}$ às $19 \mathrm{~h}$ \\
\hline Metrô & & $8 \mathrm{~h}$ às $9 \mathrm{~h}$ & Após as $19 \mathrm{~h}$ \\
\hline À pé & & $9 \mathrm{~h}$ às $10 \mathrm{~h}$ & $18 \mathrm{~h}$ às $19 \mathrm{~h}$ \\
\hline Metrồ & Sim & $9 \mathrm{~h}$ às $10 \mathrm{~h}$ & $18 \mathrm{~h}$ às $19 \mathrm{~h}$ \\
\hline & Sim & $8 \mathrm{~h}$ às $9 \mathrm{~h}$ & $18 \mathrm{~h}$ às $19 \mathrm{~h}$ \\
\hline \multirow{2}{*}{ Trem } & Sim & $8 \mathrm{~h}$ às $9 \mathrm{~h}$ & $17 \mathrm{~h}$ às $18 \mathrm{~h}$ \\
\hline & sim & 6h às $7 \mathrm{~h}$ & $16 \mathrm{~h}$ às $17 \mathrm{~h}$ \\
\hline Trem & sim & $7 \mathrm{~h}$ às $8 \mathrm{~h}$ & $17 \mathrm{~h}$ às $18 \mathrm{~h}$ \\
\hline Metrô & Sim & $8 \mathrm{~h}$ às $9 \mathrm{~h}$ & $18 \mathrm{~h}$ às $19 \mathrm{~h}$ \\
\hline Ōnibus & Sim & $9 \mathrm{~h}$ às $10 \mathrm{~h}$ & Após as $19 \mathrm{~h}$ \\
\hline Metrô & & $7 \mathrm{~h}$ às $8 \mathrm{~h}$ & $17 \mathrm{~h}$ às $18 \mathrm{~h}$ \\
\hline & $\operatorname{sim}$ & $8 \mathrm{~h}$ às $9 \mathrm{~h}$ & $18 \mathrm{~h}$ às $19 \mathrm{~h}$ \\
\hline \multirow[t]{6}{*}{ Ônibus } & Sim & $6 \mathrm{~h}$ as $7 \mathrm{~h}$ & $15 \mathrm{~h}$ às $16 \mathrm{~h}$ \\
\hline & & $6 \mathrm{~h}$ às $7 \mathrm{~h}$ & $16 \mathrm{~h}$ às $17 \mathrm{~h}$ \\
\hline & & $8 \mathrm{~h}$ às $9 \mathrm{~h}$ & $18 \mathrm{~h}$ às $19 \mathrm{~h}$ \\
\hline & Sim & $8 \mathrm{~h}$ às $9 \mathrm{~h}$ & $17 \mathrm{~h}$ às $18 \mathrm{~h}$ \\
\hline & & $8 \mathrm{~h}$ às $9 \mathrm{~h}$ & $17 \mathrm{~h}$ às $18 \mathrm{~h}$ \\
\hline & Sim & $8 \mathrm{~h}$ às $9 \mathrm{~h}$ & $17 \mathrm{~h}$ às $18 \mathrm{~h}$ \\
\hline
\end{tabular}




\section{APÊNDICE C - Cálculo das tarifas no Rio de Janeiro}

\section{Premissas:}

Base de dados referente as tarifas aplicadas no município do Rio de Janeiro:

\begin{tabular}{cccc} 
& Ônibus & $\mathrm{R} \$$ & 4,05 \\
\hline \multirow{2}{*}{$\begin{array}{c}\text { Tarifas } \\
\text { Integrais de }\end{array}$} & $\mathrm{BRT}$ & $\mathrm{R} \$$ & 4,05 \\
\hline $\begin{array}{c}\text { Transportes } \\
\text { do Rio de } \\
\text { Janeiro }\end{array}$ & $\mathrm{VLT}$ & $\mathrm{R} \$$ & 3,80 \\
& Metrô & $\mathrm{R} \$$ & 4,60 \\
& Vans Municipais & $\mathrm{R} \$$ & 4,05 \\
\hline & Barcas & $\mathrm{R} \$$ & 6,30 \\
& Valor médio: & $\mathbf{R} \$$ & $\mathbf{4 , 4 5}$ \\
\hline
\end{tabular}

Fonte: https://www.cartaoriocard.com.br/rcc/institucional/tarifas

Dos 143 respondentes que utilizam vale transporte, 55 residem fora do município do Rio, portanto, aplicada tarifa média de $\mathrm{R} \$ 7,94$.

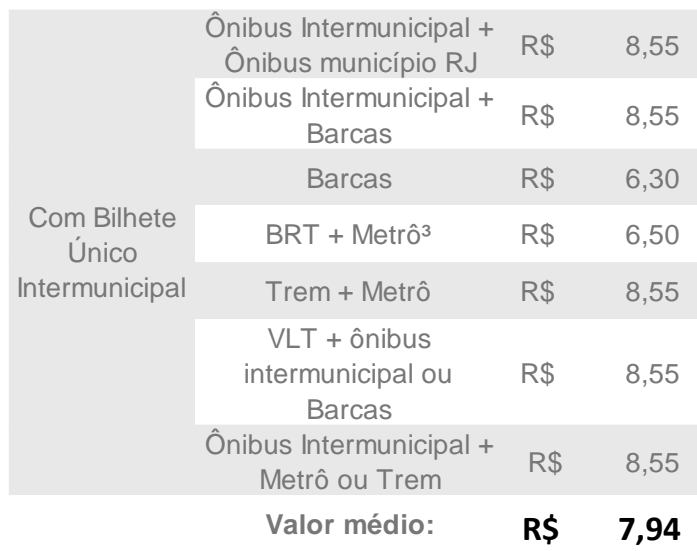

\section{Valor diário:}

Município do Rio : $\mathrm{R} \$ 4,45 \times 2=\mathrm{R} \$ 8,90$ / Intermunicipal : $\mathrm{R} \$ 7,94 \times 2=\mathrm{R} \$ 15,88$

$(88 \times \mathrm{R} \$ 4,45 \times 2)+(55 \times \mathrm{R} \$ 7,94 \times 2)=\mathrm{R} \$ 783,20+\mathrm{R} \$ 873,40=\mathbf{R} \$ \mathbf{1 . 6 5 6 , 6 0}$ totais.

\section{Valor mensal:}

Considerando 23 dias úteis por mês, tem se

Município do Rio : $\mathrm{R} \$ 4,45 \times 2 \times 23=\mathrm{R} \$ 204,70$ / Intermunicipal : $\mathrm{R} \$ 7,94 \times 2 \times 23$ $=\mathrm{R} \$ 365,24(88 \times 204,70)+(55 \times 365,24)=\mathbf{R} \mathbf{3 8 . 1 0 1 , 8 0}$ totais. 


\section{APÊNDICE D - Cálculo do preço médio da gasolina}

\section{Premissas:}

Base de dados referente ao preço médio ANP da gasolina comum em 2017 no estado do Rio de Janeiro. Desconsiderando o uso do etanol ou gás natural.

Preço médio gasolina no Rio de Janeiro: $\mathbf{R} \mathbf{4 , 0 9 1}$ por litro

\section{Valor diário:}

Levando em conta as distâncias médias dos 565 funcionários que não usufruem do vale transporte, e considerando um carro com consumo de $10 \mathrm{~km}$ por litro, tem se, valor médio de $\mathrm{R} \$ 43,05$ por dia na gasolina.

\begin{tabular}{|c|c|c|}
\hline \multicolumn{2}{|c|}{ Usuário VT } & \multirow[b]{2}{*}{ Distância média (km) } \\
\hline Município & $\begin{array}{l}\text { Média de valor gasto com } \\
\text { gasolina a } R \$ 4,091 \text { (ida e volta) }\end{array}$ & \\
\hline ARARUAMA & 96,55 & 118,0 \\
\hline BELFORD ROXO & 26,69 & 32,6 \\
\hline DUQUE DE CAXIAS & 25,25 & 30,9 \\
\hline MARICA & 44,05 & 53,8 \\
\hline MESQUITA & 24,06 & 29,4 \\
\hline MIGUEL PEREIRA & 93,27 & 114,0 \\
\hline NILÓPOLIS & 25,36 & 31,0 \\
\hline NITERÓI & 18,81 & 23,0 \\
\hline NOVA IGUAÇU & 33,28 & 40,7 \\
\hline PETRÓPOLIS & 51,71 & 63,2 \\
\hline RIO DE JANEIRO & 12,60 & 15,4 \\
\hline SÃO GONÇALO & 23,80 & 29,1 \\
\hline SÃO JOÃO DE MERITI & 20,05 & 24,5 \\
\hline VOLTA REDONDA & 107,18 & 131,0 \\
\hline Total Geral & 43,05 & 52,6 \\
\hline
\end{tabular}

Fonte: http://www.anp.gov.br/precos-e-defesa-da-concorrencia/precos/levantamento-deprecos

$(43,05 \times 565)=\mathbf{R} \$ \mathbf{2 4 . 3 2 3 , 2 5}$ totais

\section{Valor mensal:}

Considerando 23 dias úteis por mês, tem se

$(43,05 \times 23)=\mathbf{R} \$ 990,15$

$(43,05 \times 23) \times 565=\mathbf{R} \$ \mathbf{5 5 9 . 4 3 4 , 7 5}$ totais. 


\section{APÊNDICE E - Custo de deslocamento (Questionário)}

\section{Premissas:}

O gasto semanal foi calculado por meio da contagem da frequência com que cada funcionário utiliza determinado modal, multiplicado pelo custo com gasolina ou passagem de transporte público.

\begin{tabular}{|c|c|c|c|c|}
\hline Uso do ônibus & $\checkmark$ & Quant.Ônibus & Quant.pessoas x Preço passagem & Gasto semanal \\
\hline 1 vez na semana & & 3 & 24,3 & 24,3 \\
\hline 3 vezes na semana & & 2 & 16,2 & 48,6 \\
\hline 4 vezes na semana & & 1 & 8,1 & 32,4 \\
\hline Todos os dias & & 17 & 137,7 & 688,5 \\
\hline Total Geral & & 23 & 186,30 & 793,80 \\
\hline Uso do metrô & $\checkmark$ & Quant.Metrô & Quant.pessoas x Preço passagem & Gasto semanal \\
\hline 1 vez na semana & & 5 & 43 & 43 \\
\hline 3 vezes na semana & & 4 & 34,4 & 103,2 \\
\hline 4 vezes na semana & & 2 & 17,2 & 68,8 \\
\hline Todos os dias & & 20 & 172 & 860 \\
\hline Total Geral & & 31 & 266,60 & 1075,00 \\
\hline Uso do trem & $\checkmark$ & Quant.Trem & Quant.pessoas x Preço passagem & Gasto semanal \\
\hline 1 vez na semana & & 2 & 18,4 & 18,4 \\
\hline Todos os dias & & 12 & 110,4 & 552 \\
\hline Total Geral & & 14 & 128,80 & 570,40 \\
\hline Uso do carro próprio & $\nabla$ & Quant.Carro próprio & Quant.pessoas x Gasto com gasolina & Gasto semanal \\
\hline 1 vez na semana & & 1 & 26,35 & 26,35 \\
\hline 2 vezes na semana & & 4 & 82,23 & 164,46 \\
\hline 3 vezes na semana & & 1 & 6,46 & 19,39 \\
\hline 4 vezes na semana & & 1 & 11,29 & 45,16 \\
\hline Todos os dias & & 44 & 577,35 & 2886,77 \\
\hline \multirow[t]{2}{*}{ Total Geral } & & 51 & 1471,76 & 3142,13 \\
\hline & & & 703,68 & \\
\hline Uso do carro uber & $\checkmark$ & Quant.Uber & Soma de gasto com gasolina por dia & Gasto semanal \\
\hline 1 vez na semana & & 5 & 57,19 & 57,19 \\
\hline 2 vezes na semana & & 2 & 32,97 & 65,95 \\
\hline 4 vezes na semana & & 2 & 16,36 & 65,46 \\
\hline Todos os dias & & 4 & 25,04 & 125,18 \\
\hline Total Geral & & 13 & 1471,76 & 313,78 \\
\hline
\end{tabular}

\begin{tabular}{crrrr} 
Meio de Transporte & \multicolumn{2}{c}{ Somatório de gasto semanal } & \multicolumn{2}{c}{ Somatório da média gasto diário } \\
Ônibus & $\mathrm{R} \$$ & 793,80 & $\mathrm{R} \$$ & 158,76 \\
Metrô & $\mathrm{R} \$$ & $1.075,00$ & $\mathrm{R} \$$ & 215,00 \\
Trem & $\mathrm{R} \$$ & 570,40 & $\mathrm{R} \$$ & 114,08 \\
Carro (próprio/uber) & $\mathrm{R} \$$ & $3.455,91$ & $\mathrm{R} \$$ & 691,18 \\
Total: & $\mathbf{R} \$$ & $\mathbf{5 . 8 9 5 , 1 1}$ & $\mathbf{R} \$$ & $\mathbf{1 . 1 7 9 , 0 2}$
\end{tabular}




\section{APÊNDICE F - Questionário}

*Obrigatório

() Assinalar apenas uma opção

[ ] Caso tenha mais de uma resposta

- Gênero*

() Masculino

( ) Feminino

- Faixa etária*

() Até 25 anos

( ) 26 à 35 anos

( ) 36 à 55 anos

( ) 56 à 65 anos

() Mais de 66 anos

- Qual seu local de residência (BAIRRO)? *

Fundamental para cálculo da distância percorrida casa-trabalho. Item a ser digitado

- Possui carro ou moto?*
[ ] Carro
[] Moto
[ ] Os dois
[] Nenhum dos dois
[] Dirijo carro da empresa

- Caso possua carro ou moto, informe o tipo de combustível que mais utiliza:

[ ] Gasolina

[] Etanol (Álcool)

[] GNV

[] Meu carro é híbrido ou elétrico

[ ] Prefiro não responder

- Quais destes benefícios você possui hoje na empresa?*

[ ] Vale Transporte

[ ] Vale Combustível

[ ] Nenhum benefício

- Caso possua carro, você tem vaga de estacionamento no local de trabalho?

( ) Sim

( ) Não

- Caso sua empresa não possua estacionamento, e o local mais próximo para estacionar fosse a $2 \mathbf{~ k m}$ de distância, qual modal utilizaria?
( ) Continuaria no carro
( ) Ônibus
() Metrô
() Trem
( ) Barcas
( ) Bicicleta
( ) à pé

- Caso possua carro, você optaria por oferecer ou dar carona para o local de trabalho?

( ) Sim 
( ) Não

- Informe seu horário de ENTRADA na empresa*

Informar o horário convencional

( ) $6 \mathrm{~h}$ às $7 \mathrm{~h}$

( ) $7 \mathrm{~h}$ às $8 \mathrm{~h}$

() $8 \mathrm{~h}$ às $9 \mathrm{~h}$

() $9 \mathrm{~h}$ às $10 \mathrm{~h}$

( ) Outro:

- Informe seu horário de SAÍDA na empresa *

Informar o horário convencional

( ) $15 \mathrm{~h}$ às $16 \mathrm{~h}$

() $16 \mathrm{~h}$ às $17 \mathrm{~h}$

() $17 \mathrm{~h}$ às $18 \mathrm{~h}$

() $18 \mathrm{~h}$ às $19 \mathrm{~h}$

( ) Outro:

- Você tem a opção de trabalhar remotamente DURANTE TODO O EXPEDIENTE? *

( ) $\mathrm{Sim}$

( ) Não

- Marque qual/quais modos de transporte utiliza para CHEGAR ao trabalho, e quantas vezes na semana o utiliza? *

(Ex: Integração trem-ônibus, marcar os dois modais)

\begin{tabular}{|l|l|l|l|l|l|}
\hline & 1 vez na sem & 2 vez na sem & 3 vez na sem & 4 vez na sem & $\begin{array}{c}\text { Todos os } \\
\text { dias }\end{array}$ \\
\hline Ônibus & & & & & \\
\hline Metrô & & & & & \\
\hline Trem & & & & & \\
\hline Carro (Próprio) & & & & & \\
\hline Carro (Über) & & & & & \\
\hline Carro (Carona) & & & & & \\
\hline À pé & & & & & \\
\hline Bicicleta & & & & & \\
\hline Outros & & & & & \\
\hline
\end{tabular}

- Quanto tempo, por dia, você leva para CHEGAR no trabalho? *

Informar a média de duração
() Até 30min
( ) 30min à $1 \mathrm{~h}$
() $1 \mathrm{~h}$ à $1 \mathrm{~h} 30 \mathrm{~min}$
( ) $1 \mathrm{~h} 30 \mathrm{~min}$ à $2 \mathrm{~h}$
( ) Mais de $2 \mathrm{~h}$ 
- Marque qual/quais modos de transporte utiliza para SAIR do trabalho, e quantas vezes na semana o utiliza? *

(Ex: Integração trem-ônibus, marcar os dois modais).

\begin{tabular}{|l|l|l|l|l|l|}
\hline & 1 vez na sem & 2 vez na sem & 3 vez na sem & 4 vez na sem & $\begin{array}{c}\text { Todos os } \\
\text { dias }\end{array}$ \\
\hline Ônibus & & & & & \\
\hline Metrô & & & & & \\
\hline Trem & & & & & \\
\hline Carro (Próprio) & & & & & \\
\hline Carro (Über) & & & & & \\
\hline Carro (Carona) & & & & & \\
\hline À pé & & & & & \\
\hline Bicicleta & & & & & \\
\hline Outros & & & & & \\
\hline
\end{tabular}

- Quanto tempo, por dia, você leva para SAIR do trabalho? *

Informar a média de duração
() Até 30min
( ) 30min à $1 \mathrm{~h}$
() $1 \mathrm{~h}$ à $1 \mathrm{~h} 30 \mathrm{~min}$
() $1 \mathrm{~h} 30 \mathrm{~min}$ à $2 \mathrm{~h}$
( ) Mais de $2 \mathrm{~h}$ 